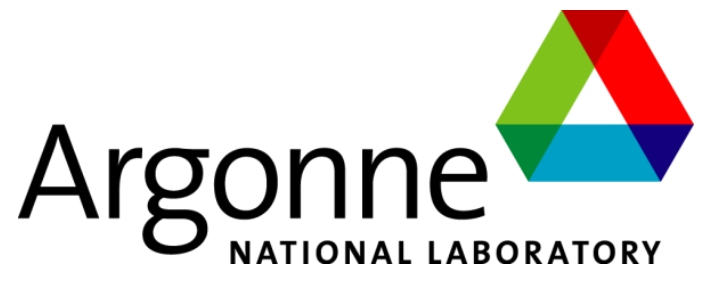

ANL-19/20

\title{
Hydraulic Study of the South Carolina DOT Catch Basin Type 25
}

Nuclear Science and Engineering Division 


\section{About Argonne National Laboratory}

Argonne is a U.S. Department of Energy laboratory managed by UChicago Argonne, LLC under contract DE-AC02-06CH11357. The Laboratory's main facility is outside Chicago, at 9700 South Cass Avenue, Argonne, Illinois 60439. For information about Argonne and its pioneering science and technology programs, see www.anl.gov.

\section{DOCUMENT AVAILABILITY}

Online Access: U.S. Department of Energy (DOE) reports produced after 1991 and a growing number of pre-1991 documents are available free at OSTI.GOV

(http://www.osti.gov/), a service of the U.S. Dept. of Energy's Office of Scientific and

Technical Information

Reports not in digital format may be purchased by the public from the National Technical Information Service (NTIS):

U.S. Department of Commerce

National Technical Information Service

5301 Shawnee Rd

Alexandra, VA 22312

www.ntis.gov

Phone: (800) 553-NTIS (6847) or (703) 605-6000

Fax: (703) 605-6900

Email: orders@ntis.gov

\section{Reports not in digital format are available to DOE and DOE contractors from the} Office of Scientific and Technical Information (OSTI):

U.S. Department of Energy

Office of Scientific and Technical Information

P.O. Box 62

Oak Ridge, TN 37831-0062

www.osti.gov

Phone: (865) 576-8401

Fax: (865) 576-5728

Email: reports@osti.gov

\section{Disclaimer}

This report was prepared as an account of work sponsored by an agency of the United States Government. Neither the United States Government nor any agency thereof, nor UChicago Argonne, LLC, nor any of their employees or officers, makes any warranty, express or implied, or assumes any legal liability or responsibility for the accuracy, completeness, or usefulness of any information, apparatus, product, or process disclosed, or represents that its use would not infringe privately owned rights. Reference herein to any specific commercial product, process, or service by trade name, trademark, manufacturer, or otherwise, does not necessarily constitute or imply its endorsement, recommendation, or favoring by the United States Government or any agency thereof. The views and opinions of document authors expressed herein do not necessarily state or reflect those of the United States Government or any agency thereof, Argonne National Laboratory, or UChicago Argonne, LLC. 


\section{Hydraulic Study of the South Carolina DOT Catch Basin Type 25}

prepared by

M.A. Sitek, S.A. Lottes, N. Sinha

Nuclear Science and Engineering Division, Argonne National Laboratory

May 2019 
Table of Contents

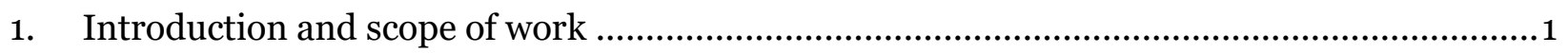

2. Procedure to assess the efficiency of the grate .............................................................. 4

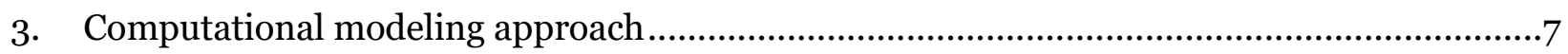

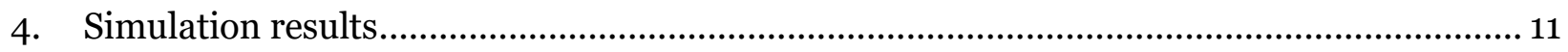

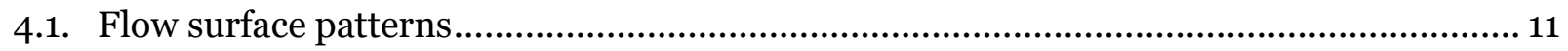

4.2. Recommendations for reducing the bypass flow......................................................14

4.3. Influence of the initial conditions in CFD simulations on the flow pattern ....................20

4.4. Influence of a model of debris on the grate efficiency .............................................. 22

4.5. Influence of introducing imperfections in the roadway surface to the CFD model ......... 24

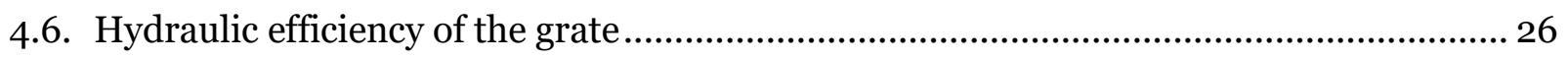

4.7. Correlations of the grate efficiency with Reynolds and Froude number........................ 33

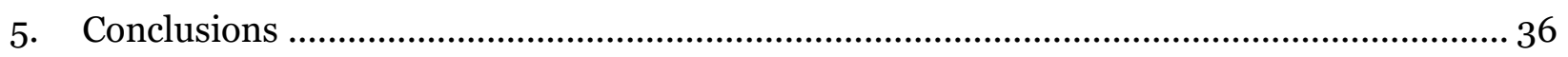

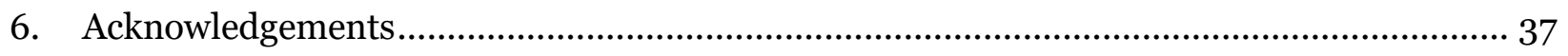

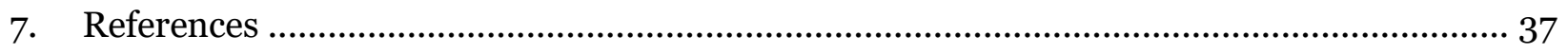

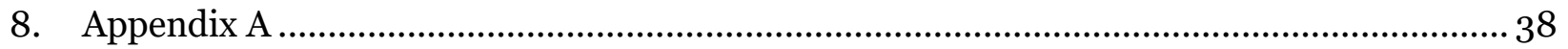

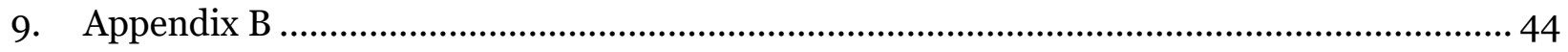

Hydraulic Study of the South Carolina DOT Catch Basin Type 25 


\section{List of Figures}

Figure 1-1: Views of the CB25 grate, (a) cross section through a barrier and grates, and (b) top view with marked dimensions ...............................................................................................

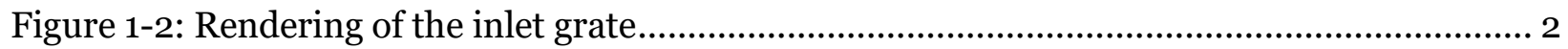

Figure 1-3. A cross-section of a typical rural/urban six-lane divided freeway ............................ 2

Figure 1-4. A cross section through the drainage area of a freeway ......................................... 3

Figure 2-1: Cross-section through the roadway with the maximum, minimum, and intermediate spreads at the inflow surface, where $T_{\max }$ is the allowable spread, $T_{i}$ is the spread for $\mathrm{i}$-th case, $\mathrm{T}_{\mathrm{gr}}$ is the minimum spread equal to the grate width, $\mathrm{W}$ is the shoulder width, $\mathrm{D}_{1}$ is the flow depth in a uniform gutter cross-section, $\mathrm{D}_{2}$ is flow depth in composite gutter cross-section.

Figure 3-1: Sketches of the CFD domain, (a) a cross-section through the computational domain, (b) a top view of the computational domain with flow direction (blue arrow) and example flow spread (blue line)

Figure 3-2: The full width of the shoulder and the $12 \mathrm{ft}$ roadway lane (black edges), and the part chosen as the computational domain (dark blue)

Figure 3-3: Geometry of the computational domain in the vicinity of the grate. The domain was divided into three regions: below the grate, above the grate and the remaining shoulder and roadway

Figure 3-4: Location of the cross-sections used for monitoring the mesh

Figure 3-5: Domain discretization on cross-section planes through the domain (a) along the flow, and (b) perpendicular to the flow .10

Figure 3-6: Example water flow through the grate. The yellow planes show the surfaces used to monitor the flow: (a) front flow, (b) side flow, (c) back flow and (d) outflow through the grate.. 11 Figure 4-1: Flow pattern with water depth plotted on the water surface. Shoulder width $4 \mathrm{ft}$, flow spread $2 \mathrm{ft}$, longitudinal slope $0.3 \%$.

Figure 4-2: Flow pattern with water depth plotted on the water surface. Shoulder width $4 \mathrm{ft}$, flow spread $6 \mathrm{ft}$, longitudinal slope $7 \%$.

Figure 4-3: Flow pattern with water depth plotted on the water surface. Shoulder width $10 \mathrm{ft}$, flow spread $10 \mathrm{ft}$, longitudinal slope $4 \%$.

Figure 4-4: Streamlines showing the fallback distances d1 and d2, and plots of water depth; 4-ft

shoulder, 6-ft flow spread, and varying longitudinal slope.... 
Figure 4-6: Distance d2 (description in the text) in function of the longitudinal slope. .19

Figure 4-7: Flow pattern above the grate with the flow initiated (a) in an empty domain, (b) filled domain and blocked grate, (c) with a solution from a run with a smaller longitudinal slope

Figure 4-8: A model of stacked debris at the inlet. 23

Figure 4-9: Flow pattern in the vicinity of the inlet grate for a case of a 4-foot shoulder, at longitudinal slope $0.3 \%$, (a) without obstruction, (b) with obstruction..... 24

Figure 4-10: A model of an imperfection of the shoulder surface. 25

Figure 4-11: Flow pattern in the vicinity of the inlet grate for a case of a 4-foot shoulder, at longitudinal slope $0.3 \%$, (a) with a flat shoulder surface, (b) with imperfection on the shoulder surface

Figure 4-12: Flow rate through the grate for a road with a 4-foot shoulder, (a) flow rate vs. longitudinal slope, (b) flow rate vs. flow spread, (c) hydraulic efficiency of the grate vs. spread 27

Figure 4-13: Flow rate through the grate for a road with a 4.75-foot shoulder, (a) flow rate vs. longitudinal slope, (b) flow rate vs. flow spread, (c) hydraulic efficiency of the grate vs. spread 28 Figure 4-14: Flow rate through the grate for a road with a 7.5-foot shoulder, (a) flow rate vs. longitudinal slope, (b) flow rate vs. flow spread, (c) hydraulic efficiency of the grate vs. spread 29

Figure 4-15: Flow rate through the grate for a road with a 10-foot shoulder, (a) flow rate vs. longitudinal slope, (b) flow rate vs. flow spread, (c) hydraulic efficiency of the grate vs. spread 30

Figure 4-16: Streamlines of water velocity crossing surfaces: on the grate front (yellow) and grate side (green). The red line marks the extent of the water surface on the road. In each case the flow spread is $6 \mathrm{ft}$, on a road with a 4 foot shoulder, and varying longitudinal slope (a) $0.3 \%$, (b) $1 \%$, (c) $3 \%$, (d) $5 \%$, (e) $7 \%$.

Figure 4-17: Percentage of flow rate through the grate vs. upstream Reynolds number with a best fit linear function

Figure 4-18: Percentage flow rate through the side of the grate vs. upstream Froude number with a best fit function 


\section{List of Tables}

Table 1-1: Variables of the study with ranges ...................................................................... 3

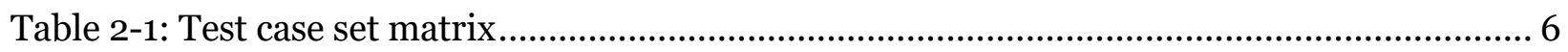

Table 4-1: Flow surface pattern types: $\mathbb{V}$ - fully captured flow, $\vec{\nabla}$ - broken water surface with bypass flow, $\vec{H}$ - overtopped grate, $(-)$ - case not considered in the study ................................14

Table 4-2: Distances d1 and d2 (description in the text); 4-foot shoulder, 6-foot flow spread,

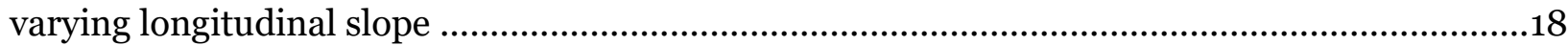

Table 4-3: Percentage of the front flow through the grate to total inflow ....................................31

Table 4-4: Percentage of the side flow through the grate to total inflow ................................. 32

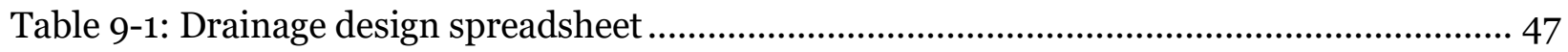




\section{Introduction and scope of work}

Proper design of surface drainage of both rural and urban highways is essential to minimize flooding and provide traffic safety. Inlets collect the excess storm water from a roadway and discharge it to storm drains. Knowing the performance of inlets (or hydraulic efficiency), defined as the percentage of intercepted flow to the total street flow, is necessary in the design of inlet spacing. The location of inlets can be determined such that the system can transport all or a majority of the road surface flow during rain events.

A new type of a catch basin with an inlet grate, Type 25 (CB25), to use as drainage on South Carolina's freeways was designed by the South Carolina Department of Transportation engineers. Because it is a new design, a study was necessary to establish the hydraulic capacity of the grate. Computational fluid dynamics (CFD) modeling was chosen for this purpose, instead of more expensive and time consuming laboratory testing. CFD has been widely used in design of new transportation infrastructure, as well as performance analysis of the existing structures. Threedimensional computational fluid dynamic simulations were developed by scientists at Argonne's Transportation Research and Analysis Computing Center with the use of high performance cluster computing. The work was performed under an inter-agency agreement between the U.S. Department of Transportation and the U.S Department of Energy and funded by the South Carolina Department of Transportation.

The type 25 catch basin can be installed as single or double. A single CB25 has one inlet adjacent to a barrier in the center of the highway separating directions of travel. The double CB25 catch basin has two inlets, one on each side of the barrier. The barrier is a part of the CB25 structure, blocking the water from one side of the roadway from seeping through to the other side. According to the design drawing, obtained from SCDOT, the grate has dimensions of 2' 4.5" by 4' 4.5”, with 30 openings of $87 / 8$ " by $33 / 8$ ". Sketches of a cross-section through catch basin type 25 and a top view of the grate are presented in Figure 1-1.

(a)

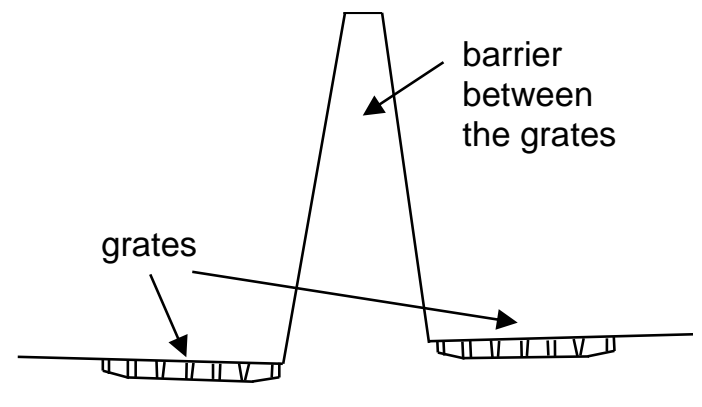

(b)

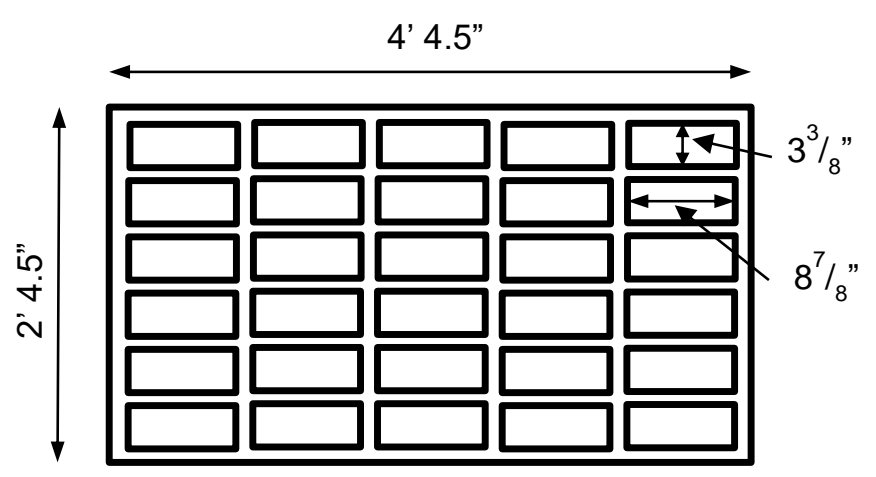

Figure 1-1: Views of the CB25 grate, (a) cross section through a barrier and grates, and (b) top view with marked dimensions 


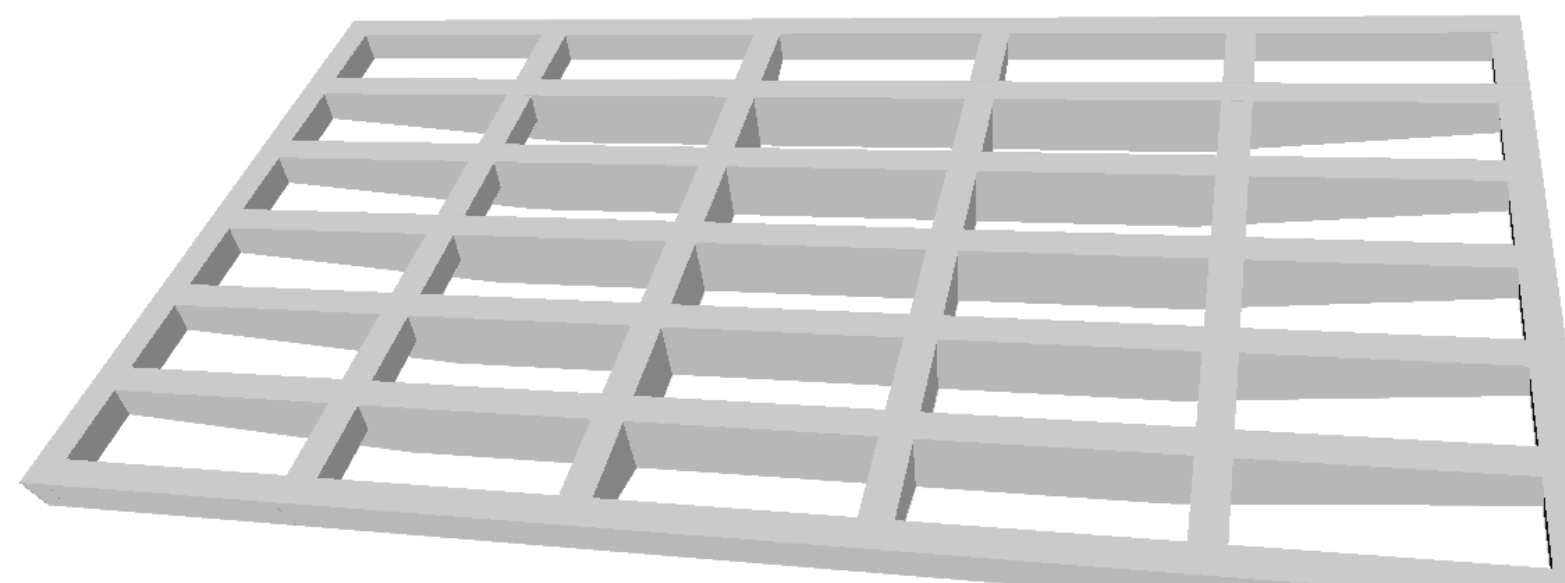

Figure 1-2: Rendering of the inlet grate

A typical cross-section through an interstate highway is shown in Figure 1-3. It was assumed in this study that the roadway and shoulder cross-slopes are equal to the typically used values: $2 \%$ for the roadway and $4 \%$ for the shoulder. These cross-slopes were not parameters of the study and were taken to be constant. The travel lane is 12 feet wide. Four widths of the shoulder were tested: 4, 4.75, 7.5, $10 \mathrm{ft}$. The purpose of the catch basin is to intercept water from the center part of one direction of travel on the road. The drainage area width is equal to one travel lane plus the shoulder (from the road crown to the median), as shown in Figure 1-4. The design length, which is equal to the spacing between inlets, is such that the spread of water measured from the median is less than the allowable spread for the design rain intensity. The allowable spread differs depending on the type of the road, mostly it is limited by the width of the shoulder. The longitudinal slope of the roadway may vary. Longitudinal slopes of $0.3 \%, 1 \%, 3 \%, 5 \%$, and $7 \%$ were tested in this study for shoulder widths up to $7.5 \mathrm{ft}$. In some cases, an additional slope of $4 \%$ was considered. When shoulder width was $10 \mathrm{ft}$, the tested longitudinal slopes were: $0.3 \%, 1 \%, 2 \%$, $3 \%$, and $4 \%$. It was assumed that the roadway surface Manning number equals 0.011. Table 1-1 lists the variables of the study with the combinations of value ranges considered in this study.

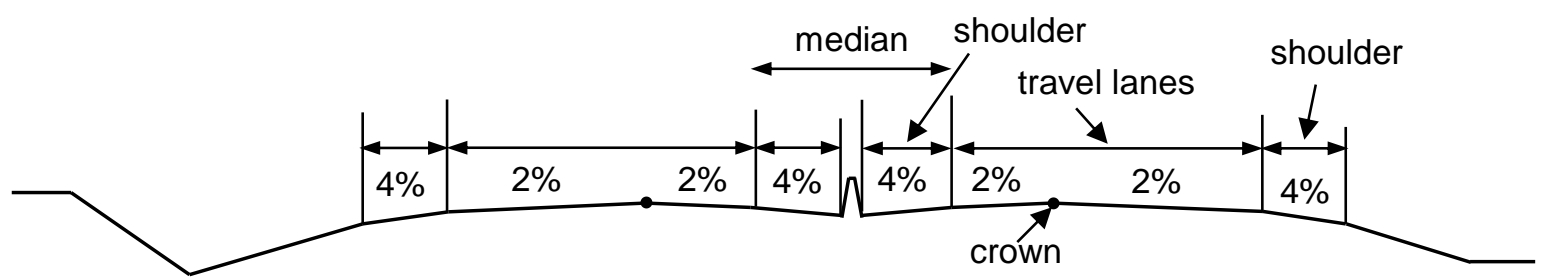

Figure 1-3. A cross-section of a typical rural/urban six-lane divided freeway 


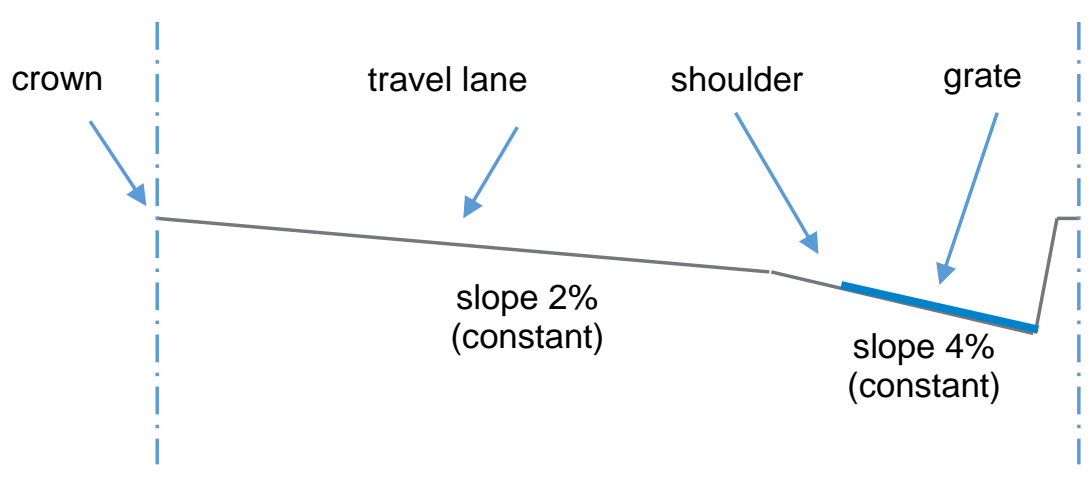

Figure 1-4. A cross section through the drainage area of a freeway

Table 1-1: Variables of the study with ranges

\begin{tabular}{|c|c|c|}
\hline $\begin{array}{c}\text { Shoulder } \\
\text { width }\end{array}$ & $\begin{array}{c}\text { Longitudinal } \\
\text { slope range }\end{array}$ & Max considered spread width \\
\hline $4 \mathrm{ft}$ & & $2 \mathrm{ft} \div 6 \mathrm{ft}$ \\
\hline $4.75 \mathrm{ft}$ & $0.3 \% \div 7 \%$ & $2 \mathrm{ft} \div 6.75 \mathrm{ft}$ \\
\cline { 3 - 3 } & & $2 \mathrm{ft} \div 7.5 \mathrm{ft}$ \\
\hline $7.5 \mathrm{ft}$ & & $8 \mathrm{ft} \div 10 \mathrm{ft}$ \\
\hline $10 \mathrm{ft}$ & $0.3 \% \div 4 \%$ & \multicolumn{2}{|c}{} \\
\hline
\end{tabular}

Because CB25 is a relatively new design, there was a need to perform a hydraulic study and assess the hydraulic performance of the design. The researchers at TRACC were asked to perform CFD analysis that would lead to obtaining all data needed for designing the spacing between drains, such as the efficiency curves as function of the spread or volume flow rate, the longitudinal slope, and the shoulder width, as well as the flow spread along the roadway in the vicinity the catch basin inlet. In addition, a description of the analysis case runs was included, covering all data from the simulations and programing explanations.

Appendix A contains the results for each of the CFD simulations. Results are combined in the tables of the appendix. The information includes the input parameters describing the geometry of the roadway, such as width of the shoulder, longitudinal slope, and the inflow rate, and output parameters, such as maximum water depth, water spread, flow intercepted by the grate through the front and side, fraction of total flow, and efficiency of the grate.

A design aid was provided in the form of a Microsoft Excel file containing the necessary information, collected from the CFD simulations, as well as formulas required to calculate the spacing between catch basins. Detailed instructions on how to use the spreadsheet, as well as a screenshot of the spreadsheet with example calculations are presented in Appendix B. 


\section{Procedure to assess the efficiency of the grate}

Each geometry case was studied for a set of flow rate (or flow spread) values. The following procedure was implemented to assess the efficiency of the catch basin at various flow rates. For each road geometry:

1. Take set of flow spread values ranging from the width of the grate $T_{g}$ to the allowable spread $T_{\text {max }}$.

The set of spread widths $T_{i}$ was chosen in the range from the grate width $T_{g}=2 \mathrm{ft}$ to $T_{\text {max }}$, which was assumed to be the combined width of the shoulder and a $2 \mathrm{ft}$ strip of the travel lane. Figure 2-1 shows the upper and lower limit of the considered range and an example spread width $T_{i}$. Initially five points in this range were chosen.

2. Calculate the inlet values of the flow rate $Q$ and flow velocity $V$ for each spread.

For each assumed spread, combined with the road geometry variables, the gutter flow was used to calculate the volume flow rate of water [1]:

- for uniform gutter cross sections (when the spread is smaller than the shoulder width):

$$
D_{2}=S_{g} T, Q=\frac{K_{u}}{n} S_{g}^{-1} S_{l}^{0.5} D_{2}^{2.67}
$$

- for composite gutter cross sections (when the spread is bigger than the shoulder width):

$$
D_{2}=S_{x}(T-W), D_{1}=D_{2}+S_{g} W, Q=\frac{K_{u}}{n} S_{l}^{0.5}\left[S_{x}^{-1} D_{2}^{2.67}+S_{g}^{-1}\left(D_{1}^{2.67}-D_{2}^{2.67}\right)\right] \text {, }
$$

and also the inlet flow velocity as:

$$
V=Q / A,
$$

where: $Q$ is the volume flow rate, $K_{u}$ is 0.376 for metric units or 0.56 for English units, $D_{1}$ and $D_{2}$ are gutter depths for a composite and uniform gutter cross-sections, $S_{x}$ is the roadway cross slope, $S_{g}$ is the shoulder cross slope, $S_{l}$ is the longitudinal slope, $n$ is Manning's coefficient ( $n$ is o.011 for smooth asphalt), $T$ is the spread in meters or feet, $W$ is the shoulder width, $V$ is upstream mean inlet velocity, $A$ is the inlet area computed from the road geometry, spread, and implied water depth at the barrier, assuming a level water surface (see Figure 2-1 for illustration of geometry parameters):

- for uniform gutter cross sections:

$$
A=0.5 S_{x} T^{2},
$$

- for composite gutter cross sections:

$$
A=0.5 S_{x}\left(T^{2}-W^{2}\right)+0.5 S_{g} W^{2} .
$$


3. Run CFD simulations with the calculated inlet parameters. Monitor the flow intercepted by the catch basin, $Q_{i}$, and the bypass flow, $Q_{b}$, for the known the upstream inflow $Q$ to check global mass balance in a converged solution. Establish the efficiency, $Q_{i} / Q$, of the CB25 for each flow rate (spread).

For a steady state, the inflow will be equal to the outflow intercepted by the grate plus the flow that bypasses the grate and continues down the roadway, satisfying conservation of mass. In the computations, the mass rate balance was monitored during the simulations as one of the measures of convergence of the solution. The model was set up in a way that allows tracking of the mass flow across all surfaces of the grate: front, side, and back. During the post processing the ratios of the front, side, and back flow to total flow were established. Also, the collected data was used to calculate the efficiency of the grate, $E$, as a ratio of the flow intercepted by the grate, $Q_{i}$, to total flow, $Q$,

$$
E=\frac{Q_{i}}{Q}
$$

as well as the bypass (carryover) flow, $Q_{b}$, that is not intercepted by the inlet

$$
Q_{b}=Q-Q_{i}
$$

4. Generate curves and fitted functions of efficiency vs. spread or flow rate: $E(T)$ or $E(Q)$ for each road geometry.

A point plot from the collected results was created and curve fitting was done.

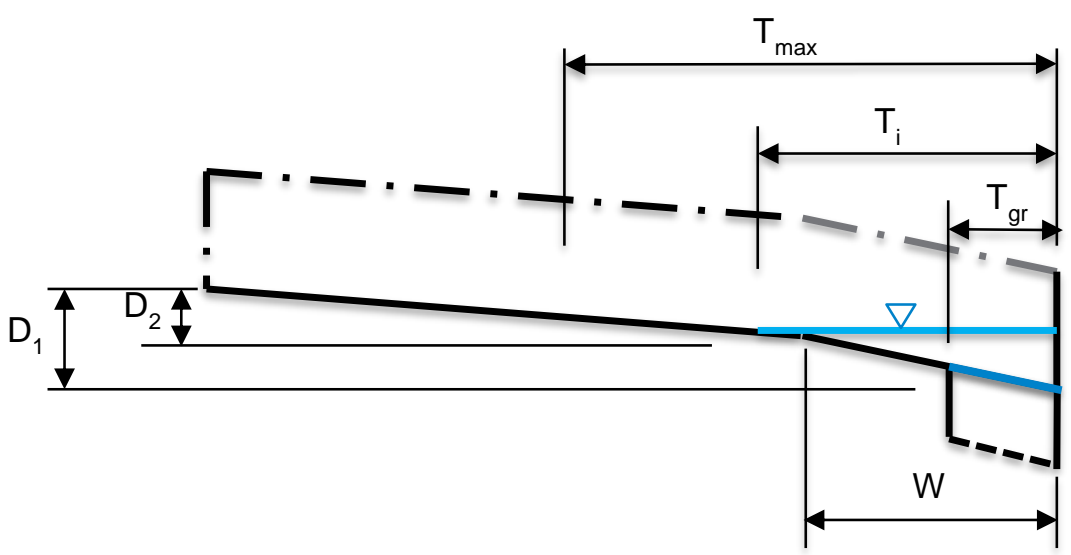

Figure 2-1: Cross-section through the roadway with the maximum, minimum, and intermediate spreads at the inflow surface, where $\mathrm{T}_{\max }$ is the allowable spread, $\mathrm{T}_{\mathrm{i}}$ is the spread for $\mathrm{i}$-th case, $\mathrm{T}_{\mathrm{gr}}$ is the minimum spread equal to the grate width, $W$ is the shoulder width, $D_{1}$ is the flow depth in a uniform gutter cross-section, $\mathrm{D}_{2}$ is flow depth in composite gutter cross-section

Table 2-1 combines the test case sets for the considered shoulder widths and longitudinal slopes. The test case matrix initially included simulations for: 4 shoulder widths, 5 longitudinal slopes, and 5 spread widths for each case set. The tested shoulder widths were: $4,4.75,7.5$, and $10 \mathrm{ft}$, and 
the longitudinal slopes varied from $0.3 \%$ to $7 \%$, as these are commonly used in South Carolina highways. The flow spread measured from the median should not exceed the allowable value at the design rainfall intensity. The allowable spread is equal to the shoulder width or minimum 6 feet. The values tested in the analysis were ranging from $T_{\min }$ equal to the grate width, up to $T_{\max }$, equal to the allowable spread plus 2 feet.

In some cases, i.e. $4.75 \mathrm{ft}$ shoulder width with spread $4.75 \mathrm{ft}$ and $6.75 \mathrm{ft}$, as well as $7.5 \mathrm{ft}$ shoulder with $6 \mathrm{ft}$ and $7.5 \mathrm{ft}$ spread, an analysis showed that an additional data point was necessary to find a clear trend in dependence of various quantities on longitudinal slope. Therefore, an additional model with a $4 \%$ longitudinal slope was prepared.

Each CFD simulation was documented in Appendix A. The information included the input parameters describing the geometry of the roadway and the inflow rate, and output parameters, such as maximum water depth, water spread, and the flow intercepted by the grate.

Table 2-1: Test case set matrix

\begin{tabular}{|c|c|c|c|c|c|c|}
\hline \multirow{2}{*}{$\begin{array}{c}\text { Shoulder } \\
\text { width, W } \\
\text { [ft] }\end{array}$} & \multirow{2}{*}{$\begin{array}{c}\text { Longitudinal } \\
\text { slope [\%] }\end{array}$} & \multicolumn{5}{|c|}{ Spread width, T [ft] } \\
\hline & & 2 & 3 & 4 & 5 & 6 \\
\hline \multirow{4}{*}{4} & 1 & 2 & 3 & 4 & 5 & 6 \\
\hline & 3 & 2 & 3 & 4 & 5 & 6 \\
\hline & 5 & 2 & 3 & 4 & 5 & 6 \\
\hline & 7 & 2 & 3 & 4 & 5 & 6 \\
\hline \multirow{6}{*}{4.75} & 0.3 & 2 & 3 & 4 & 4.75 & 6.75 \\
\hline & 1 & 2 & 3 & 4 & 4.75 & 6.75 \\
\hline & 3 & 2 & 3 & 4 & 4.75 & 6.75 \\
\hline & 4 & - & - & - & 4.75 & 6.75 \\
\hline & 5 & 2 & 3 & 4 & 4.75 & 6.75 \\
\hline & 7 & 2 & 3 & 4 & 4.75 & 6.75 \\
\hline \multirow{6}{*}{7.5} & 0.3 & 2 & 3 & 4 & 6 & 7.5 \\
\hline & 1 & 2 & 3 & 4 & 6 & 7.5 \\
\hline & 3 & 2 & 3 & 4 & 6 & 7.5 \\
\hline & 4 & - & - & - & 6 & 7.5 \\
\hline & 5 & 2 & 3 & 4 & 6 & 7.5 \\
\hline & 7 & 2 & 3 & 4 & 6 & 7.5 \\
\hline \multirow{5}{*}{10} & 0.3 & 8 & 10 & & & \\
\hline & 1 & 8 & 10 & & & \\
\hline & 2 & 8 & 10 & & & \\
\hline & 3 & 8 & 10 & & & \\
\hline & 4 & 8 & 10 & & & \\
\hline
\end{tabular}




\section{Computational modeling approach}

The proposed scope of work covers a Computational Fluid Dynamics (CFD) parametric study with varying longitudinal slope of the roadway and shoulder width. The following road geometry variables were tested: longitudinal slope in the range from $0.3 \%$ to $7 \%$ and shoulder width from $4 \mathrm{ft}$ to $10 \mathrm{ft}$. Each geometry case was studied for a set of flow rate values.

Figure 3-1 illustrates a cross-section through the CFD domain and its top view. The computational model resembles a full-scale model of an 8o-foot long section of a highway [2]. The width of the section is limited by the road crown and the barrier at the median and covers the width of the shoulder and one travel lane (12-foot wide) or part of a lane. In order to decrease the size of the domain to an acceptable minimum to conserve computer resources, without any loss in the accuracy of computations, the width of the domain was decreased further when smaller flow spreads were analyzed; e.g. for a 6 foot spread the domain width was $7 \mathrm{ft}$ (see Figure 3-2, where the part marked in white is not essential for the computations, as the entire flow fits into the blue part). The travel lane has a $2 \%$ cross slope and the surface of the shoulder has a $4 \%$ cross slope. The grate is located approximately $50 \mathrm{ft}(15.24 \mathrm{~m})$ away from the surface where the flow enters the domain.

(a)

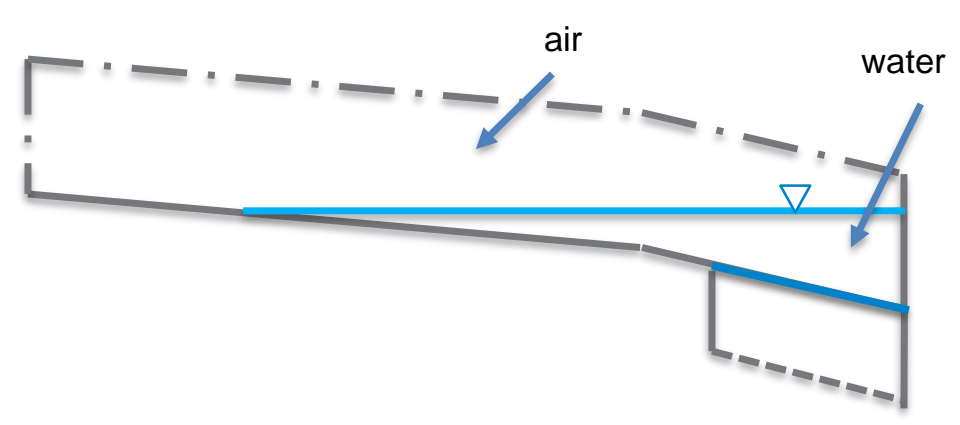

(b)

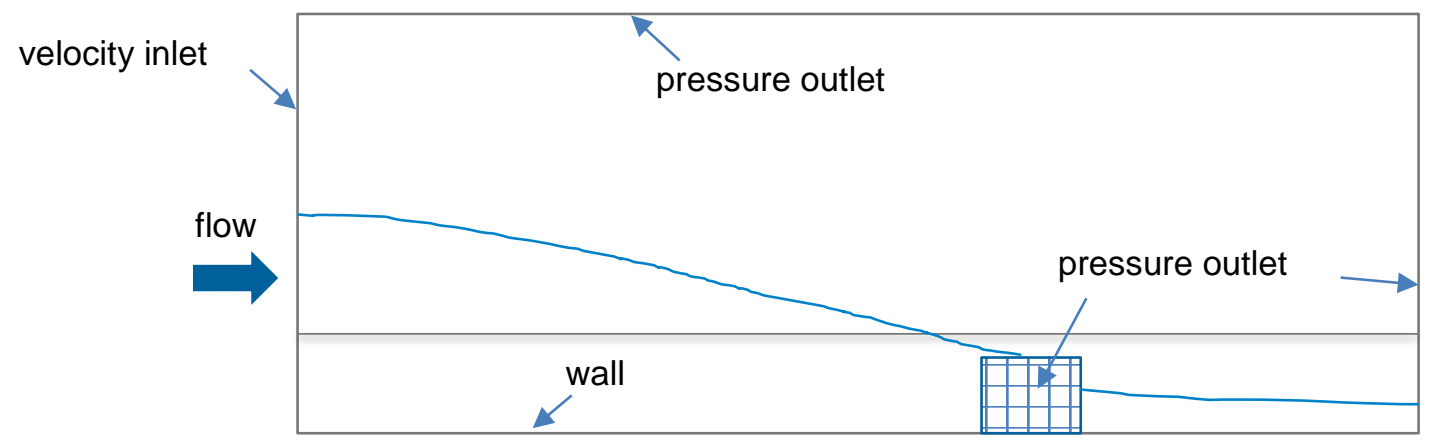

Figure 3-1: Sketches of the CFD domain, (a) a cross-section through the computational domain, (b) a top view of the computational domain with flow direction (blue arrow) and example flow spread (blue line) 


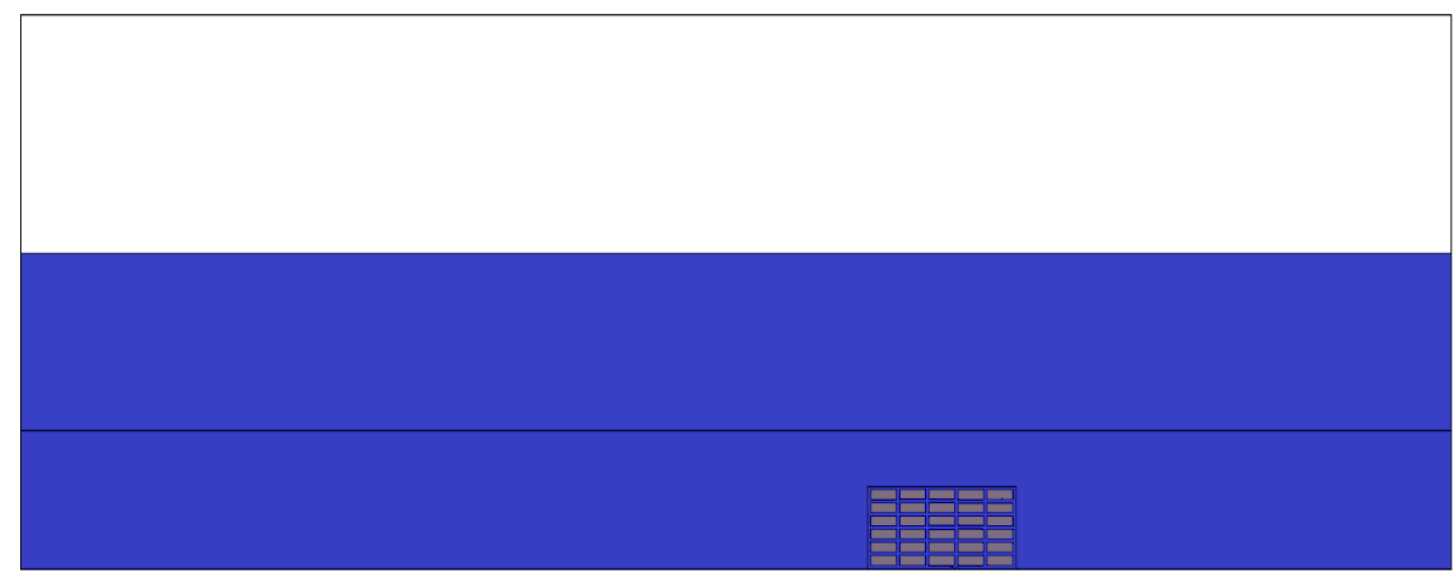

Figure 3-2: The full width of the shoulder and the $12 \mathrm{ft}$ roadway lane (black edges), and the part chosen as the computational domain (dark blue)

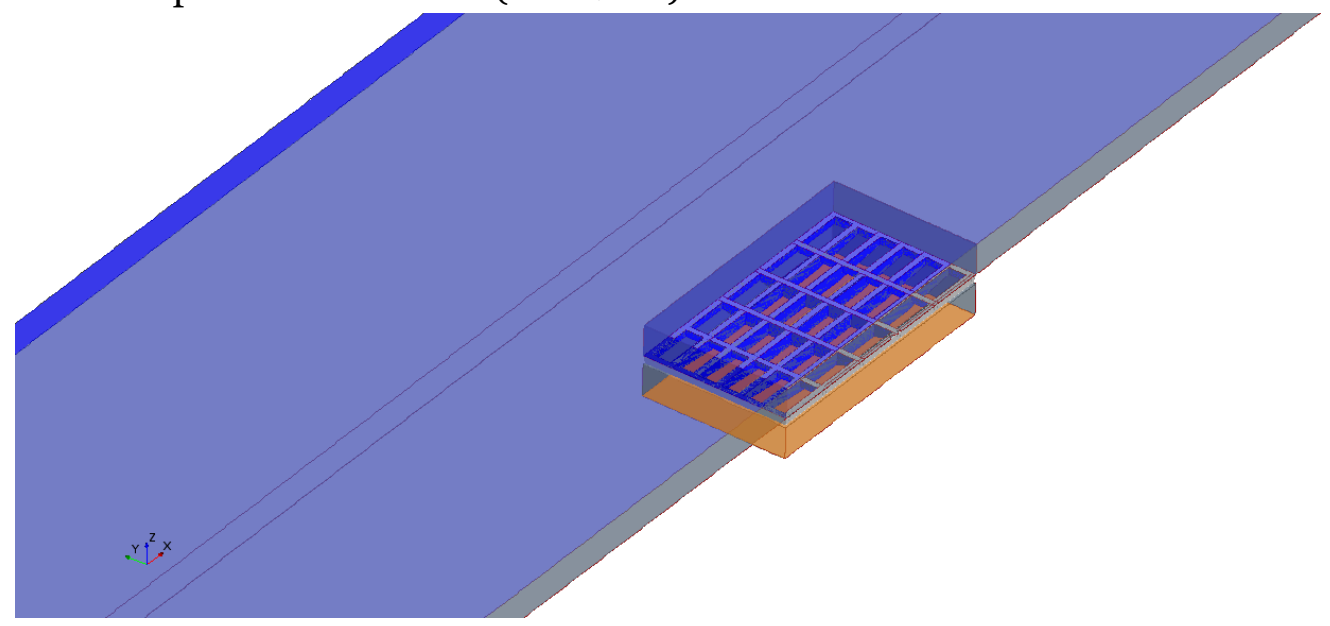

Figure 3-3: Geometry of the computational domain in the vicinity of the grate. The domain was divided into three regions: below the grate, above the grate and the remaining shoulder and roadway

A Volume of Fluid (VOF) multiphase flow model for water on the road with air above was used along with an unsteady Reynolds averaged Navier-Stokes (URANS) solver for the fluid flow governing equations with a k- $\varepsilon$ turbulence model and standard wall functions to compute shear stress at the street and barrier wall boundaries. The VOF model makes it possible to model water and air in the same domain with only one momentum equation and to track the free surface between the two phases. The free surface is shown in Figure 3-1(a) with a blue line between the water and air.

The left hand side surface was defined with a velocity inlet boundary (see Figure 3-1(b)). The mean flow velocity was calculated from an assumed flow rate, $Q$, established according to HEC-22 [1] for any given flow spread according to the procedure described in Chapter 2. The right hand side surface has a pressure outlet boundary condition assigned. The water can also leave the domain through the grate. An additional region was created below the grate. The bottom surface of this 
region is an outflow surface. Thanks to this approach the outlet surface is far enough from the grate so it doesn't influence the numerical result. The location of the inlet (on the left) and outlet (on the right) boundaries was determined so that they also are far enough from the grate not to influence the flow in the area of the grate. A similar approach was used in a previous study [3].

On the roadway and shoulder surfaces, a rough wall boundary condition was specified. Star$\mathrm{CCM}+$ specifies roughness with the use of roughness height parameter, $k_{s}$ [4]. Strickler's formula relates the roughness height and Manning's number in the following way [5]:

$$
n=0.038 k_{s}^{1 / 6} .
$$

For example if Manning number, $n$, equals 0.011, the roughness height $k_{s}$ is $0.5 \mathrm{~mm}$.

The median barrier was modeled with a smooth no-slip wall boundary condition assuming that it was smooth concrete.

The top surface of the model as well as the surface on the opposite side from the curb (on the median side) were modeled as pressure outlet boundary condition. Both were far enough from the water phase, that they did not influence the solution.

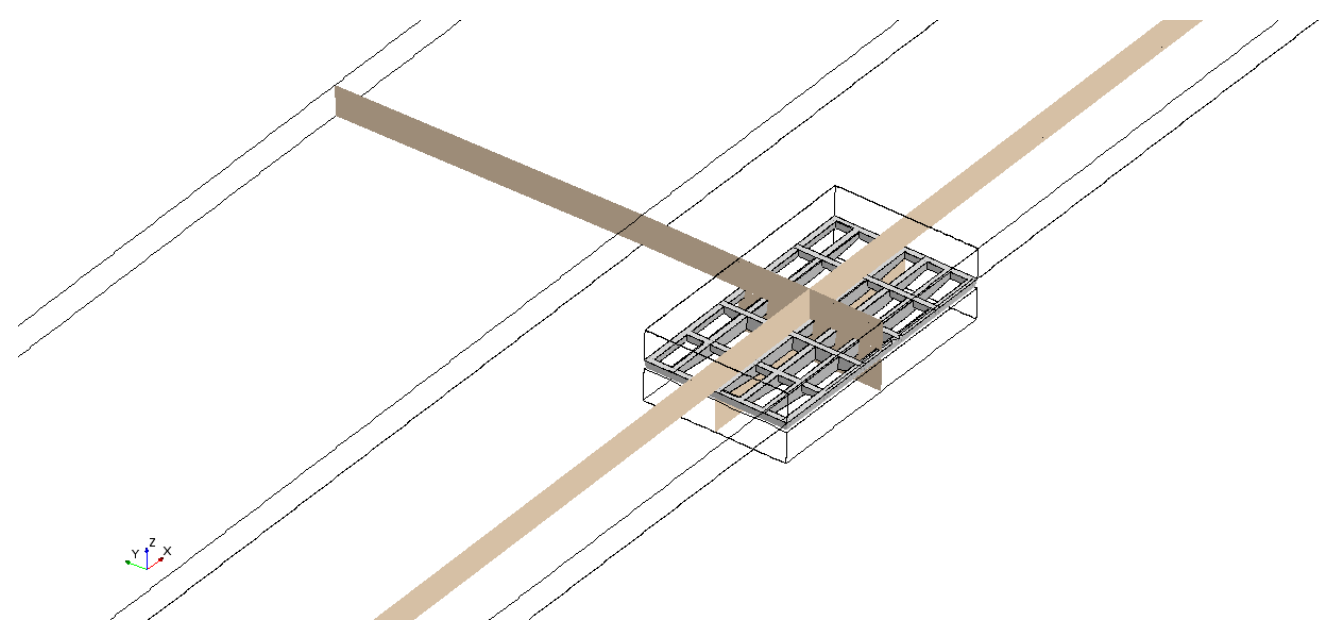

Figure 3-4: Location of the cross-sections used for monitoring the mesh 
(a)

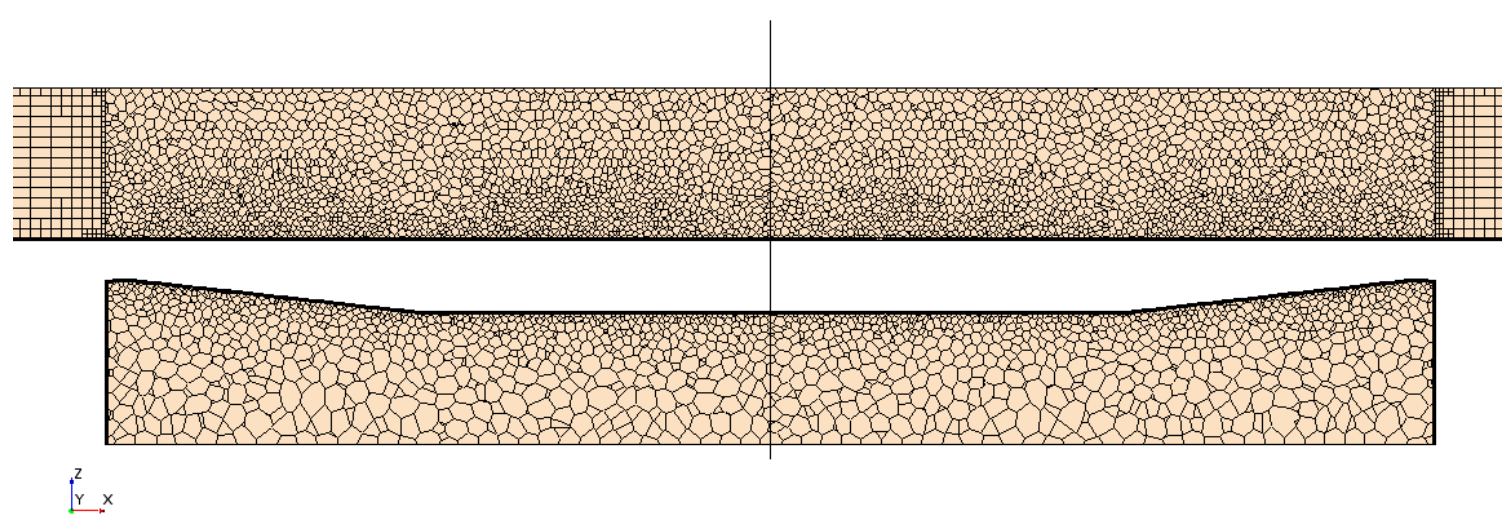

(b)

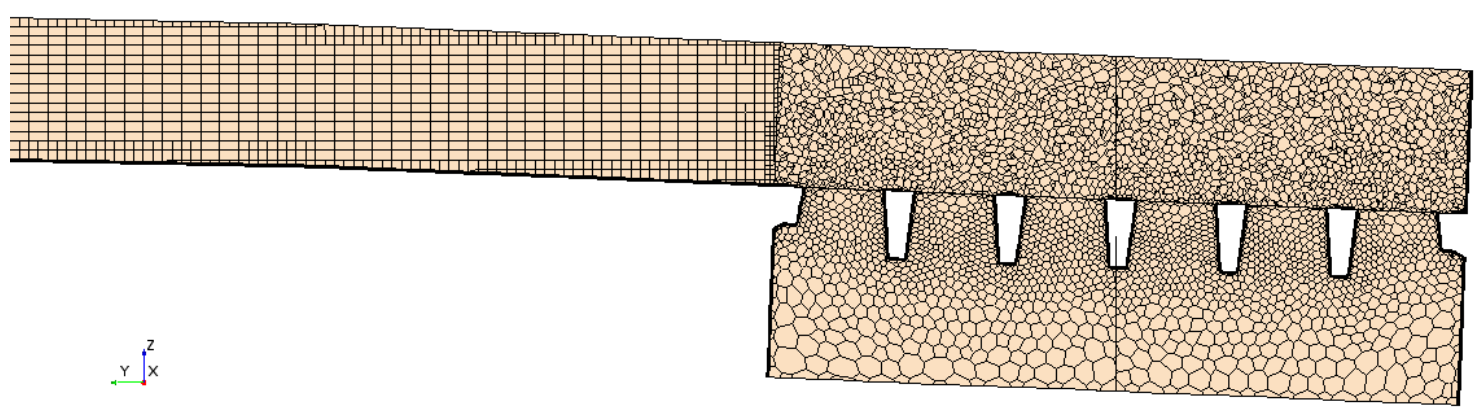

Figure 3-5: Domain discretization on cross-section planes through the domain (a) along the flow, and (b) perpendicular to the flow

Two types of mesh cell shapes were used in the model: hexahedral and polyhedral. The hexahedral mesh was used for the space above the roadway and the shoulder, and the polyhedral mesh was used in the space above and below the grate. A hexahedral mesh works best in regions where the mesh is aligned with the flow and so it was used in the areas where the flow is mostly parallel to the median barrier. The flow above and below the grate is multidirectional and using a hexahedral mesh there would cause numerical diffusion. Polyhedral cells reduce the numerical diffusion and therefore they were chosen for this region. The domain was divided into three regions, which made it easier to assign various mesh settings, such as the cell shape, its target, and its minimum size. The total number of computational cells depends on the size of the domain, and it varied between $\sim 5$ million to $\sim 10$ million cells. Figure 3-4 shows the location of the cross-sections used for monitoring the mesh, and Figure 3-5 shows the domain discretization on cross-section planes through the domain (a) along the flow, and (b) perpendicular to the flow.

The simulated time, needed to obtain a converged solution, differs from case to case. It depends on the residence time of the flow, and therefore the mean flow velocity. The computations were stopped when the mass rate of the inflowing and outflowing fluid was in balance. Note that there were two outlets, (1) through the grate, and (2) bypass flow on the street leaving the domain at the left end of the domain. The time step was also chosen due to the input parameters of the simulation. For the cases with faster moving water it was decreased to capture the details of the flow pattern above the grate. 
Two plane sections were defined: 1 foot and 2 feet away from the grate, on the upstream side with the purpose of monitoring of the water depth, spread, and mean flow velocity. Also, section planes were placed: at the front (a), on the side (b), and at the back side of the grate (c), and across the grate (d), see Figure 3-6. The water mass flow was monitored on these planes for the purpose of calculating the ratio of the front and side flow to the total flow going through the inlet grate.

The mass flow rate was computed internally in the software as an integral over a plane surface

$$
\dot{m}=\iint \rho v d A,
$$

where $\rho$ is water density, $v$ is water velocity, and $A$ is the area of the surface.

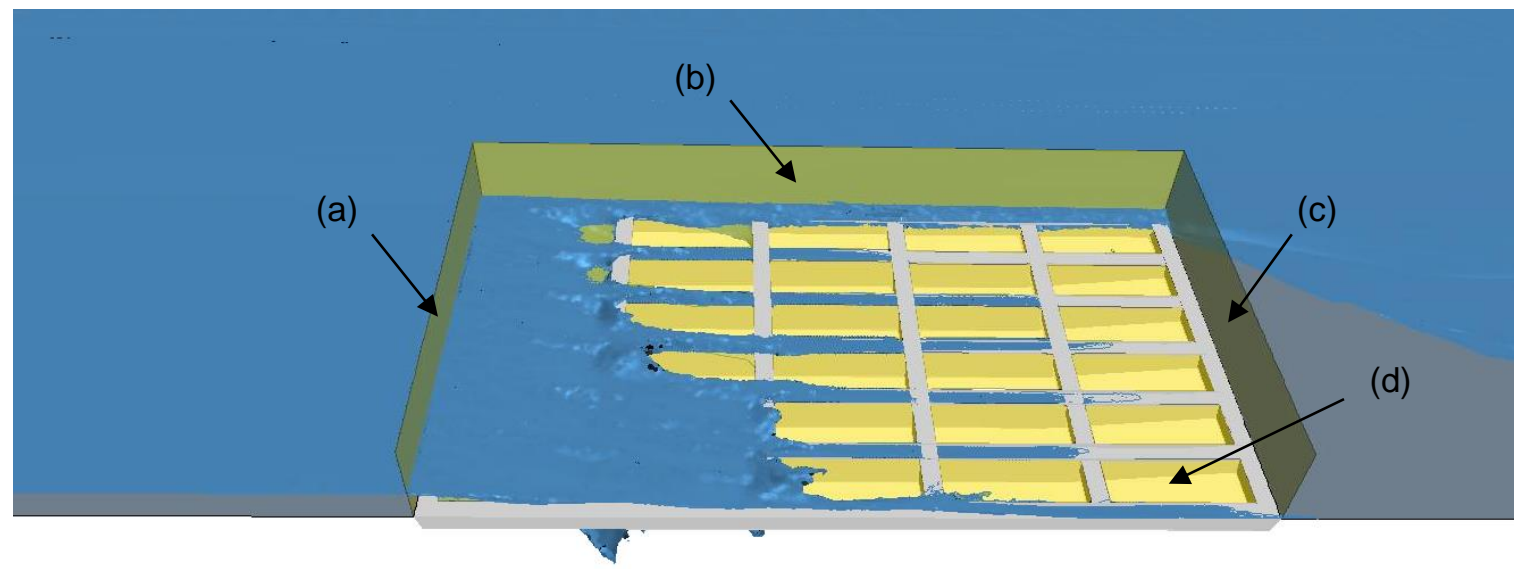

Figure 3-6: Example water flow through the grate. The yellow planes show the surfaces used to monitor the flow: (a) front flow, (b) side flow, (c) back flow and (d) outflow through the grate

\section{Simulation results}

The following chapter presents the three dimensional computational fluid dynamics simulations results. The chapter covers an analysis of various flow patterns observed in the simulations, illustrated with a few examples. The dependence of the computational solution, and hydraulic efficiency of the grate, on the initial conditions is discussed. Moreover, the computational interception rates of flow through the grate were combined and plotted against flow spread and longitudinal slope for each road geometry. The fractions of flow over the grate entering from the upstream end and from the side of the grate were calculated and output with the results. The hydraulic efficiency was calculated for each case and also plotted against longitudinal slope. Upstream Reynolds and Froude numbers were defined and correlations were found between the efficiency and these two non-dimensional parameters.

\subsection{Flow surface patterns}

Computational fluid dynamics simulations make it possible to observe in detail various flow patterns that depend on geometry of the roadway and hydraulic conditions. When the flow 
velocity is low and the spread doesn't exceed the width of the grate, then all or majority of the flow is intercepted by the grate. Figure 4-1 show a case with low inlet flow rate and a flow spread that is smaller than the width of the grate. In this case all of the flow enters over the grate through the upstream end, there is no splash over, and the efficiency of the grate is $100 \%$. When the spread is wider than the grate and the flow velocity is higher, part of the flow bypasses the grate due to inertia force. Figure 4-2 presents a flow with a higher flow rate and spread wider than the grate width. The surface of the water over the grate breaks and enters the catch basin, but not over the entire grate width, so some water entering over the grate near the curb is not intercepted by the grate. The flow through the upstream end of the grate exceeds the side inflow. The grate does not capture all of the water flowing over it, and there is a significant amount of bypass flow that does not cross over the grate, which results in a bypass flow. When the spread is wider than the grate there is a possibility of splash-over occurrence. In this case, if the grate is long enough, the splashed water can be still intercepted by the grate; otherwise, the hydraulic efficiency of the grate decreases. Figure 4-2 shows a few streaks of water splashing over the grate. The flow is partially intercepted by the grate. In the situation of extreme values of the flow rate, the grate can be overtopped by the water. An example of overtopping was shown in Figure 4-3. Table 4-1 illustrates the flow surface pattern types for all simulated geometry and flow conditions. The patterns were divided into three types: fully captured flow, broken water surface with bypass flow, and overtopped grate.
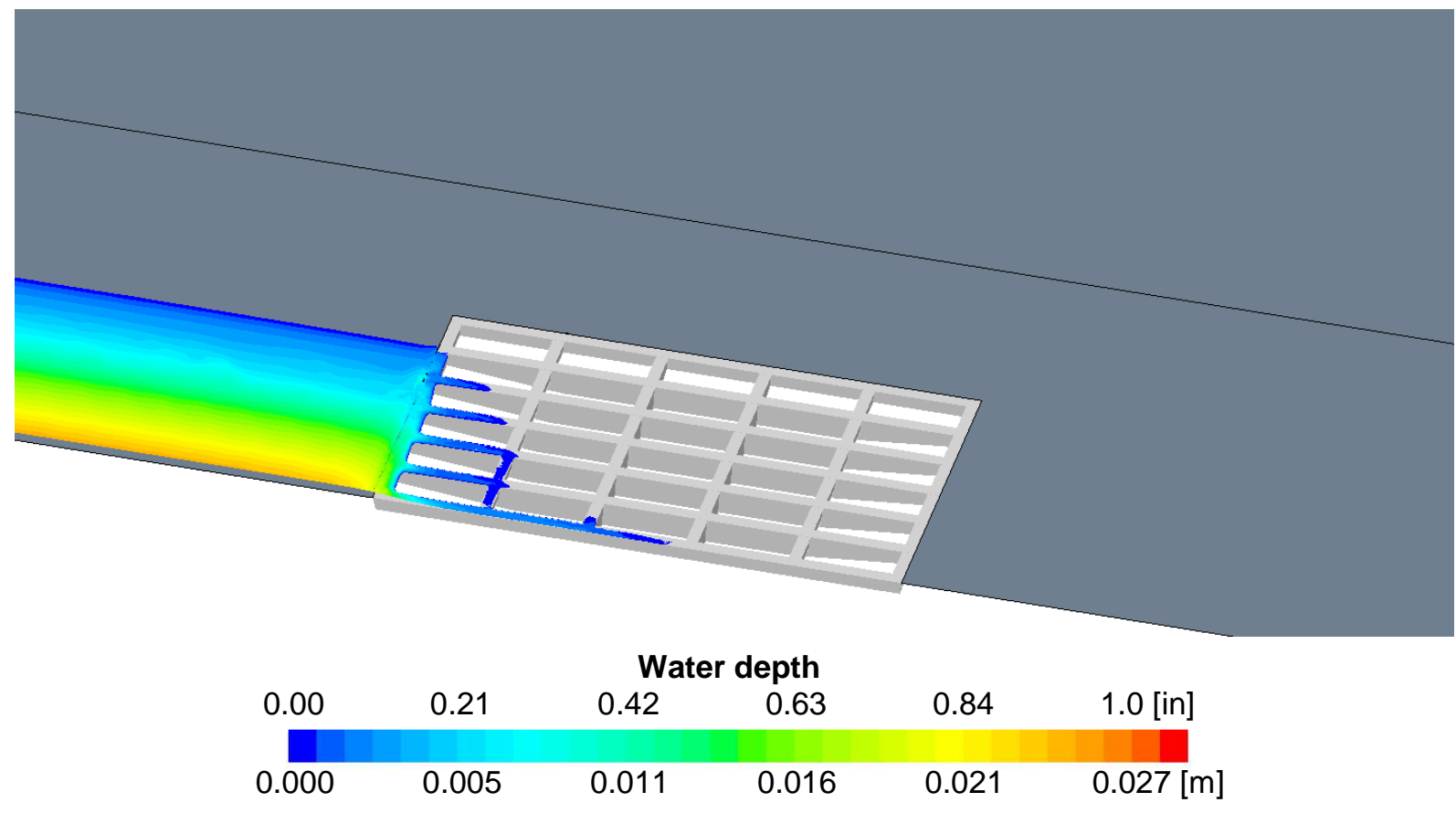

Figure 4-1: Flow pattern with water depth plotted on the water surface. Shoulder width $4 \mathrm{ft}$, flow spread $2 \mathrm{ft}$, longitudinal slope $0.3 \%$. 


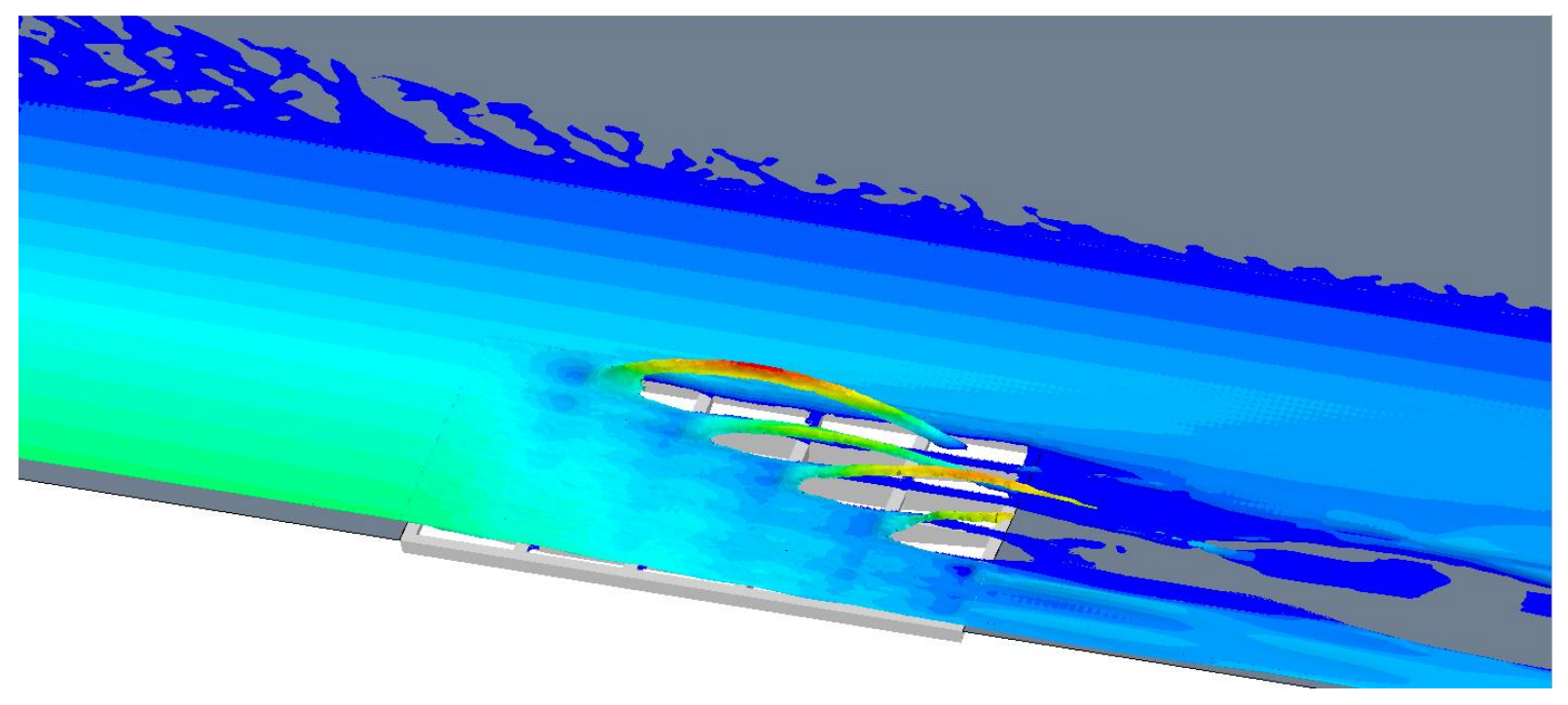

\begin{tabular}{llllll}
\multicolumn{7}{c}{ Water depth } \\
0.00 & 1.0 & 2.05 & 3.07 & 4.0 & $5.12[\mathrm{in}]$ \\
\hline 0.000 & 0.026 & 0.052 & 0.078 & 0.1 & $0.13[\mathrm{~m}]$
\end{tabular}

Figure 4-2: Flow pattern with water depth plotted on the water surface. Shoulder width $4 \mathrm{ft}$, flow spread $6 \mathrm{ft}$, longitudinal slope $7 \%$.

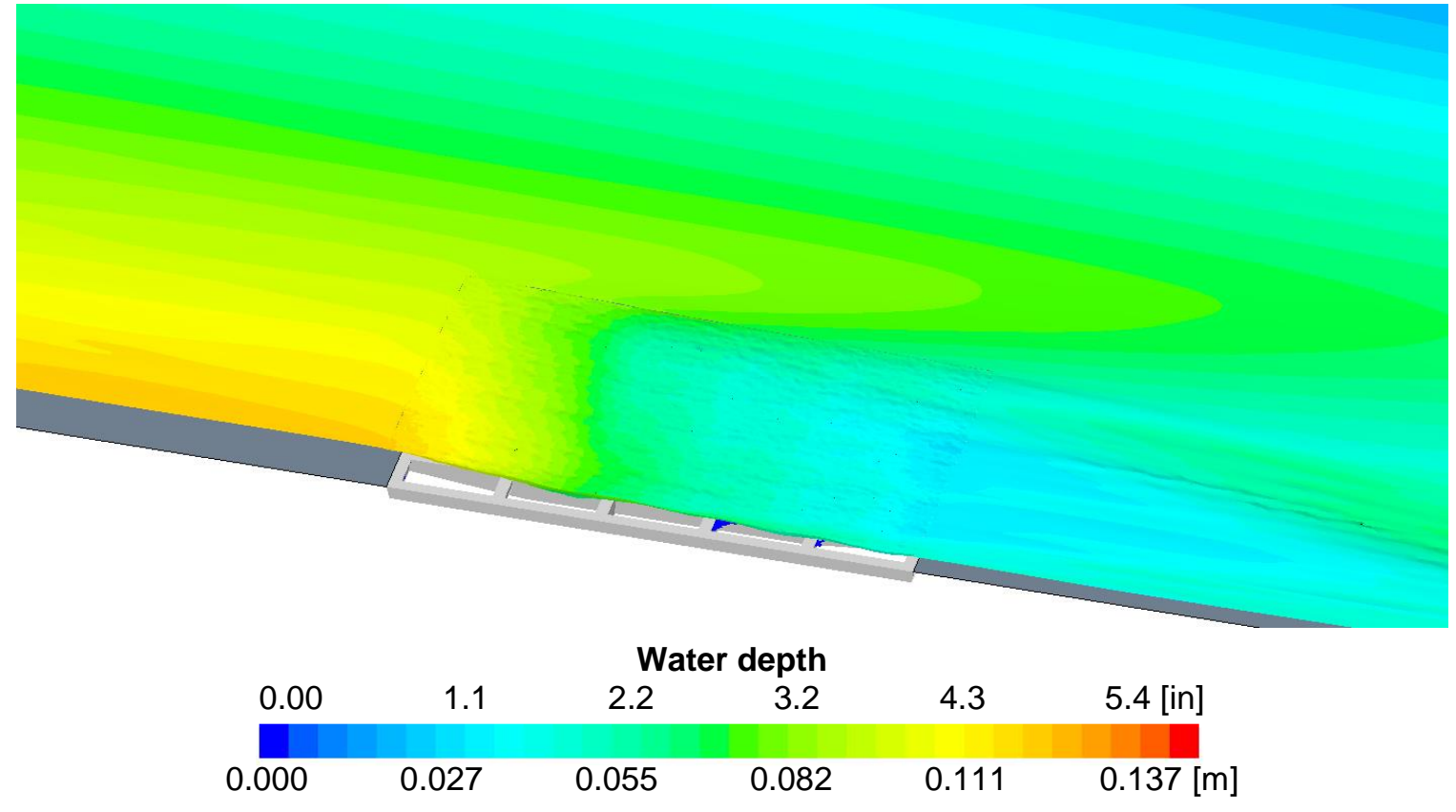

Figure 4-3: Flow pattern with water depth plotted on the water surface. Shoulder width $10 \mathrm{ft}$, flow spread $10 \mathrm{ft}$, longitudinal slope $4 \%$. 
Table 4-1: Flow surface pattern types: $\forall$ - fully captured flow, $\vec{\nabla}$ - broken water surface with bypass flow, $\Rightarrow$ - overtopped grate, $(-)$ - case not considered in the study

\begin{tabular}{|c|c|c|c|c|c|c|c|c|c|}
\hline & W4ft & W4ft & W4ft & W4ft & W4ft & W4.75ft & W4.75ft & W7.5ft & W7.5ft \\
\hline SL & T2ft & T3ft & T4ft & T5ft & T6ft & T4.75ft & T6.75ft & T6ft & T7.5ft \\
\hline 0.3 & & & & & & 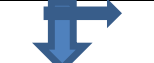 & & & \\
\hline 1 & & & & & & & & & \\
\hline 3 & & & & & & & & & \\
\hline 4 & & - & - & - & 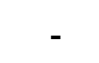 & & & & \\
\hline 5 & & & & & & & & & \\
\hline 7 & & & & & & & & & \\
\hline
\end{tabular}

\begin{tabular}{|c|c|c|}
\hline & W10ft & W10ft \\
\hline SL & T8ft & T10ft \\
\hline 0.3 & & \\
\hline 1 & & \\
\hline 2 & & \\
\hline 3 & & \\
\hline 4 & & \\
\hline
\end{tabular}

\subsection{Recommendations for reducing the bypass flow}

In the majority of the considered cases of roadway geometry and flow rate, only part of the flow is captured by the grate. In the worst scenario, the resulting bypass flow makes up for $67 \%$ of the total inflowing water. This bypassing flow could be intercepted in full, or partially, by a double grate, with the second inlet located downstream of the first one. Usually double grates are designed to be installed one next to the other. In some cases, it is more beneficial to build the second grate away from the first one, because there is a length of road just beyond the grate where the spread is contracting as water falls back to the curb, filling space created by water diverted into the grate. The distance over which this occurs is called the 'reattachment length', or 'fallback distance'. This behavior was illustrated in Figure 4-4. It shows streamlines of water velocity downstream from the grate, for a set of simulations using a 6-foot flow spread on a roadway with 4-foot shoulder, and longitudinal slope (a) $0.3 \%$, (b) $1 \%$, (c) $3 \%$, (d) $5 \%$, (e) $7 \%$. The fallback 
distance, $\mathrm{d} 1$, was marked in the figure, along with distance $\mathrm{d} 2$, which is the distance from the grate to a point where the spread is the narrowest, and starts to stabilize. For the two smallest longitudinal slopes the fallback of the bypass flow occurs directly behind the grate, therefore installing the second grate next to the first one will assure its full interception. When the slope is bigger, both distances, $\mathrm{d} 1$, and $\mathrm{d} 2$, are larger than one grate width. In this case it would be more beneficial to install the second grate further away, in the area just beyond where the bypassing flow falls back to, and follows, the curb. Additional study is needed to determine which distance should be chosen to maximize the intercepted flow. In authors opinion, it is possible that, if the width of the bypass flow is less than grate width, then distance $\mathrm{d} 2$ is more reasonable, but if the flow is wider, this determination is not trivial.

Table 4-2 shows the distances established for a road with a 4-foot shoulder and flow rates corresponding to a 6-foot spread. Figure 4-5 and Figure 4-6 present the distances d 1 and d2 for all geometry and flow conditions, where it was possible to determine their location (there was no overtopping of the grate). Cases with efficiency close to $100 \%$ were omitted, as well as cases in which distance $\mathrm{d} 2$ fell outside of the domain.

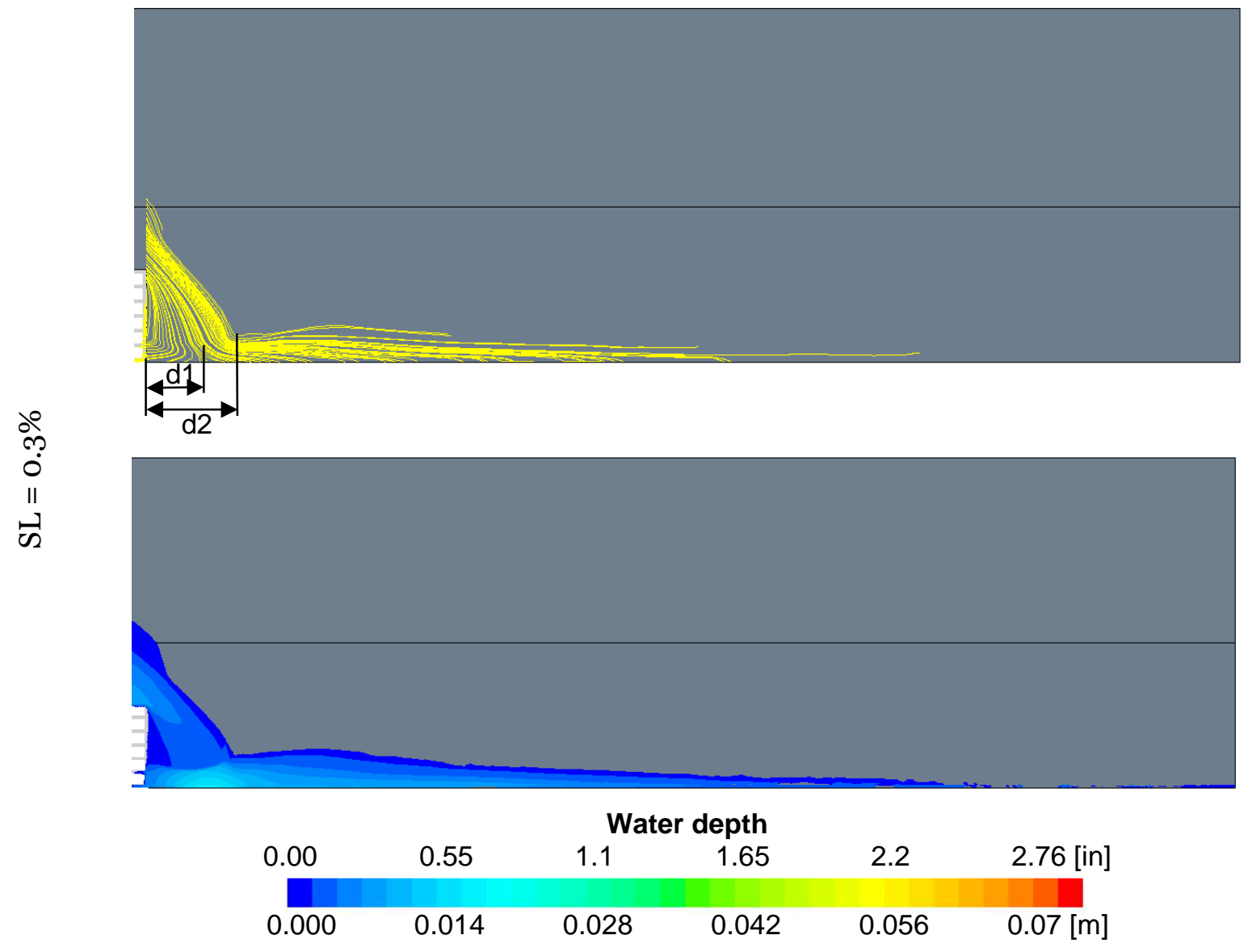



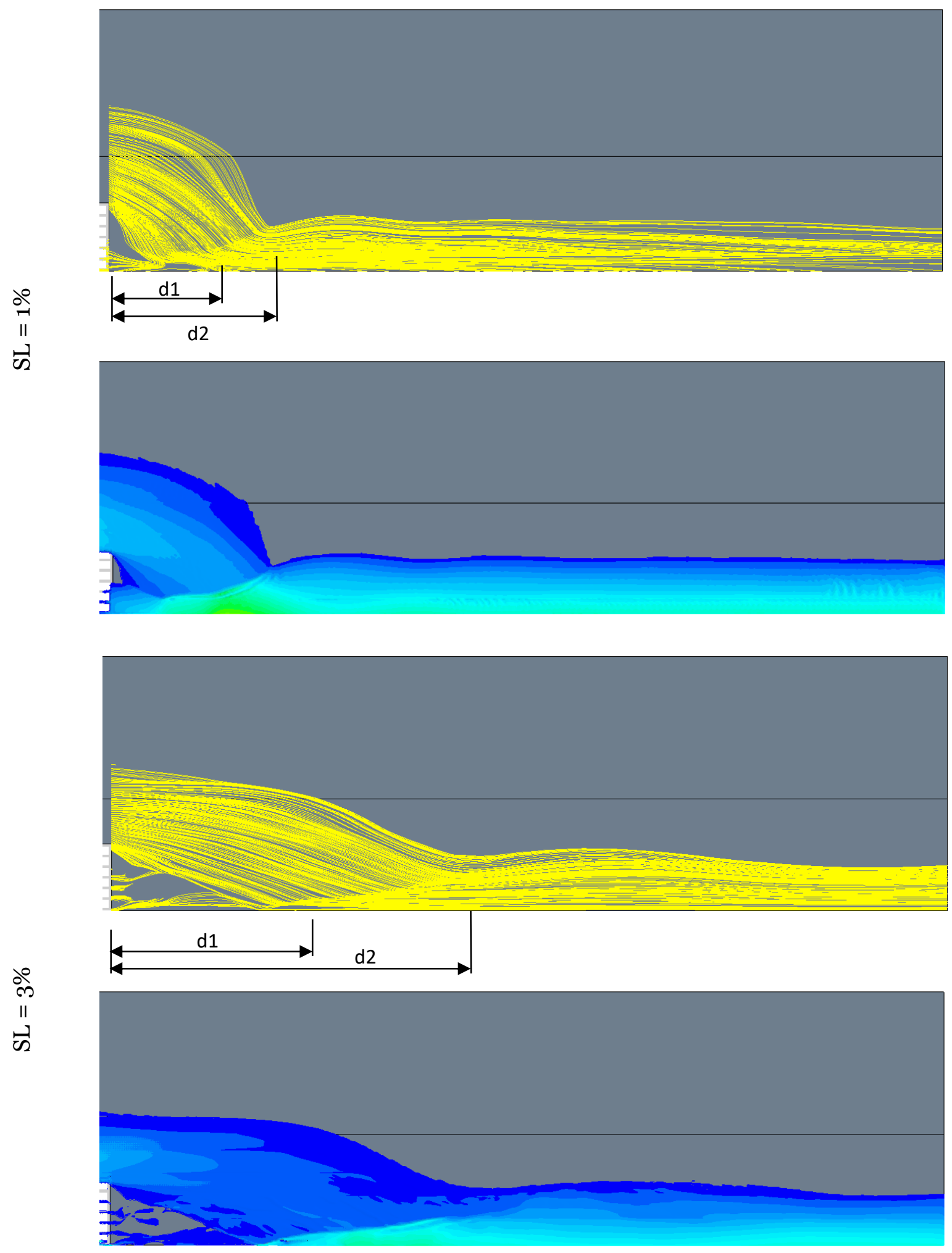

\begin{tabular}{llllll}
\multicolumn{5}{c}{ Water depth } \\
0.00 & 0.55 & 1.1 & 1.65 & 2.2 & 2.76 [in] \\
0.000 & 0.014 & 0.028 & 0.042 & 0.056 & $0.07[\mathrm{~m}]$
\end{tabular}

Hydraulic Study of the South Carolina DOT Catch Basin Type 25 


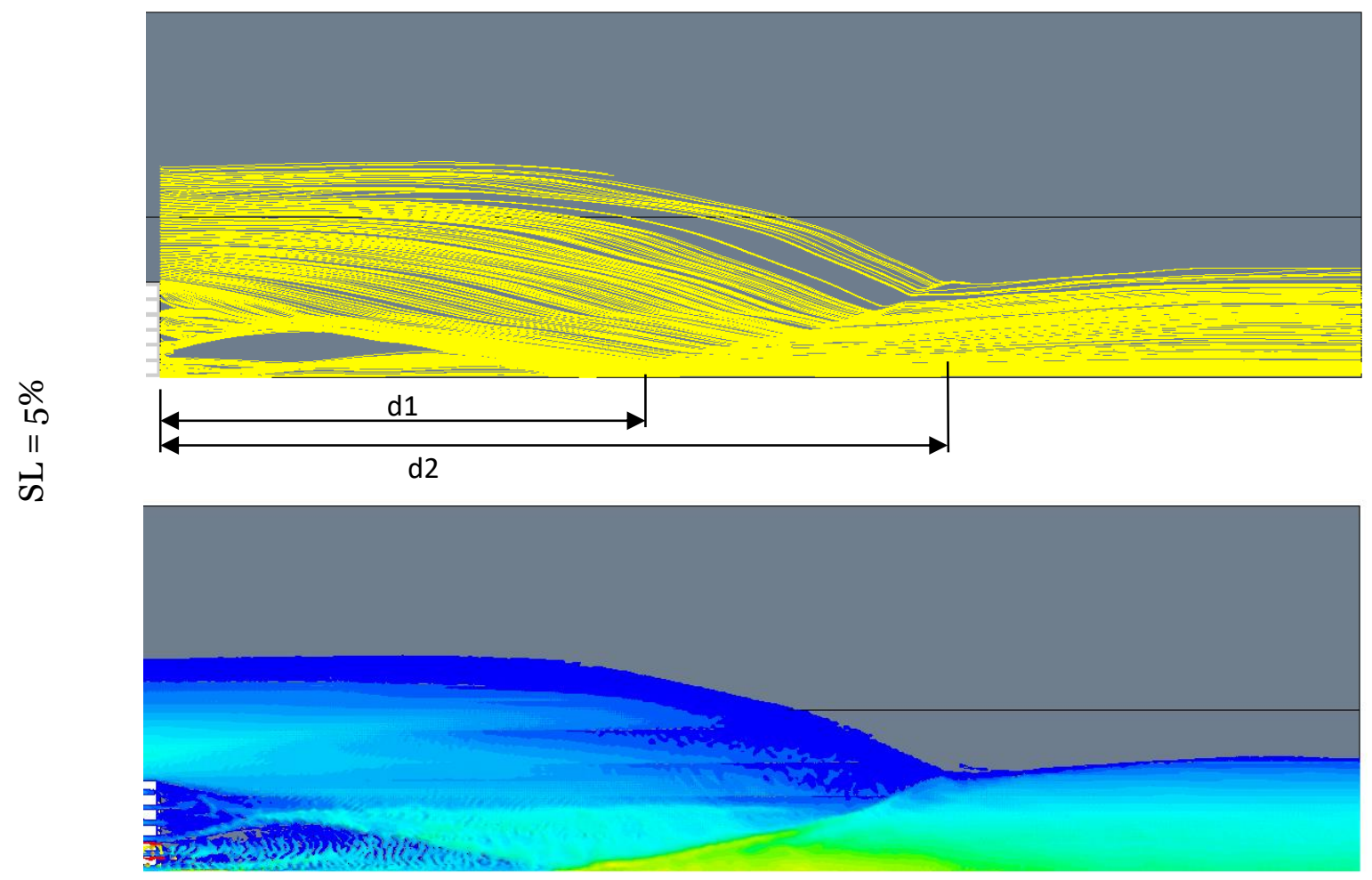

Hydraulic Study of the South Carolina DOT Catch Basin Type 25 

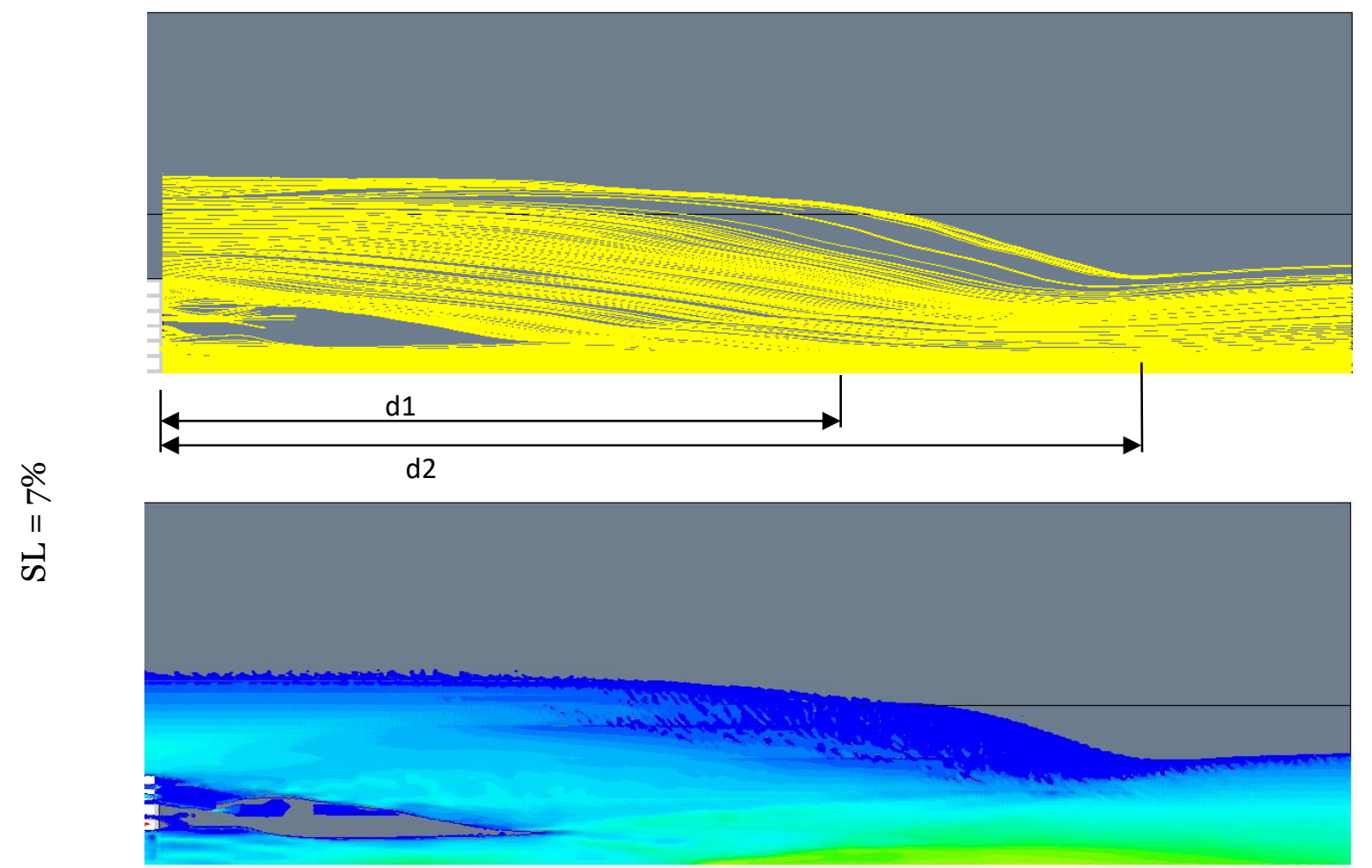

\begin{tabular}{cccccc}
\multicolumn{7}{c}{$\begin{array}{c}\text { Water depth } \\
0.00\end{array}$} & 0.55 & 1.1 & 1.65 & 2.2 & 2.76 [in] \\
0.000 & 0.014 & 0.028 & 0.042 & 0.056 & 0.07 [m]
\end{tabular}

Figure 4-4: Streamlines showing the fallback distances d1 and d2, and plots of water depth; 4-ft shoulder, 6-ft flow spread, and varying longitudinal slope

Table 4-2: Distances d1 and d2 (description in the text); 4-foot shoulder, 6-foot flow spread, varying longitudinal slope

\begin{tabular}{|c|c|c|}
\hline $\mathbf{S L}[\%]$ & $\mathbf{d 1}[\mathbf{f t}]$ & $\mathbf{d}$ [ [ft] \\
\hline $\mathbf{0 . 3}$ & 1.3 & 2.3 \\
\hline $\mathbf{1}$ & 3.6 & 5.6 \\
\hline $\mathbf{3}$ & 10.2 & 14.4 \\
\hline $\mathbf{5}$ & 14.7 & 20.4 \\
\hline $\mathbf{7}$ & 16.6 & 25.1 \\
\hline
\end{tabular}




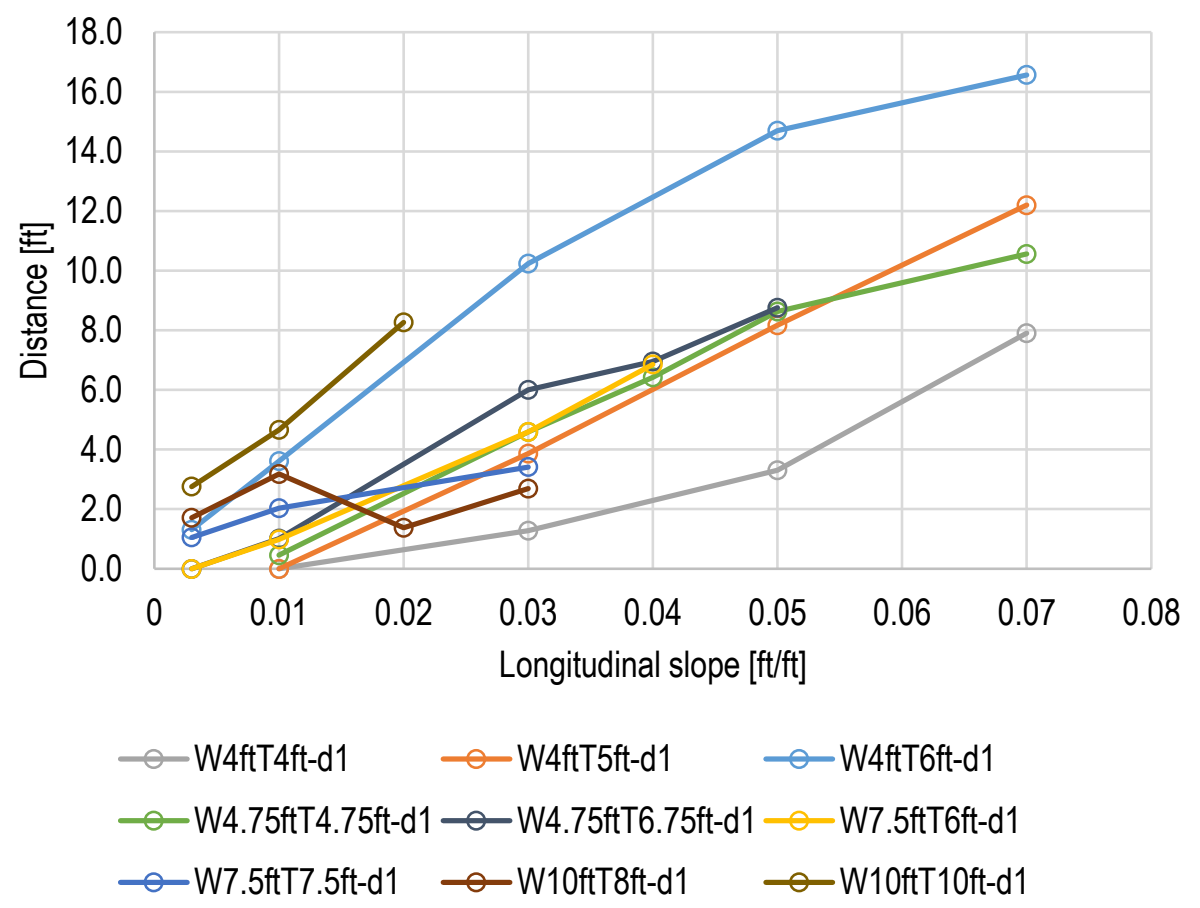

Figure 4-5: Distance d1 (description in the text) in function of the longitudinal slope

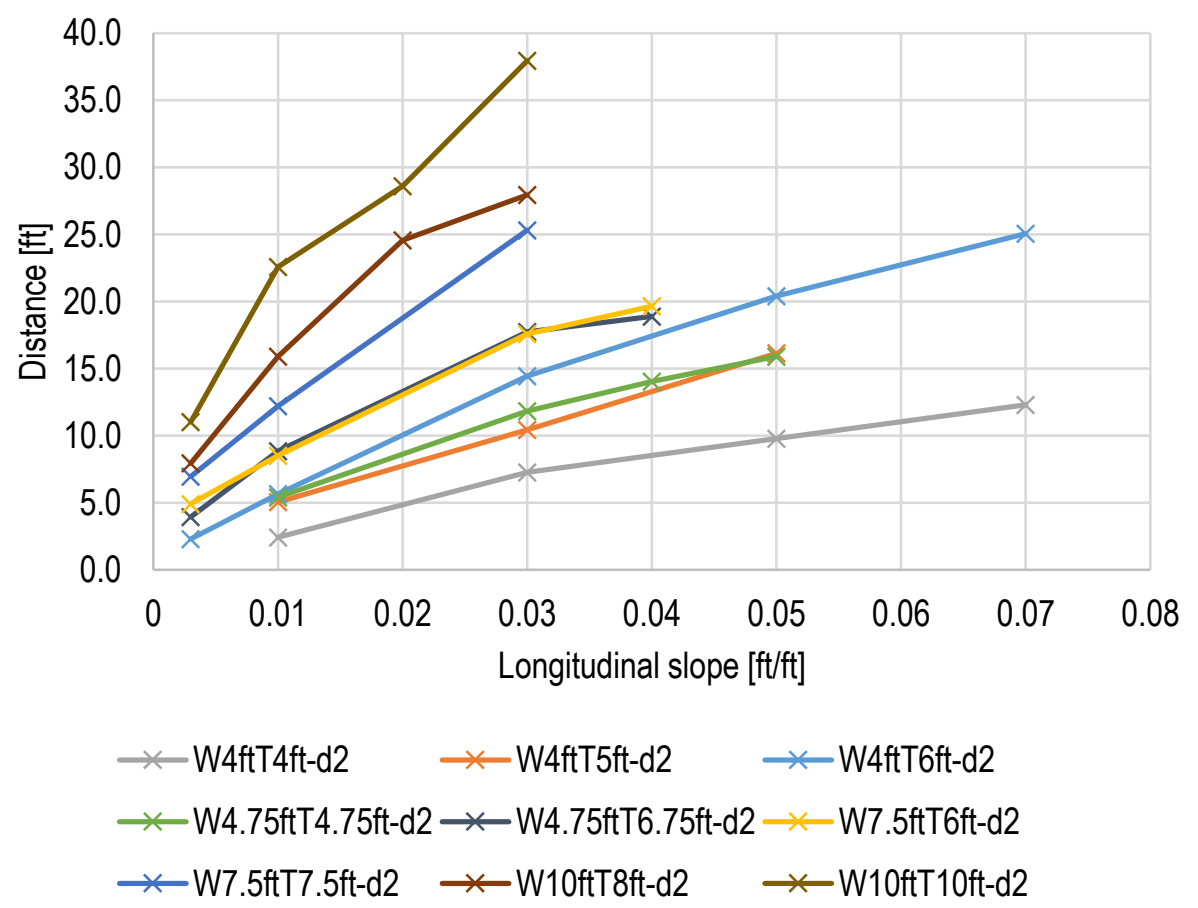

Figure 4-6: Distance d2 (description in the text) in function of the longitudinal slope 


\subsection{Influence of the initial conditions in CFD simulations on the flow pattern}

The simulations presented in this study were built based on experimental setup used in [2]. The water entered through an upstream end of the roadway physical model and exited through the inlet grate and the downstream end of the model.

In this chapter the dependence of the flow pattern over the grate and the hydraulic efficiency of the grate on the initial conditions was analyzed. Three possible initial conditions were investigated and compared: (1) The domain is empty at the beginning of the simulation and the water is introduced at a specific flow rate through an inlet surface. (2) The grate is blocked (there is no intercepted flow) when the water flow is initiated and the computations are performed until a steady state is reached with no flow into the catch basin. Then the interface between the grate and the rest of the domain is opened, so that the fluid can leave through the grate. (3) The computations are started from a previous solution for a smaller longitudinal slope with an opened grate.

In the first case it is assumed that each of the runs (experiments) start with an empty domain and the water is introduced through an inlet surface at a specific rate, calculated from equation (1) or (2). The computations are run until a steady state solution is reached and the solution is converged, with mass balance attained, meaning that the discharge through the up street inlet equals the discharge into the catch basin plus the discharge through the downstream street outlet beyond the grate. The second scenario corresponds to a situation in which the grate is closed at the beginning of the experiment, and water spreads on the roadway and can leave only through the other end of the domain. When the solution has converged, the openings of the grate are unblocked and water can flow through them into the catch basin. The simulation ends when steady state is reached and mass balance is achieved. In the third case the experiments are grouped into sets, in which the dimensions of the roadway are the same, but the longitudinal slope varies. The experiment starts with the case with the lowest longitudinal slope. When the inflowing and outflowing mass of water is balanced, the roadway is rotated to reach the second longitudinal slope from the test table.

As an example, the simulation of the flow on a roadway with a 4-foot shoulder, $7 \%$ longitudinal slope, and inlet water spread 6 feet, was performed with the described initial conditions. Figure 4-7 shows top views of the domain with a water depth plotted on the resulting water surface. The flow was initiated: (a) in an empty domain, (b) filled domain and blocked grate, (c) with a solution from a run with a smaller longitudinal slope. In all cases a broken flow pattern over the grate is present, with splash-over. The flow spread upstream from the grate is also similar. The efficiency of the grate changes slightly, and reaches (a) $71 \%$, (b) $73 \%$, (c) $75 \%$. These results show that the simulated results can vary depending on the initial conditions and the difference in hydraulic efficiency can reach a few percent. The most conservative type of simulation was adopted for the analysis. 
(a)
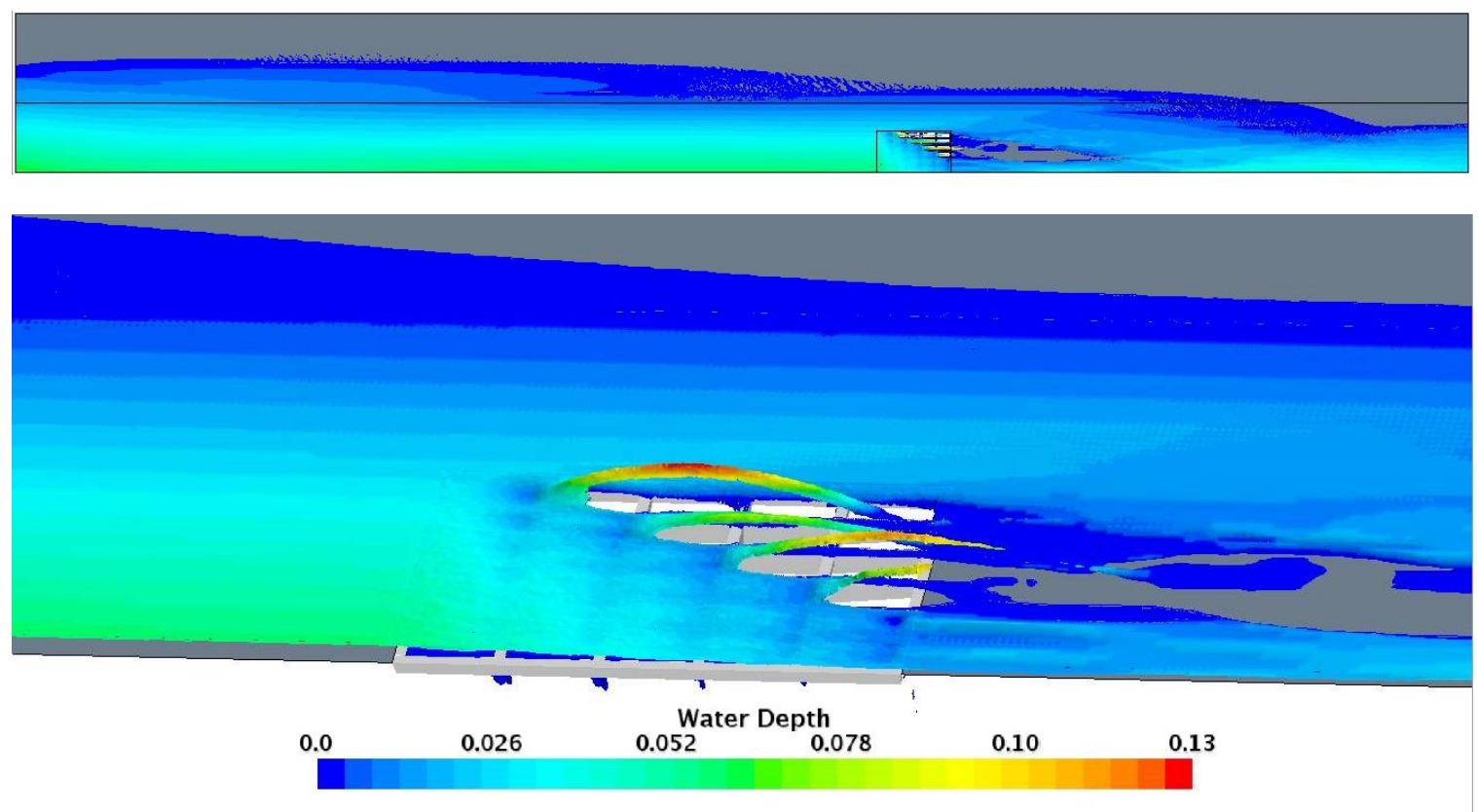

(b)
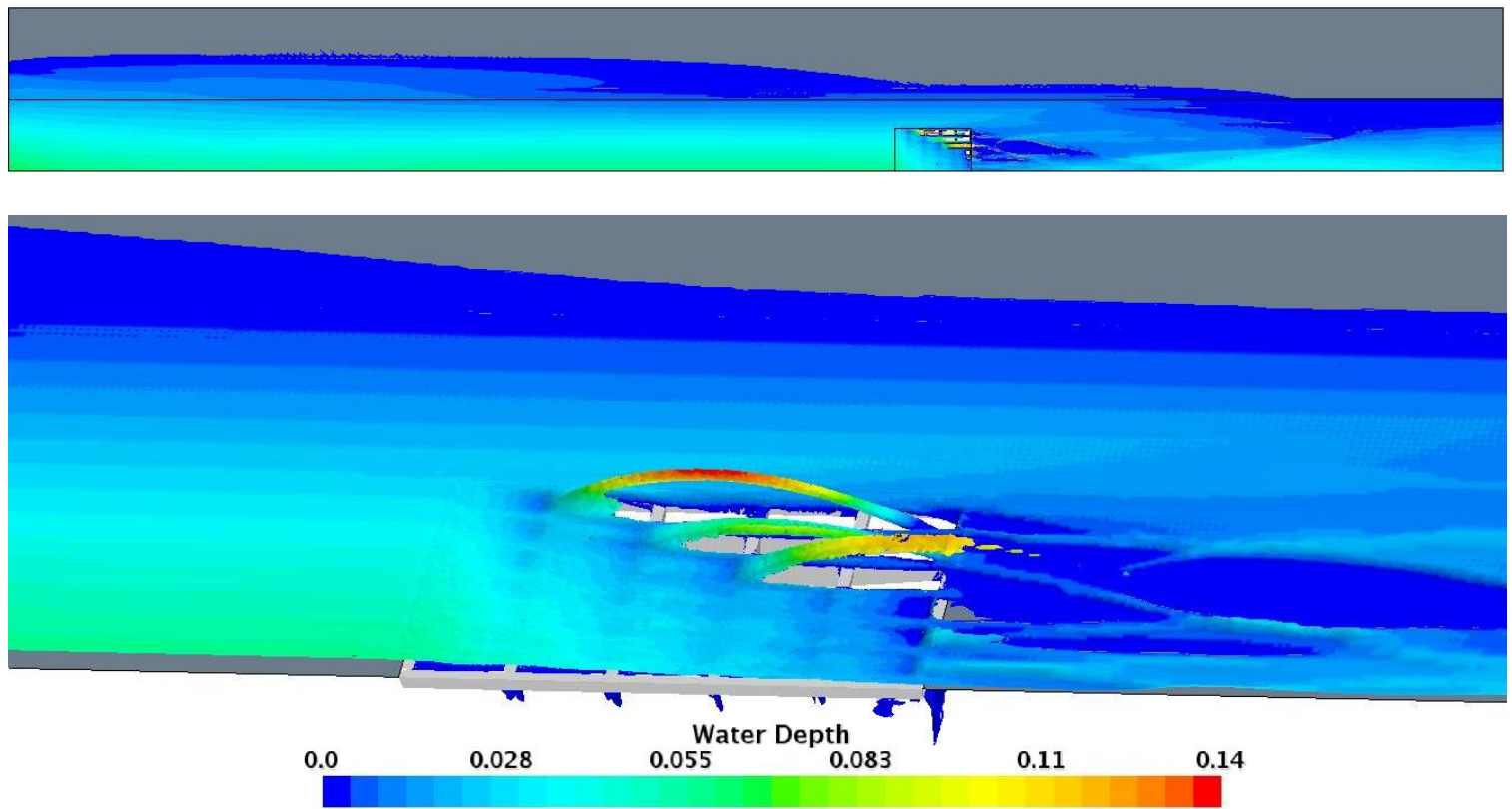

(c)

\section{$r=$}

Hydraulic Study of the South Carolina DOT Catch Basin Type 25 


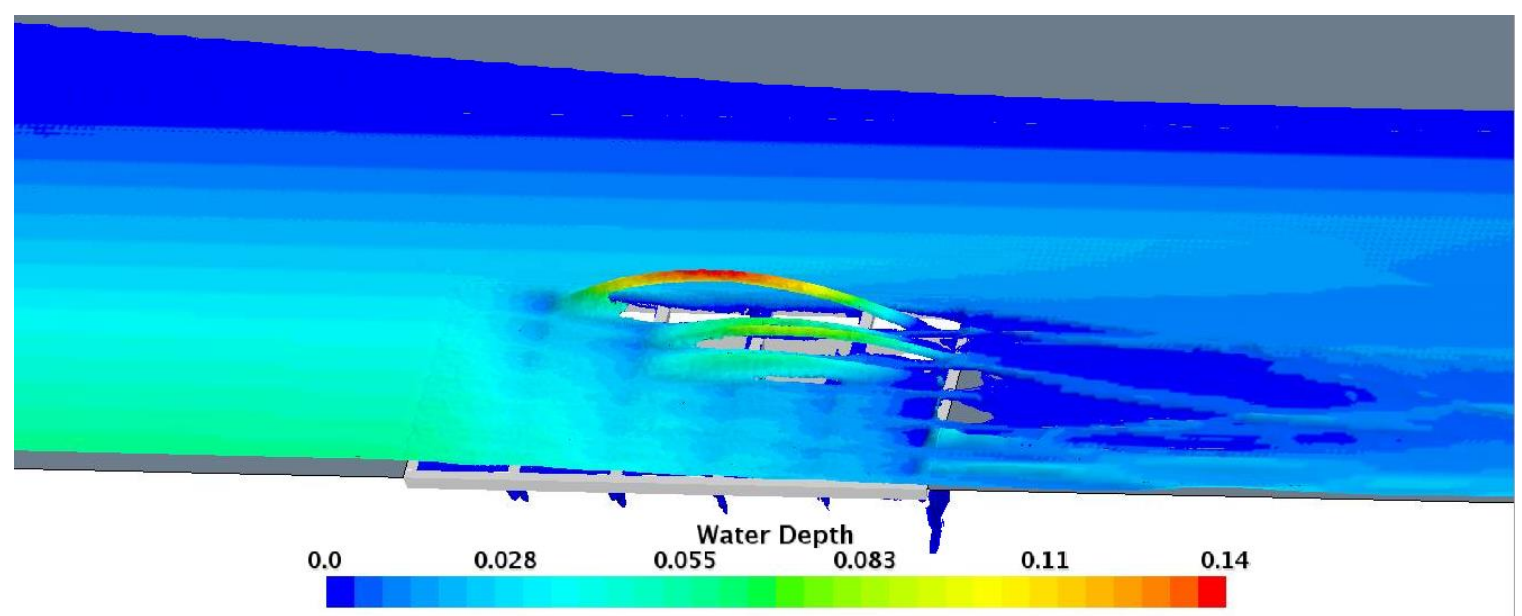

Figure 4-7: Flow pattern above the grate with the flow initiated (a) in an empty domain, (b) filled domain and blocked grate, (c) with a solution from a run with a smaller longitudinal slope

\subsection{Influence of a model of debris on the grate efficiency}

The influence of debris that can potentially collect near the grate was studied using a case of a roadway with a 4 -foot shoulder with 6 -foot flow spread with longitudinal slope equal $0.3 \%$. When no obstruction of the flow is present, majority of the flow enters through the front surface of the grate, and the rest enters through the side. The efficiency of the grate is equal to $98 \%$. To simulate debris, that often can be found around road grates after storms, four cylinder parts were added to the geometry of the domain and located at and near the upstream part of the inlet. The dimensions of the cylinders are: radius is equal to $0.02 \mathrm{~m}$, and the length is equal $0.40 \mathrm{~m}$. They were stacked in an irregular manner, as shown in Figure 4-8. Figure 4-9 shows a comparison of the flow patterns for this case when no obstruction is present and with the debris included in the model. When the debris is present, the spread of the flow in front of the grate is bigger and the flow is deeper. The flow goes around the obstacle and with this change of direction, bypasses the grate as well. Consequently, the efficiency of the grate drops to $83 \%$. 


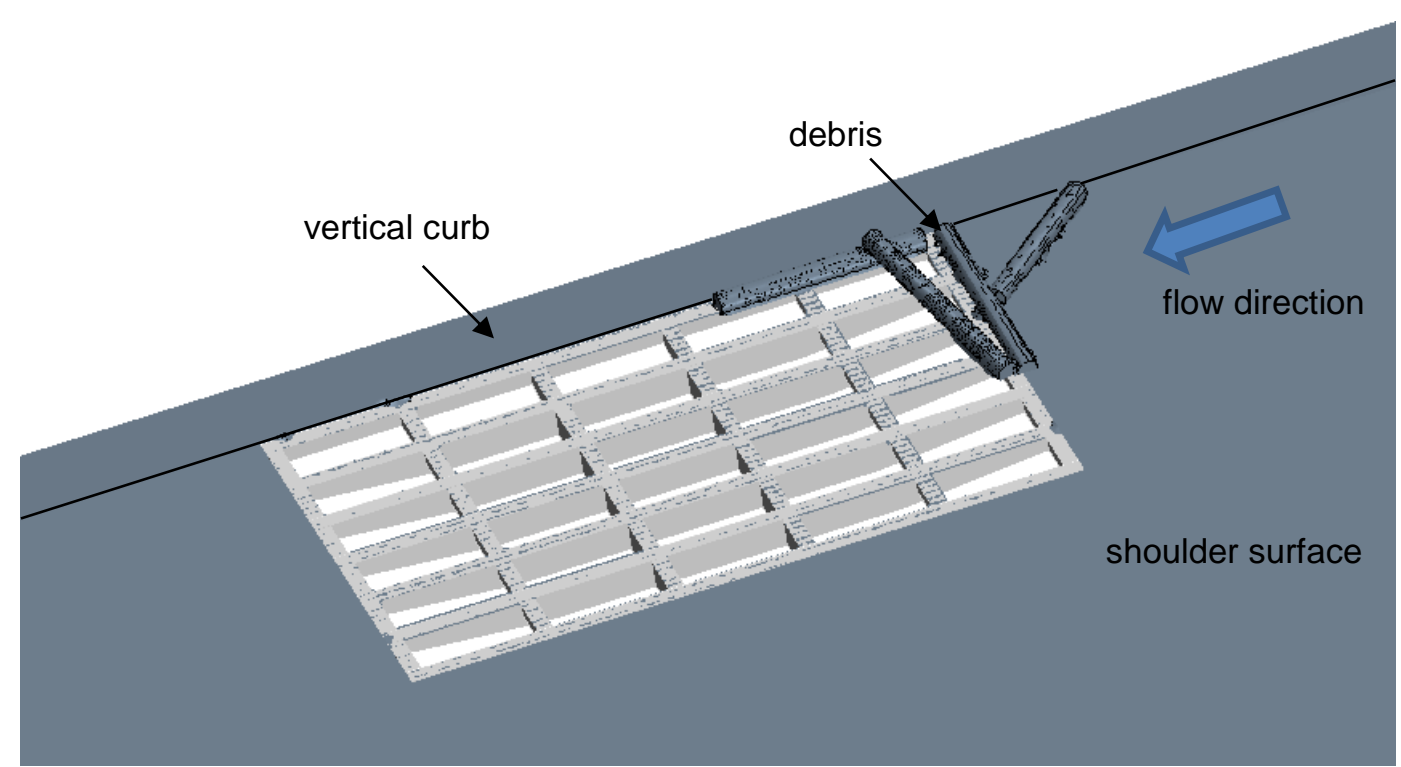

Figure 4-8: A model of stacked debris at the inlet

(a)

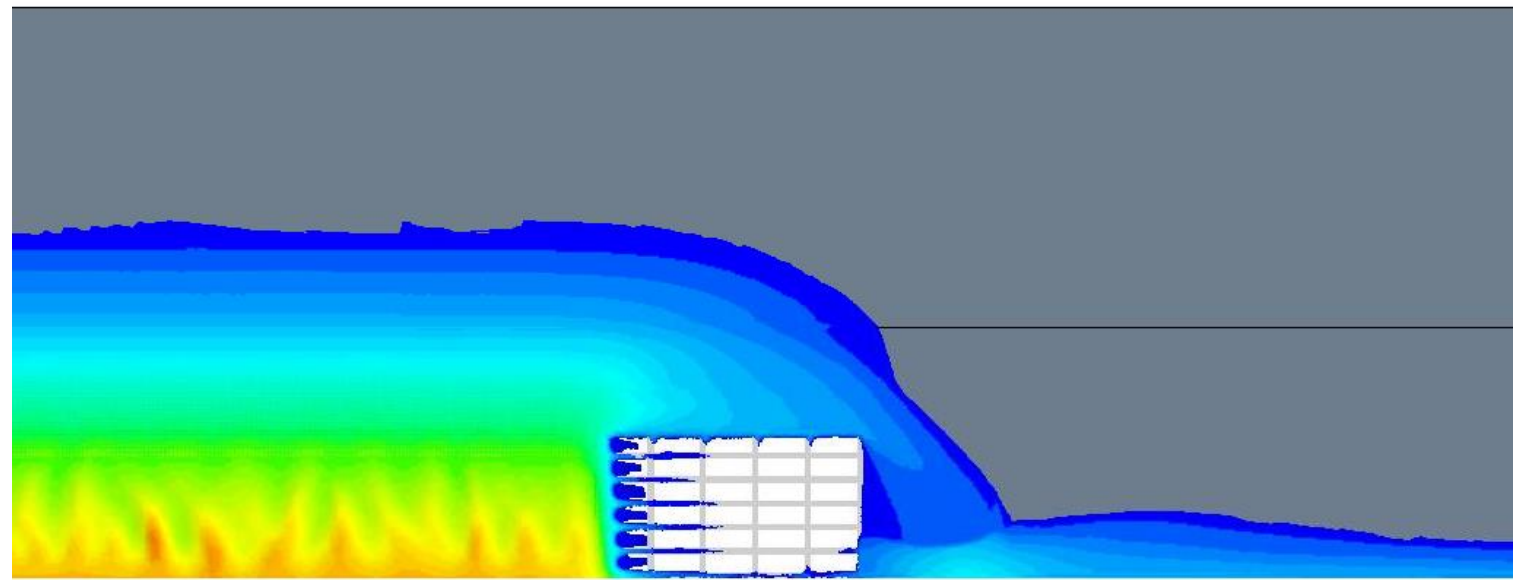

\begin{tabular}{cccccc}
\multicolumn{7}{c}{ Water depth } \\
0.00 & 0.55 & 1.1 & 1.65 & 2.2 & $2.76[\mathrm{in}]$ \\
0.000 & 0.014 & 0.028 & 0.042 & 0.056 & $0.07[\mathrm{~m}]$
\end{tabular}


(b)

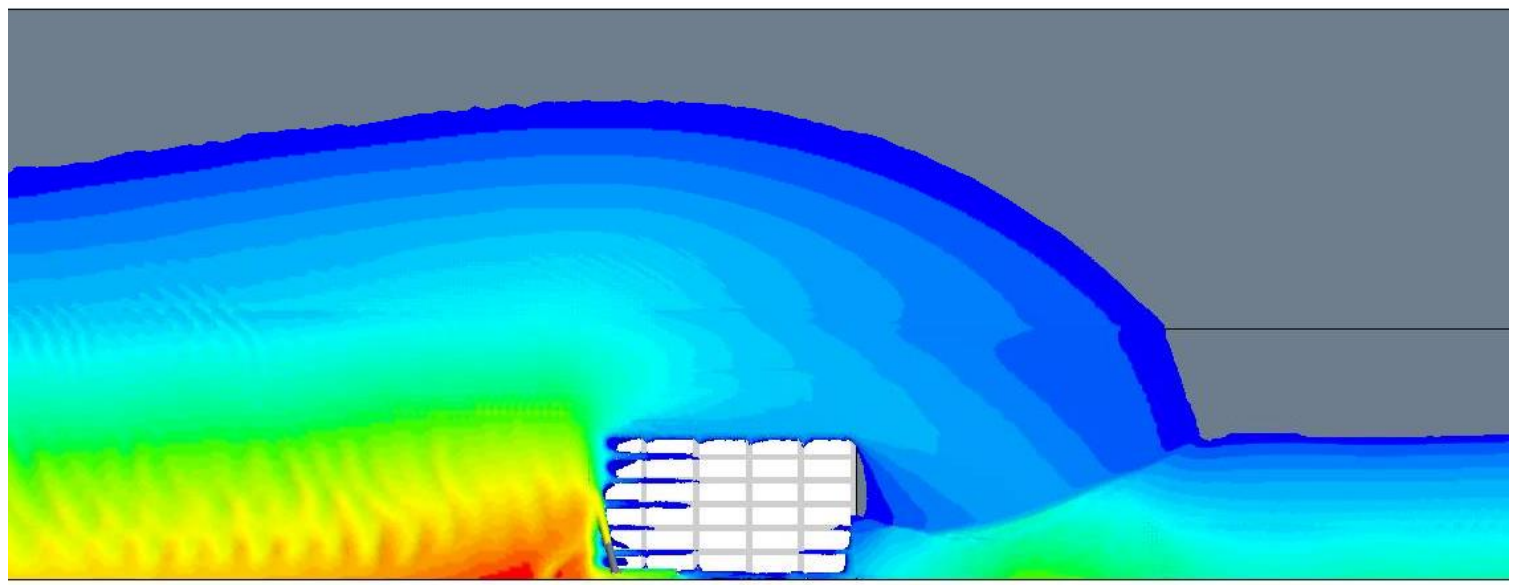

\begin{tabular}{cccccc}
\multicolumn{7}{c}{ Water depth } \\
0.00 & 0.63 & 1.26 & 1.89 & 2.52 & $3.19[\mathrm{in}]$ \\
0.000 & 0.016 & 0.032 & 0.048 & 0.064 & $0.081[\mathrm{~m}]$
\end{tabular}

Figure 4-9: Flow pattern in the vicinity of the inlet grate for a case of a 4-foot shoulder, at longitudinal slope $0.3 \%$, (a) without obstruction, (b) with obstruction

\subsection{Influence of introducing imperfections in the roadway surface to the CFD model}

An imperfection in the shoulder surface was introduced to the model of a roadway with a 4 -foot shoulder and longitudinal slope $0.3 \%$, in a form of a cylindrical 'bump', approximately $40 \mathrm{~cm}$ wide, and $3 \mathrm{~cm}$ high at the curb, which was located on the upstream side from the grate. The geometry of the domain around the grate and flow direction can be seen in Figure 4-10. This small unevenness of the surface resulted in a drop of the water captured by the grate from $98 \%$ to $88 \%$. Figure 4-11 presents the flow pattern in the vicinity of the grate (a) with a flat shoulder surface, (b) with imperfection on the shoulder surface. In consequence of the surface imperfection, the spread upstream of the grate is bigger, and therefore the bypassing flow increases. 


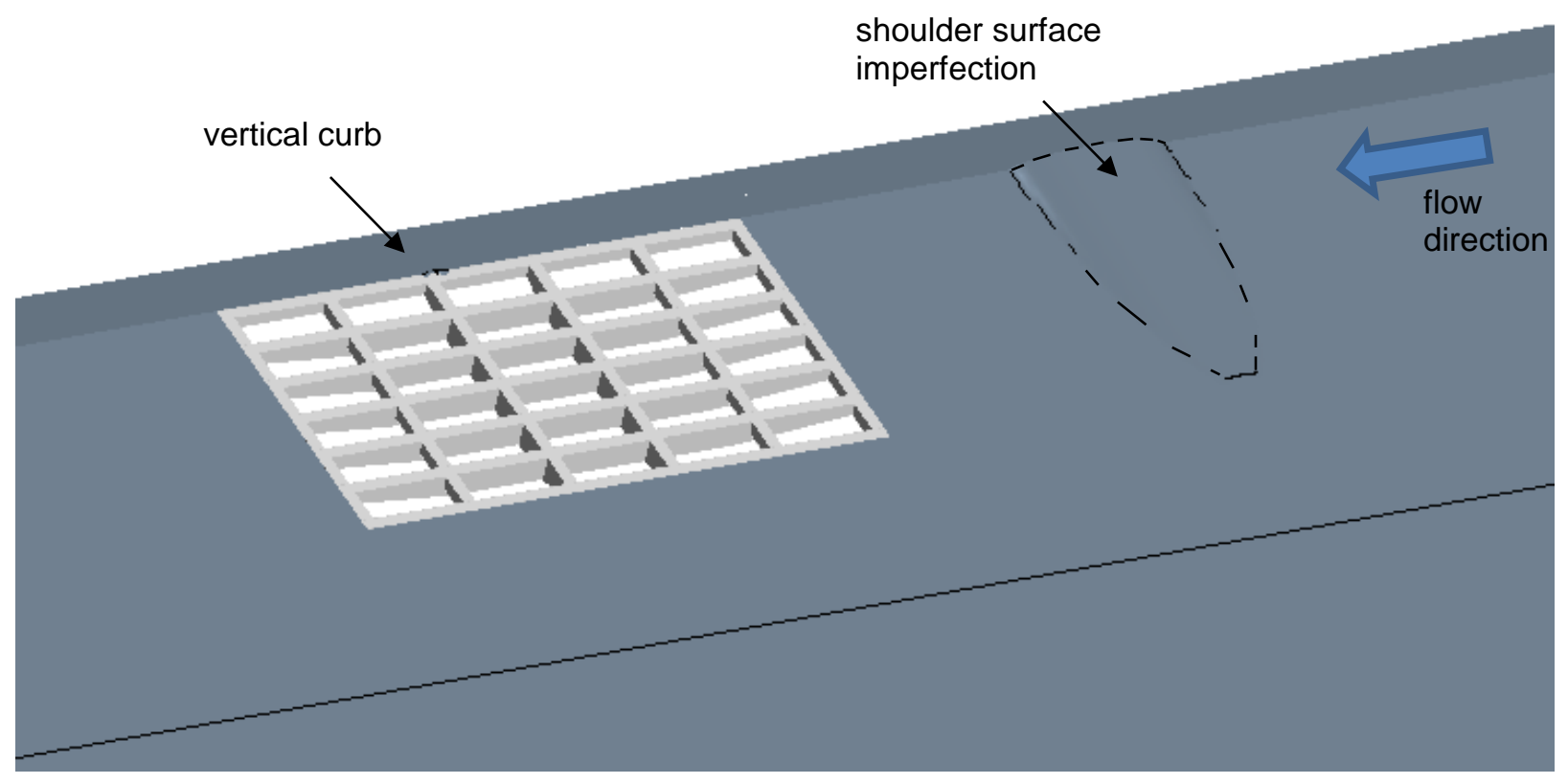

Figure 4-10: A model of an imperfection of the shoulder surface

(a)

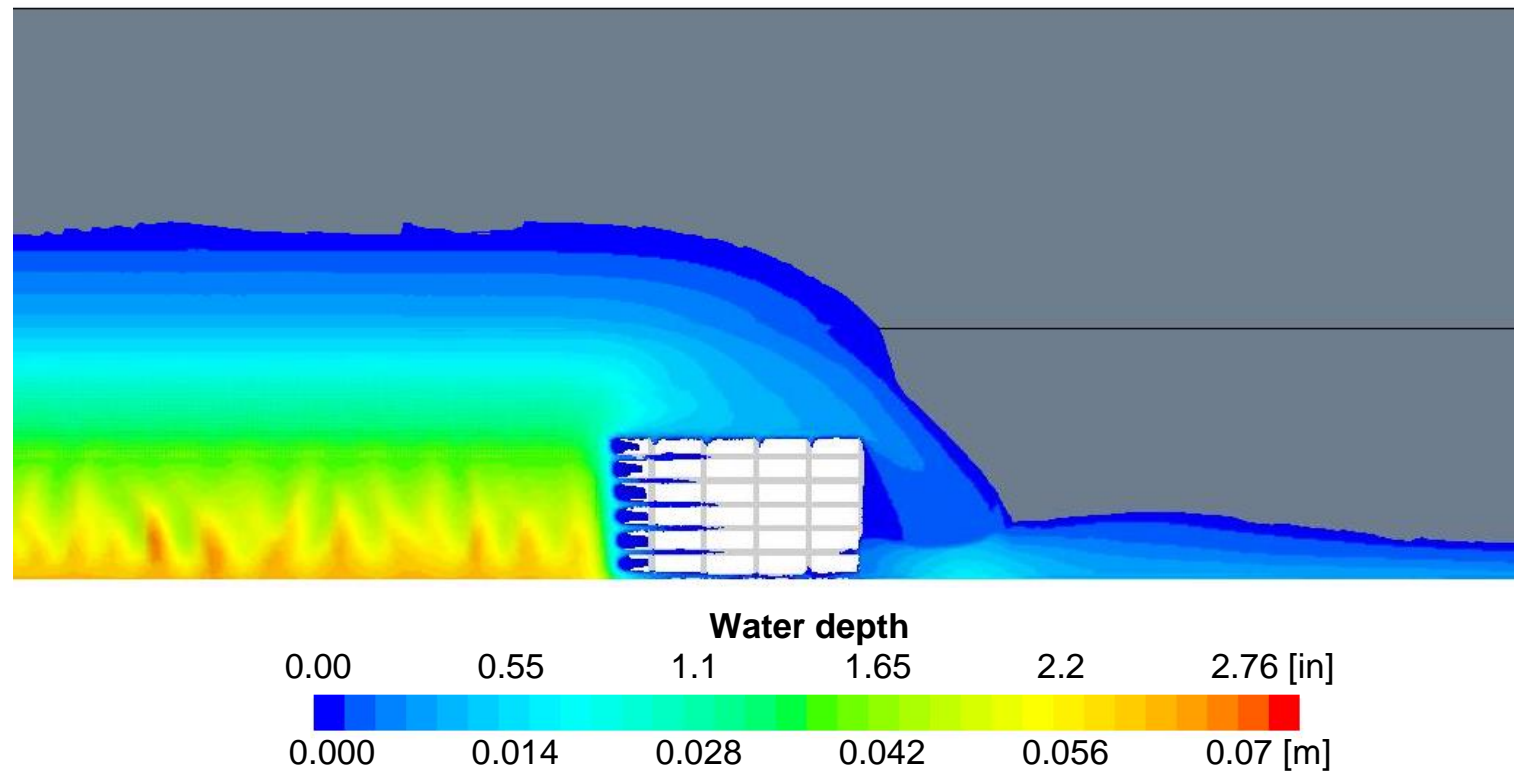

Hydraulic Study of the South Carolina DOT Catch Basin Type 25 
(b)

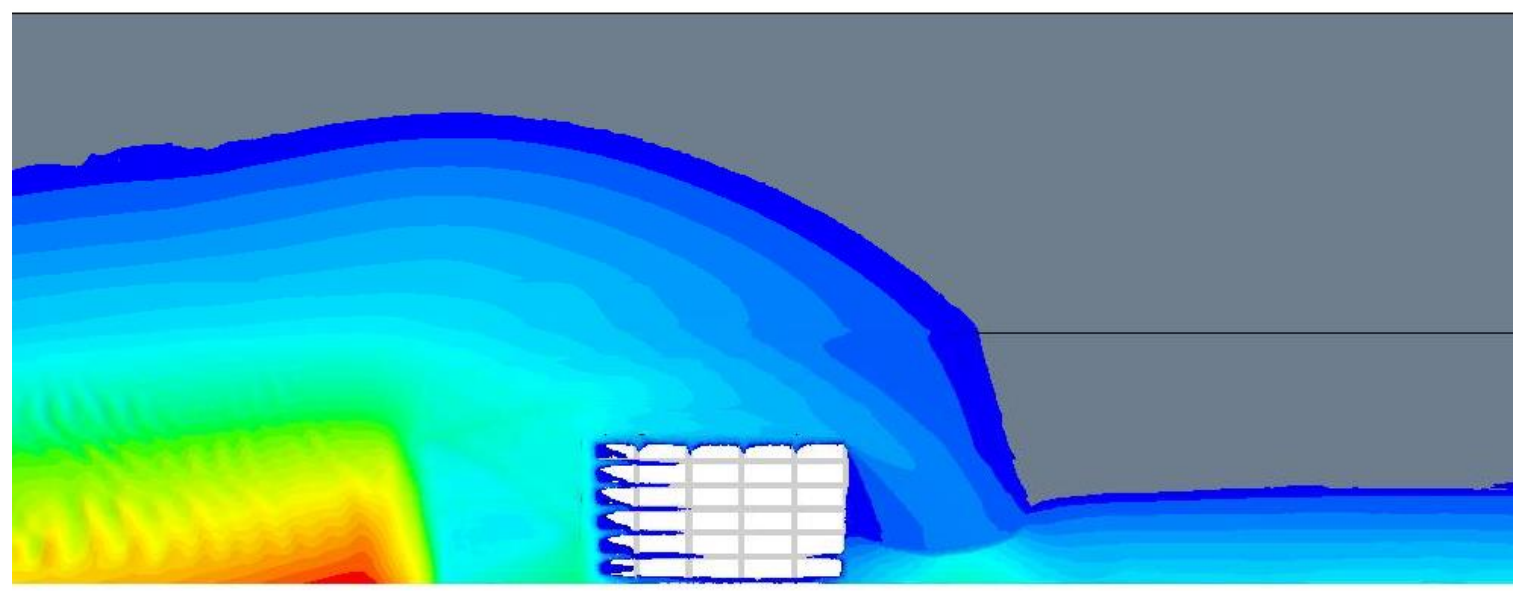

\begin{tabular}{llllll}
\multicolumn{7}{c}{$\begin{array}{c}\text { Water depth } \\
0.00\end{array}$} & 0.63 & 1.22 & 1.85 & 2.48 & 3.11 [in] \\
0.000 & 0.016 & 0.031 & 0.047 & 0.063 & $0.079[\mathrm{~m}]$
\end{tabular}

Figure 4-11: Flow pattern in the vicinity of the inlet grate for a case of a 4-foot shoulder, at longitudinal slope $0.3 \%$, (a) with a flat shoulder surface, (b) with imperfection on the shoulder surface

\subsection{Hydraulic efficiency of the grate}

The primary goal of the present research was to establish the grate efficiency, or percentage of the flow captured by the grate to the total flow on the roadway through CFD simulations. Appendix A summarizes these data for the considered test case matrix.

This chapter presents a set of plots for the considered geometries of the roadway with varying shoulder width: (a) flow rate through the grate vs. longitudinal slope for various spread widths, (b) flow rate through the grate vs. flow spread for the considered longitudinal slopes, and (c) hydraulic efficiency of the grate vs. flow spread for the set of longitudinal slopes. 
(a)

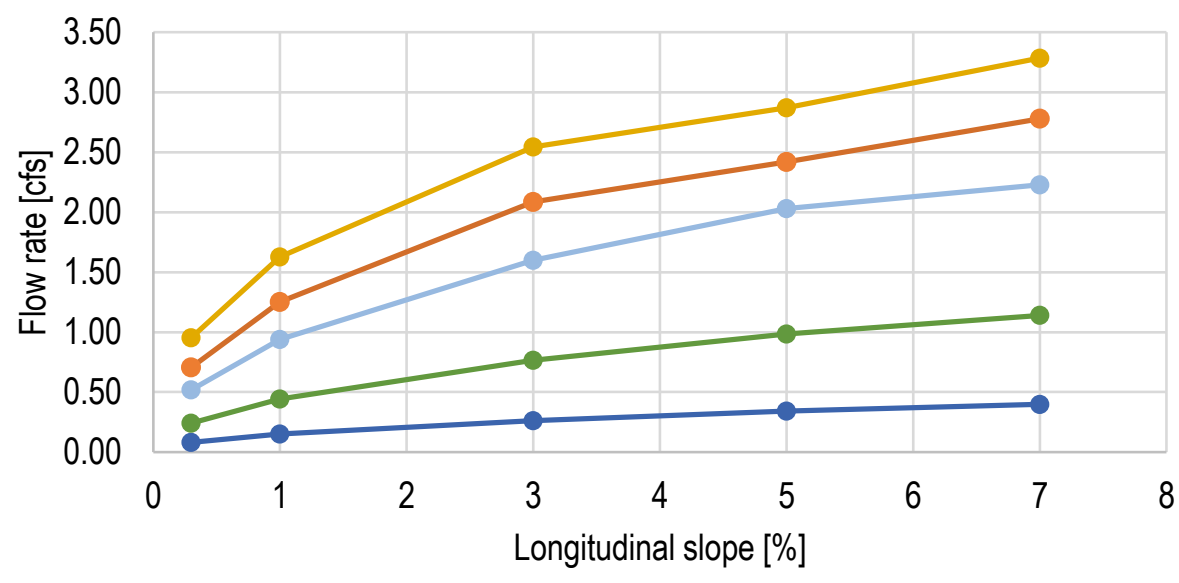

Spread $\rightarrow-2 \mathrm{ft} \rightarrow-3 \mathrm{ft} \rightarrow 4 \mathrm{ft} \rightarrow-5 \mathrm{ft} \rightarrow 6 \mathrm{ft}$

(b)
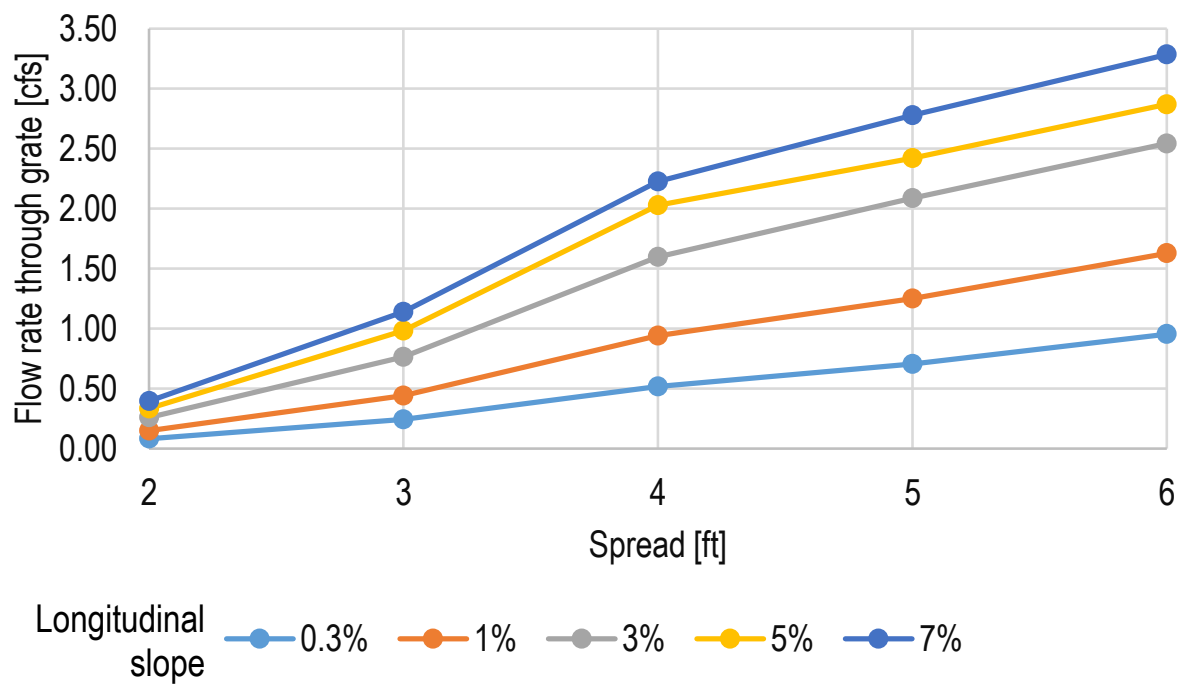

(c)

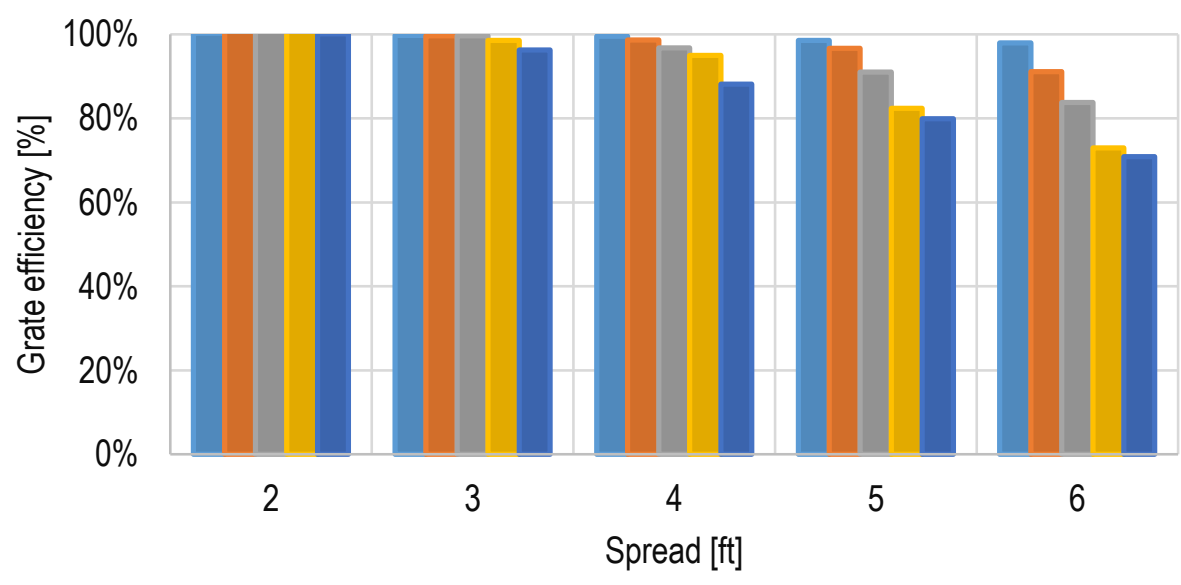

Longitudinal slope $\quad \square .3 \% \square 1 \% \square 3 \% \square 5 \% \square 7 \%$

Figure 4-12: Flow rate through the grate for a road with a 4-foot shoulder, (a) flow rate vs. longitudinal slope, (b) flow rate vs. flow spread, (c) hydraulic efficiency of the grate vs. spread 
(a)

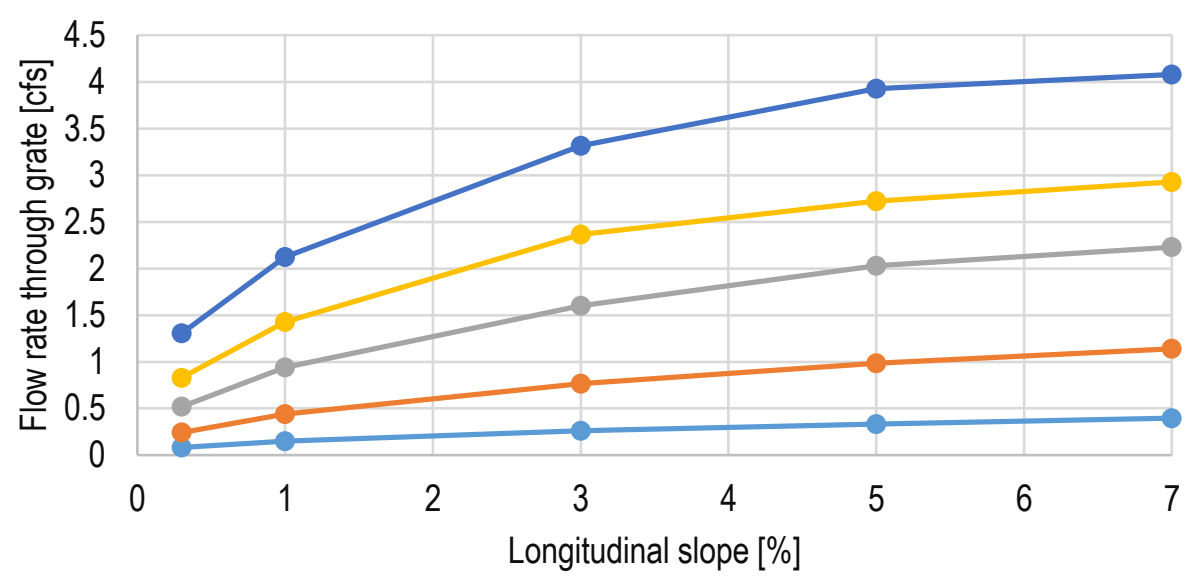

$$
\text { Spread } \rightarrow-2 \mathrm{ft} \longrightarrow-3 \mathrm{ft} \rightarrow-4 \mathrm{ft} \rightarrow-4.75 \mathrm{ft} \rightarrow 6.75 \mathrm{ft}
$$

(b)
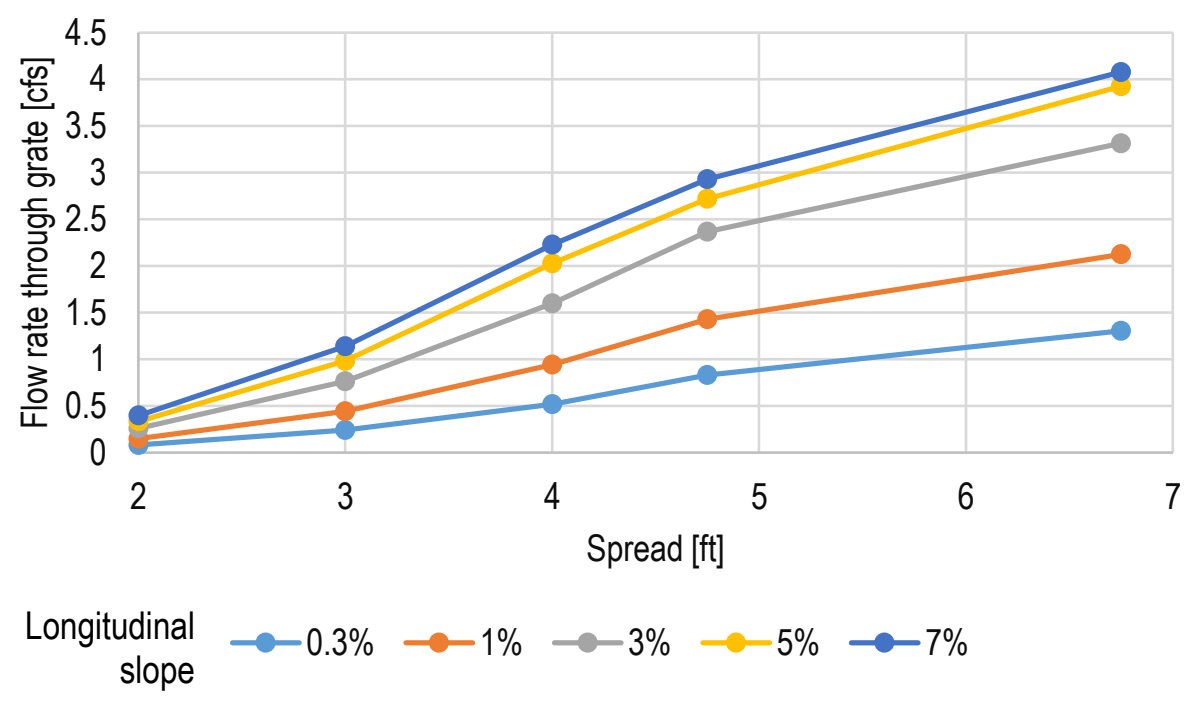

(c)

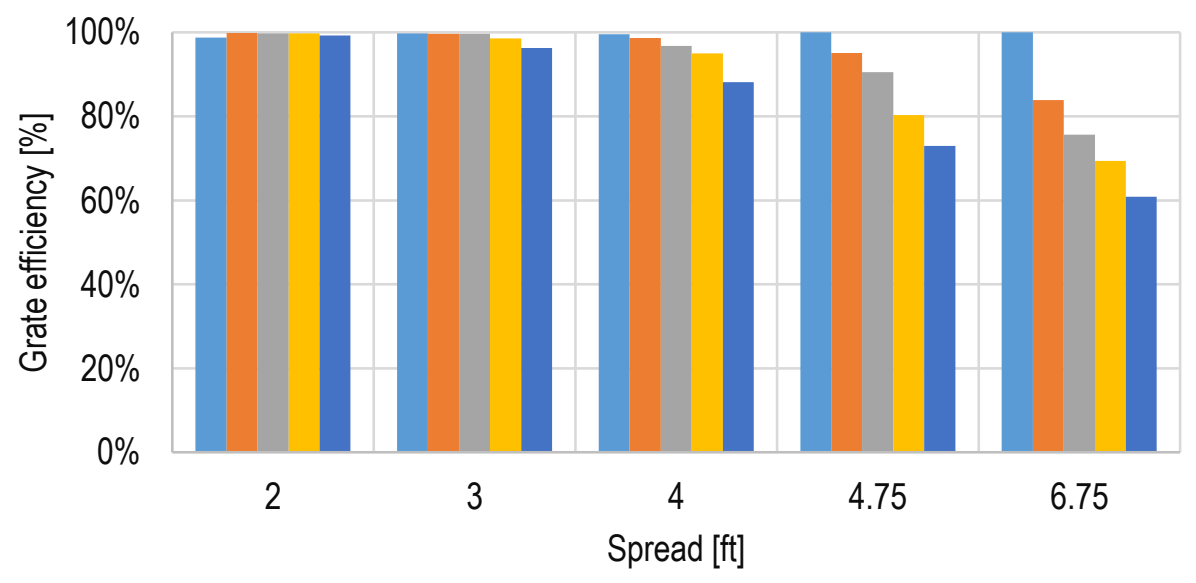

$$
\text { Longitudinal slope } \square 0.3 \%-1 \%=3 \% \square 5 \%=7 \%
$$

Figure 4-13: Flow rate through the grate for a road with a 4.75-foot shoulder, (a) flow rate vs. longitudinal slope, (b) flow rate vs. flow spread, (c) hydraulic efficiency of the grate vs. spread 
(a)

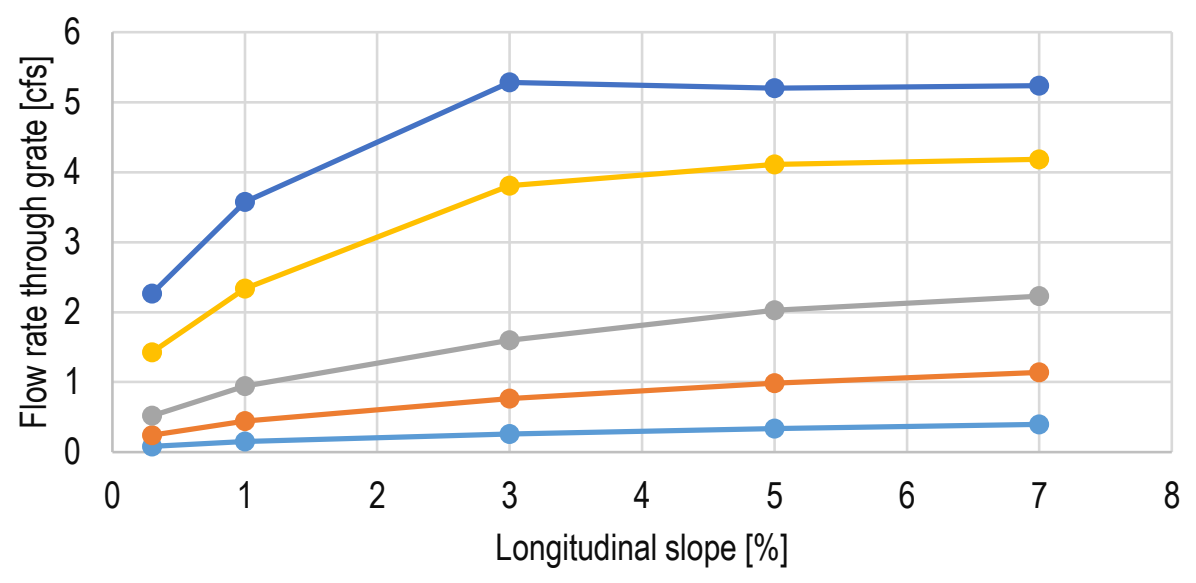

$$
\text { Spread } \multimap-2 \mathrm{ft} \longrightarrow-3 \mathrm{ft} \longrightarrow-4 \mathrm{ft} \longrightarrow-6 \mathrm{ft} \longrightarrow 7.5 \mathrm{ft}
$$

(b)

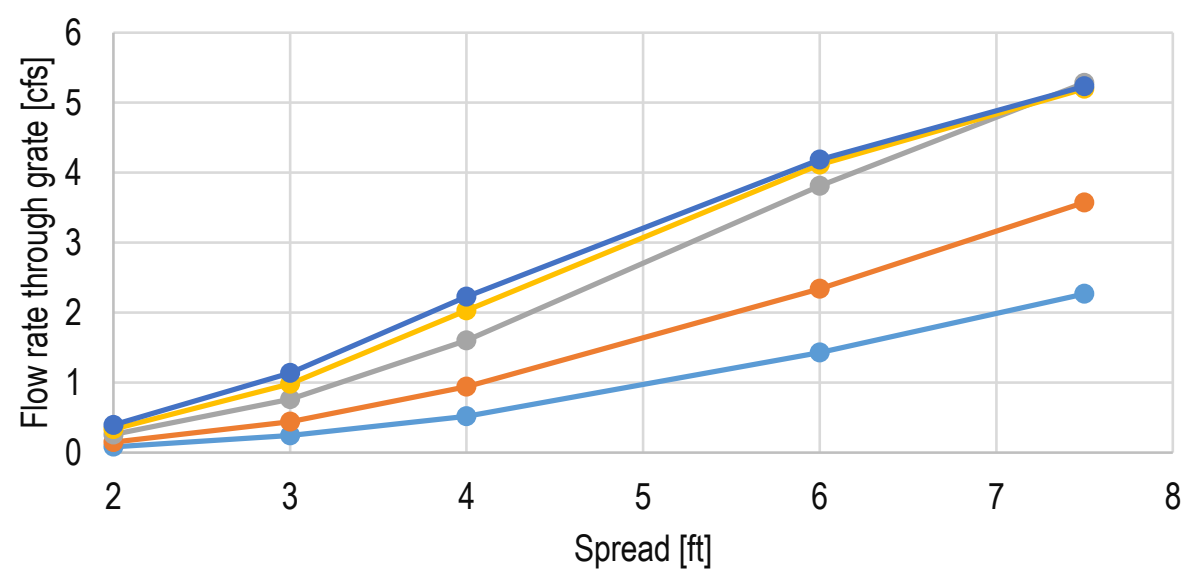

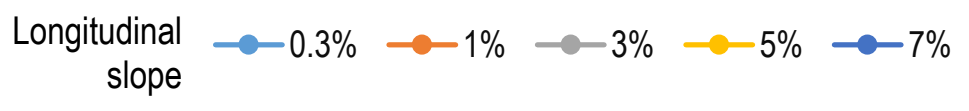

(c)

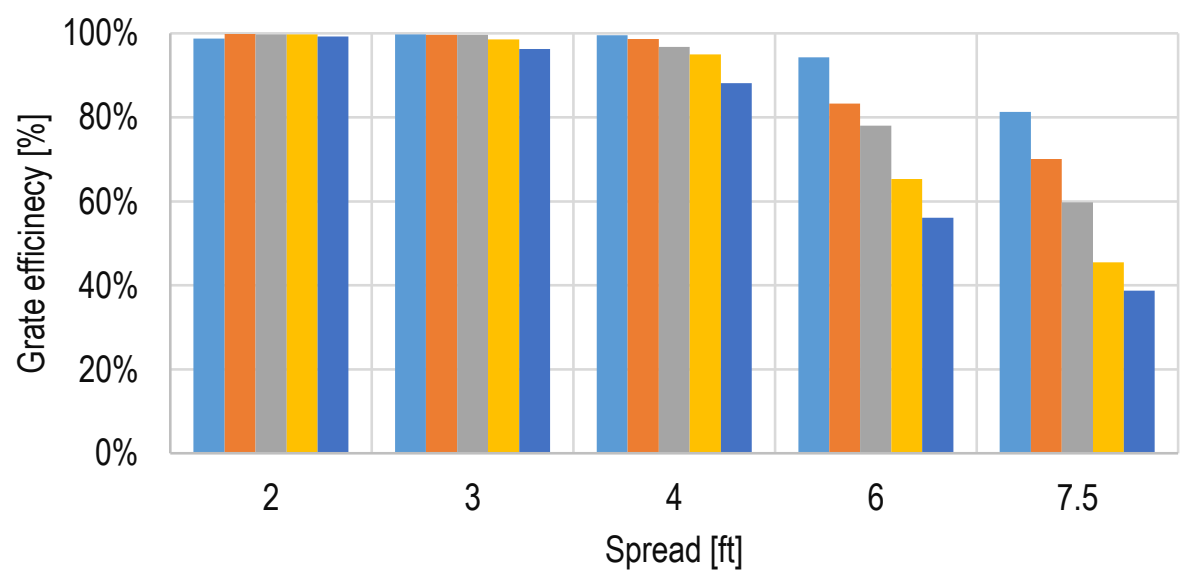

$$
\text { Longitudinal slope } \quad \square=0.3 \% \quad \square 1 \% \quad \square 3 \% \quad \square \% \quad \square 7 \%
$$

Figure 4-14: Flow rate through the grate for a road with a 7.5-foot shoulder, (a) flow rate vs. longitudinal slope, (b) flow rate vs. flow spread, (c) hydraulic efficiency of the grate vs. spread 
(a)

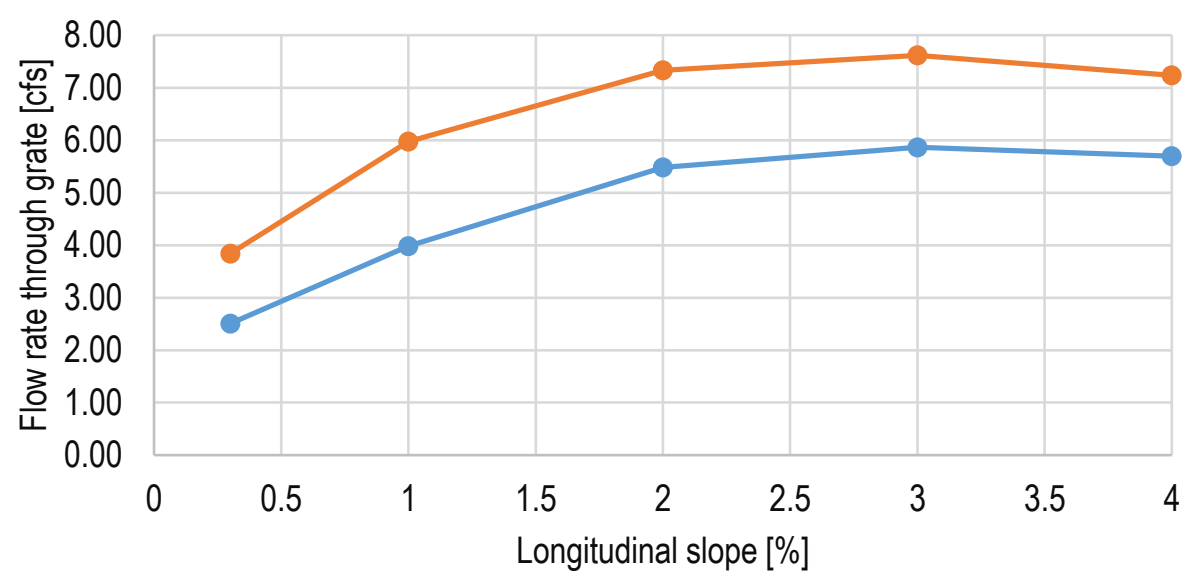

Spread $\multimap-8 f t \multimap-10 f t$

(b)
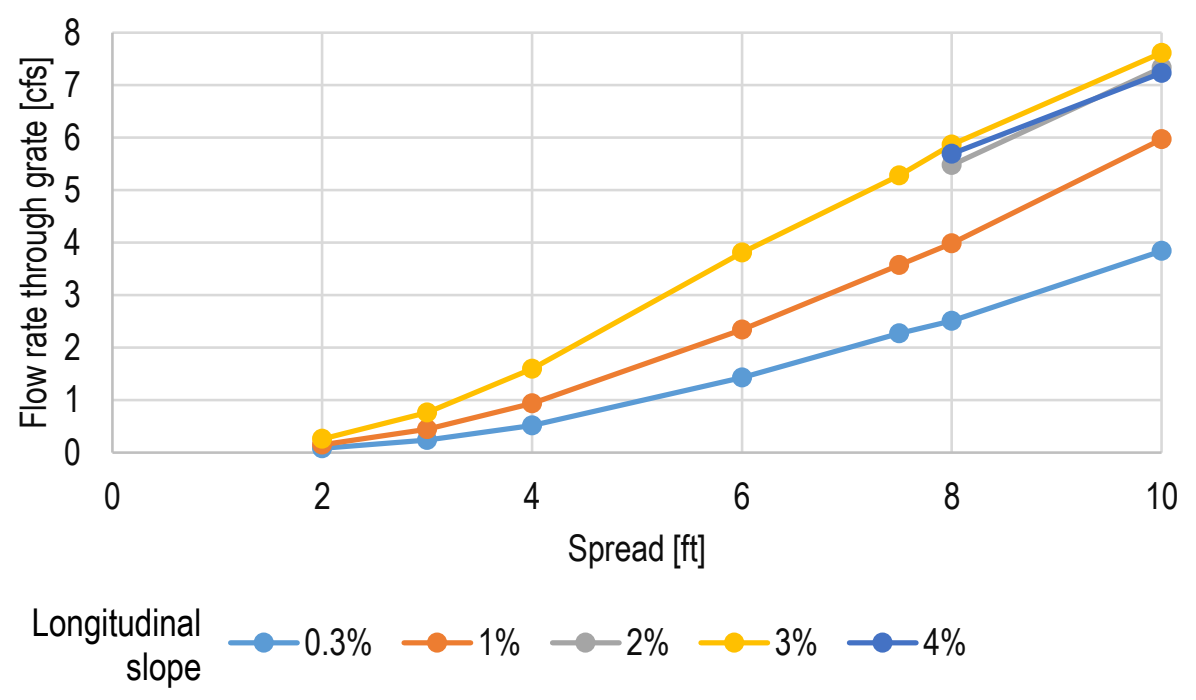

(c)

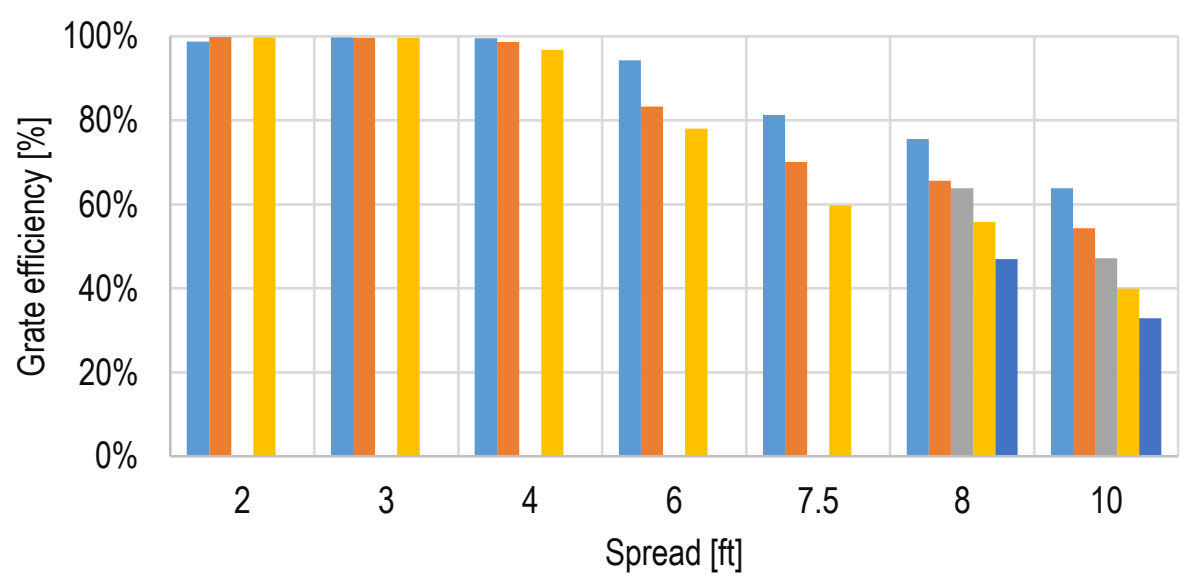

$$
\text { Longitudinal slope } \quad-0.3 \%=1 \%=2 \%-3 \%=4 \%
$$

Figure 4-15: Flow rate through the grate for a road with a 10-foot shoulder, (a) flow rate vs. longitudinal slope, (b) flow rate vs. flow spread, (c) hydraulic efficiency of the grate vs. spread 
The percentage of front flow to the total inflow to the domain in the considered cases is presented in Table 4-3. In the case of a spread narrower than the grate width, $\mathrm{T}=2 \mathrm{ft}, 100 \%$ of the flow goes through the front of the grate. When the spread exceeds the grate width, part of the flow enters through the side of the grate, and/or bypasses the inlet. The front efficiency decreases with increasing longitudinal slope of the roadway. For longitudinal slopes greater than the cross-slope, there is a sudden increase in the percentage of the bypassing flow.

Table 4-3: Percentage of the front flow through the grate to total inflow

\begin{tabular}{|c|c|c|c|c|c|c|c|c|c|}
\hline & \multicolumn{4}{|c|}{$\mathrm{W}=4 \mathrm{ft}$} & \multicolumn{2}{c|}{$\mathrm{W}=4.75 \mathrm{ft}$} & \multicolumn{2}{c|}{$\mathrm{W=7.5} \mathrm{ft}$} \\
\hline & $\mathrm{T}=2 \mathrm{ft}$ & $\mathrm{T}=3 \mathrm{ft}$ & $\mathrm{T}=4 \mathrm{ft}$ & $\mathrm{T}=5 \mathrm{ft}$ & $\mathrm{T}=6 \mathrm{ft}$ & $\mathrm{T}=4.75 \mathrm{ft}$ & $\mathrm{T}=6.75 \mathrm{ft}$ & $\mathrm{T}=6 \mathrm{ft}$ & $\mathrm{T}=7.5 \mathrm{ft}$ \\
\hline $\mathrm{SL}=0.3 \%$ & $100 \%$ & $98 \%$ & $92 \%$ & $87 \%$ & $82 \%$ & $86 \%$ & $75 \%$ & $77 \%$ & $64 \%$ \\
\hline $\mathrm{SL}=1 \%$ & $100 \%$ & $98 \%$ & $92 \%$ & $88 \%$ & $80 \%$ & $86 \%$ & $73 \%$ & $73 \%$ & $60 \%$ \\
\hline $\mathrm{SL}=3 \%$ & $100 \%$ & $98 \%$ & $93 \%$ & $86 \%$ & $79 \%$ & $85 \%$ & $70 \%$ & $68 \%$ & $56 \%$ \\
\hline $\mathrm{SL}=4 \%$ & - & - & - & - & - & $79 \%$ & $79 \%$ & $63 \%$ & $46 \%$ \\
\hline $\mathrm{SL}=5 \%$ & $100 \%$ & $98 \%$ & $92 \%$ & $79 \%$ & $70 \%$ & $77 \%$ & $62 \%$ & $62 \%$ & $42 \%$ \\
\hline $\mathrm{SL}=7 \%$ & $100 \%$ & $96 \%$ & $85 \%$ & $78 \%$ & $69 \%$ & $71 \%$ & $59 \%$ & $57 \%$ & $35 \%$ \\
\hline
\end{tabular}

\begin{tabular}{|c|c|c|}
\hline & \multicolumn{2}{|c|}{$\mathrm{W}=10 \mathrm{ft}$} \\
\hline & $\mathrm{T}=8 \mathrm{ft}$ & $\mathrm{T}=10 \mathrm{ft}$ \\
\hline $\mathrm{SL}=0.3 \%$ & $60 \%$ & $49 \%$ \\
\hline $\mathrm{SL}=1 \%$ & $56 \%$ & $46 \%$ \\
\hline $\mathrm{SL}=2 \%$ & $58 \%$ & $41 \%$ \\
\hline $\mathrm{SL}=3 \%$ & $50 \%$ & $35 \%$ \\
\hline $\mathrm{SL}=4 \%$ & $42 \%$ & $29 \%$ \\
\hline
\end{tabular}

The percentage of side flow through the grate to the total inflow to the domain was calculated and the results were combined in Table 4-4. The side flow does not exceed $18 \%$ of the total flow and reaches higher values for the lowest longitudinal slopes at high flow rates. When the longitudinal slope increases, more water flow bypasses the grate. The highest values were found for two cases at longitudinal slope $0.3 \%$ : shoulder width $4.75 \mathrm{ft}$ with spread $6.75 \mathrm{ft}$, and shoulder width $7.5 \mathrm{ft}$ with spread $6 \mathrm{ft}$. Also, when flow spread is narrower than, or close to, the width of the grate, water enters the grate through its upstream side. 
Table 4-4: Percentage of the side flow through the grate to total inflow

\begin{tabular}{|c|c|c|c|c|c|c|c|c|c|}
\hline & \multicolumn{5}{|c|}{$\mathrm{W}=4 \mathrm{ft}$} & \multicolumn{2}{c|}{$\mathrm{W}=4.75 \mathrm{ft}$} & \multicolumn{2}{c|}{$\mathrm{W=7.5} \mathrm{ft}$} \\
\hline & $\mathrm{T}=2 \mathrm{ft}$ & $\mathrm{T}=3 \mathrm{ft}$ & $\mathrm{T}=4 \mathrm{ft}$ & $\mathrm{T}=5 \mathrm{ft}$ & $\mathrm{T}=6 \mathrm{ft}$ & $\mathrm{T}=4.75 \mathrm{ft}$ & $\mathrm{T}=6.75 \mathrm{ft}$ & $\mathrm{T}=6 \mathrm{ft}$ & $\mathrm{T}=7.5 \mathrm{ft}$ \\
\hline $\mathrm{SL}=0.3 \%$ & $0 \%$ & $1.5 \%$ & $7.8 \%$ & $11 \%$ & $16 \%$ & $14 \%$ & $18 \%$ & $18 \%$ & $17 \%$ \\
\hline $\mathrm{SL}=1 \%$ & $0 \%$ & $1.3 \%$ & $6.4 \%$ & $8.1 \%$ & $11 \%$ & $8.6 \%$ & $11 \%$ & $10 \%$ & $10 \%$ \\
\hline $\mathrm{SL}=3 \%$ & $0 \%$ & $1.3 \%$ & $3.9 \%$ & $5.0 \%$ & $5.2 \%$ & $5.0 \%$ & $5.1 \%$ & $4.9 \%$ & $5.1 \%$ \\
\hline $\mathrm{SL}=4 \%$ & - & - & - & - & - & $3.4 \%$ & $4.4 \%$ & $3.7 \%$ & $4.1 \%$ \\
\hline $\mathrm{SL}=5 \%$ & $0 \%$ & $0.8 \%$ & $2.7 \%$ & $3.6 \%$ & $3.1 \%$ & $2.8 \%$ & $3.9 \%$ & $4.1 \%$ & $3.9 \%$ \\
\hline $\mathrm{SL}=7 \%$ & $0 \%$ & $0.4 \%$ & $2.6 \%$ & $2.1 \%$ & $2.1 \%$ & $2.3 \%$ & $2.3 \%$ & $4.0 \%$ & $3.5 \%$ \\
\hline
\end{tabular}

\begin{tabular}{|c|c|c|}
\hline & \multicolumn{2}{|c|}{$\mathrm{W}=10 \mathrm{ft}$} \\
\hline & $\mathrm{T}=8 \mathrm{ft}$ & $\mathrm{T}=10 \mathrm{ft}$ \\
\hline $\mathrm{SL}=0.3 \%$ & $16 \%$ & $15 \%$ \\
\hline $\mathrm{SL}=1 \%$ & $9.4 \%$ & $8.1 \%$ \\
\hline $\mathrm{SL}=2 \%$ & $6.3 \%$ & $6.2 \%$ \\
\hline $\mathrm{SL}=3 \%$ & $5.5 \%$ & $4.7 \%$ \\
\hline $\mathrm{SL}=4 \%$ & $4.5 \%$ & $3.8 \%$ \\
\hline
\end{tabular}

Figure 4-16 shows streamlines of water velocity for five different longitudinal slopes, for a roadway with a 4-foot shoulder, when spread of the oncoming flow is equal 6 feet. The streamlines marked in yellow cross a vertical surface in front of the grate, and streamlines marked in green cross a vertical surface on the side of the grate. Also, the extent of water surface (spread) is marked with a red line. In the considered road geometry, the roadway has a cross-slope of $2 \%$, and the shoulder cross-slope equals $4 \%$. The figure illustrates that the front of the grate intercepts only the shoulder flow. The side of the grate intercepts mostly the shoulder flow. Only for the $0.3 \%$ and $1 \%$ longitudinal slope, i.e. when it is smaller than the cross-slope, it also carries some of the roadway flow. 
(a)

(b)

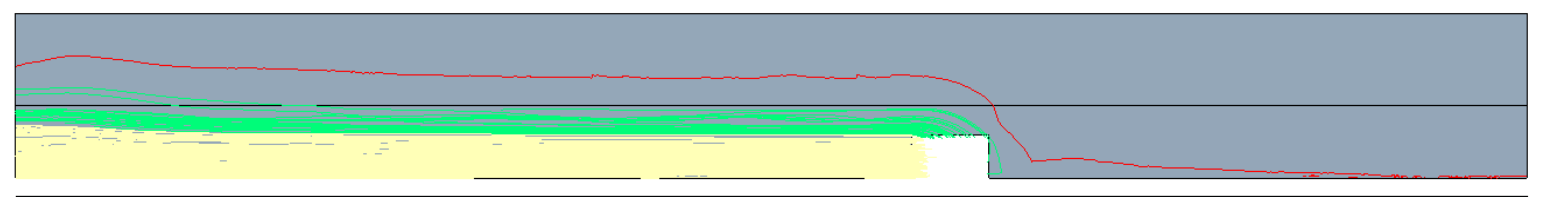

(c)

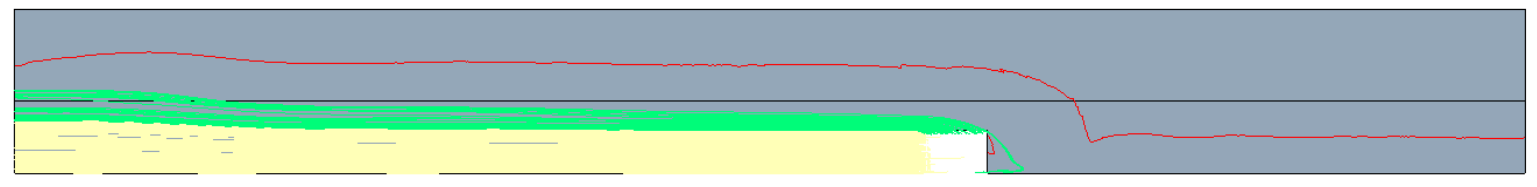

(d)

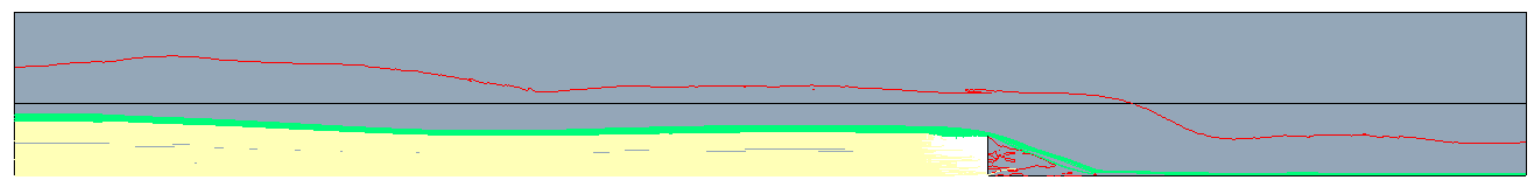

(e)
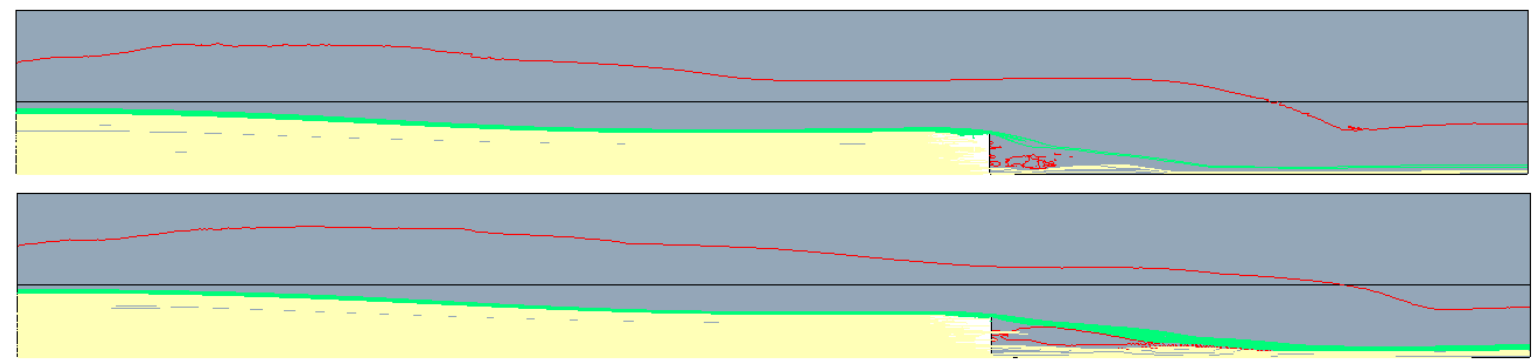

Figure 4-16: Streamlines of water velocity crossing surfaces: on the grate front (yellow) and grate side (green). The red line marks the extent of the water surface on the road. In each case the flow spread is $6 \mathrm{ft}$, on a road with a 4 foot shoulder, and varying longitudinal slope (a) $0.3 \%$, (b) $1 \%$, (c) $3 \%$, (d) $5 \%$, (e) $7 \%$.

\subsection{Correlations of the grate efficiency with Reynolds and Froude number}

The Reynolds number is an non-dimensional parameter that represents the ratio between inertial forces to viscous forces in a fluid flow. At low Reynolds numbers the behavior of the fluid depends mostly on viscosity and is laminar. For high Reynolds numbers, the momentum influences the flow more than the viscosity, which makes the flow turbulent. Intermediate values characterize flows that are transitional.

An upstream Reynolds number is defined as

$$
R e=\frac{\rho v d_{h}}{\mu}
$$

where $\rho$ is the water density, $\mu$ is the water viscosity, $v$ is the average velocity on a plane upstream of the grate, and $d_{h}$ is the hydraulic diameter of a cross street cross section upstream from the grate defined as

$$
d_{h}=\frac{4 A}{P_{w}+P_{S}+h}
$$

with $A$ is cross-section area of the flow, $P_{w}$ is gutter width, $P_{S}$ is wetted street width, $h$ is water depth at the curb. 
Figure 4-17 presents a point plot of the percentage of street flow captured by the grate vs. the upstream Reynolds number. A linear function was fitted to the data and its equation is shown in the figure. The higher the friction between road and the water, which is the denominator of the Reynolds number, the slower is the flow near the grate surface, and the easier for the water to turn and go into the grate. Conversely, the higher the momentum, which is the numerator of the Reynolds number, the easier it is for the water to splash over the grate without being captured. In consequence, the figure shows that when the Reynolds number increases, the captured flow decreases.

The Froude number is a non-dimensional parameter that represents a ratio of the flow inertia to gravity. It also characterized the ratio of flow velocity to surface wave speed. If the Froude number is less than 1, then the flow is subcritical, and if it is higher than 1, then the flow is supercritical. For subcritical flow, the flow velocity is lower than the wave velocity and downstream conditions can influence the upstream via waves. In supercritical flow the flow velocity is higher than the wave velocity, and downstream conditions cannot influence the upstream via waves.

The upstream Froude number was defined as

$$
F r=\frac{V}{\sqrt{g h}}
$$

where $g$ is gravitational acceleration.

Figure 4-18 shows a plot of the percentage of street flow through the side of the grate vs. upstream Froude number for a subset of road geometry cases in which the maximum side flow exceeds 10\% of total flow. The best fit was obtained with an exponential function. The correlation shows that as the upstream Froude number increases beyond one, flow inertia dominates over the cross street gravity body force pulling the water from the crown toward the curb, and carries more and more of the water down the street bypassing the grate. 


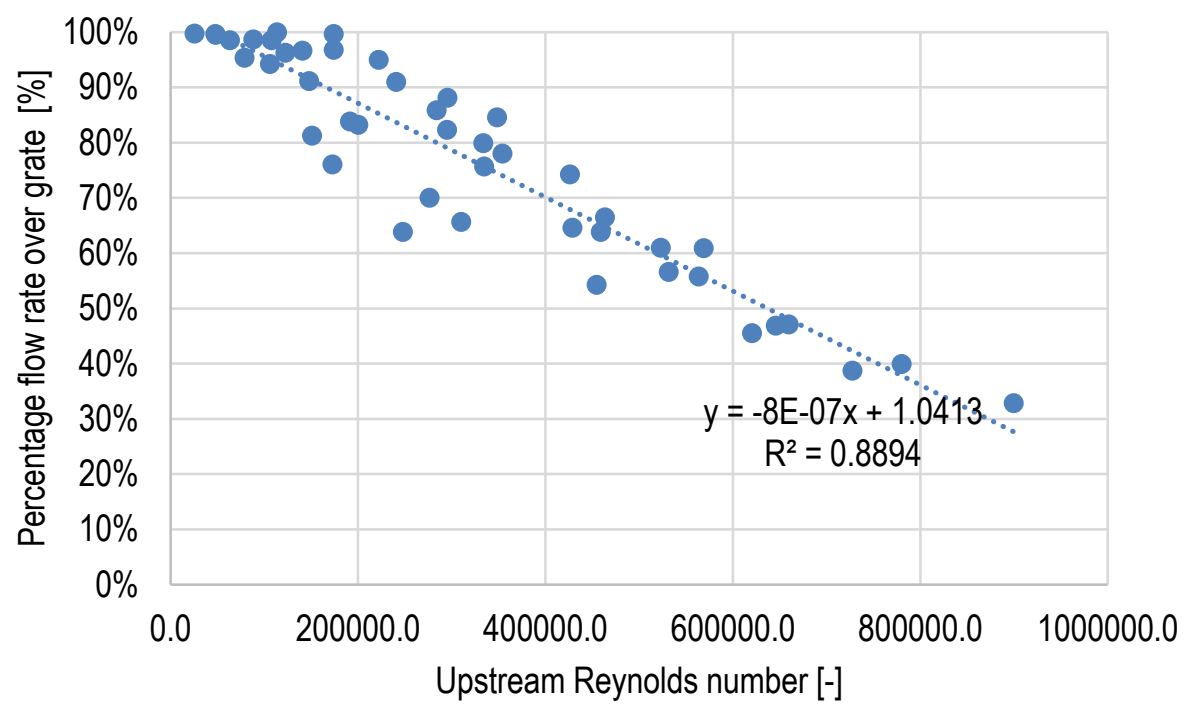

Figure 4-17: Percentage of flow rate through the grate vs. upstream Reynolds number with a best fit linear function

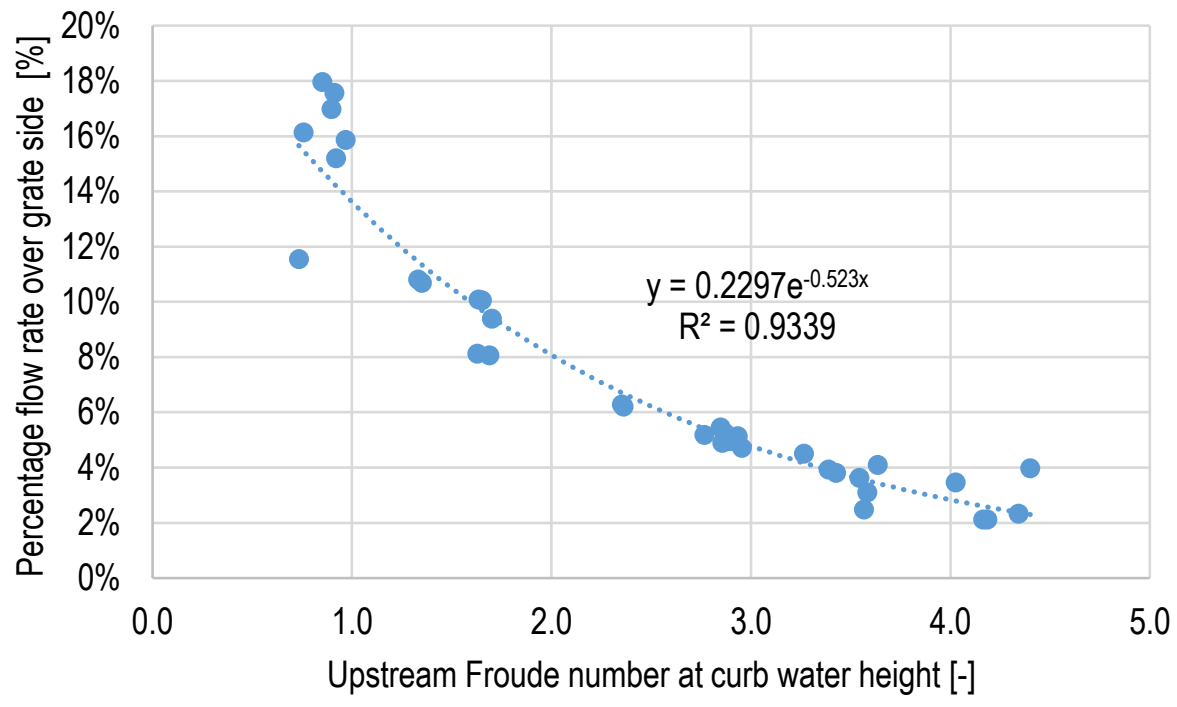

Figure 4-18: Percentage flow rate through the side of the grate vs. upstream Froude number with a best fit function 


\section{Conclusions}

A catch basin with an inlet grate, CB25, was studied to establish its hydraulic capacity. Three dimensional computational fluid dynamics modeling was chosen to perform a parametric study with varying roadway geometry and flow conditions. The unsteady Reynolds averaged NavierStokes (URANS) solver was used with a k- $\varepsilon$ turbulence model and standard wall functions to compute shear stress at the street, barrier, and grate wall boundaries. Tracking of the free surface between water and air in the computational domain was done using the Volume of Fluid (VOF) multiphase flow model [4].

The test matrix covered simulations with varying geometrical and hydraulic parameters: shoulder width, longitudinal slope, and flow rate. For each case, spread, mean flow velocity, and maximum flow depth were established. Moreover, grate and catch basin inlet efficiencies as function of: spread (volume flow rate), longitudinal slope, and shoulder width, were computed. The results were used to prepare a tool for engineers to use to design the spacing between catch basin inlets.

The sensitivity of the CFD simulations to different initial conditions was also studied. The analysis showed that the differences in the final result, meaning the flow rate over the grate and into the catch basin, can reach a few percent. The influence of geometry imperfection in the roadway and debris at the grate was also tested in the form of an imperfect (non-flat) shoulder surface upstream of the inlet and additional debris at the grate. In both cases the efficiency of the grate was decreased significantly by up to $16 \%$ percent.

Various free surface pattern types were observed in the simulations. For a set of the lowest flow rates, when the spread did not exceed the width of the grate, all or a majority of the flow was intercepted by the grate. For spreads wider than the grate, the flow was partially intercepted by the grate. Higher velocity of the flow in these cases, and therefore higher inertia forces, caused the flow to bypass the grate. In several instances a splash-over occurred. The grate was fully overtopped by the water for the cases of the highest flow rates.

The fraction of flow over the grate entering from the upstream end and from the side of the grate, as well as bypassing the grate, was established for each case. In the majority of the considered cases, part of the flow was not captured by the grate. In cases where the bypass and splash over flow is large, a double inlet could be used as a remedy. An analysis was provided showing that in some cases, significantly more bypass flow would be intercepted, if the downstream grate of the double grate is installed a short distance downstream, referred to as the fallback distance, where the flow has fallen back to the curb.

The analysis showed that the percentage of flow over the grate is linearly dependent on the upstream Reynolds number. Also, the percentage of flow rate over the grate coming from the side is exponentially dependent on the upstream Froude number. 


\section{Acknowledgements}

The funding for this project came from the Hydraulics Research Program at the Turner-Fairbank Highway Research Center through Interagency Agreement Number 693JJ318N300045 between DOT and DOE, and the work was performed under DOE's contract with UChicago Argonne, LLC, contract no. DE-ACo2-06CH11357.

\section{References}

[1] Hydraulic Engineering Circular No. 22, $3^{\text {rd }}$ Edition, Urban Drainage Design Manual, Publ. No. FHWA-NHI-10-009, rev. August 2009

[2] Fiuzat A.A., et al., 'Improvement in the structural design, construction, and maintenance of Type 5 and 6 catch basins', report no. FHWA-SC-89-02, 1989

[3] Lottes S.A., Bojanowski C., Hydraulic Capacity of an ADA Compliant Street Drain Grate, Argonne National Laboratory Technical Report ANL/ESD-15/25, September 2015

[4] Star-CCM+ v.12.06.11 documentation

[5] McGahey C., Samuels P.G., River roughness-the integration of diverse knowledge, River Flow 2004 - Greco, Carravetta \& Della Morte (eds.), Taylor\& Francis Group, London, ISBN 90-5809-658-0 


\section{Appendix A}

The results for each of the CFD simulations are combined in the tables of this appendix. The information includes the input parameters describing the geometry of the roadway, such as width of the shoulder, longitudinal slope, and the inflow rate, and output parameters, such as maximum water depth, water spread, flow intercepted by the grate through the front and side, fraction of total flow, and efficiency of the grate. The travel lane width is $12 \mathrm{ft}$, cross-slope of the roadway is $2 \%$, and cross-slope of the shoulder is $4 \%$. 


\begin{tabular}{|c|c|c|c|c|c|c|c|c|c|c|}
\hline $\begin{array}{l}\text { shoulder } \\
\text { width [ft] }\end{array}$ & $\begin{array}{l}\text { longitudinal } \\
\text { slope [ft/ft] }\end{array}$ & $\begin{array}{l}\text { spread } \\
\text { [ft] }\end{array}$ & $\begin{array}{c}\text { flow rate } \\
\text { [cfs] }\end{array}$ & $\begin{array}{l}\text { total } \\
\text { flow } \\
\text { [cfs] }\end{array}$ & $\begin{array}{l}\text { front } \\
\text { flow } \\
\text { [cfs] }\end{array}$ & $\begin{array}{l}\text { side } \\
\text { flow } \\
\text { [cfs] }\end{array}$ & $\begin{array}{l}\text { bypass } \\
\text { flow [cfs] }\end{array}$ & $\begin{array}{c}\text { efficiency } \\
{[\%]}\end{array}$ & $\begin{array}{c}\text { max } \\
\text { depth } \\
\text { [in] }\end{array}$ & $\begin{array}{c}\text { mean } \\
\text { velocity } \\
{[\mathrm{ft} / \mathrm{s}]}\end{array}$ \\
\hline 4.00 & 0.003 & 0.00 & 0.00 & 0.00 & 0.00 & 0.00 & 0.00 & $100 \%$ & 0.00 & 0.00 \\
\hline 4.00 & 0.003 & 2.00 & 0.08 & 0.08 & 0.08 & 0.00 & 0.00 & $100 \%$ & 1.01 & 0.94 \\
\hline 4.00 & 0.003 & 3.00 & 0.24 & 0.24 & 0.24 & 0.00 & 0.00 & $100 \%$ & 1.45 & 1.36 \\
\hline 4.00 & 0.003 & 4.00 & 0.52 & 0.52 & 0.48 & 0.04 & 0.00 & $100 \%$ & 2.03 & 1.48 \\
\hline 4.00 & 0.003 & 5.00 & 0.72 & 0.71 & 0.62 & 0.08 & 0.01 & $99 \%$ & 2.18 & 1.66 \\
\hline 4.00 & 0.003 & 6.00 & 0.97 & 0.95 & 0.80 & 0.16 & 0.02 & $98 \%$ & 2.41 & 1.84 \\
\hline 4.00 & 0.01 & 0.00 & 0.00 & 0.00 & 0.00 & 0.00 & 0.00 & $100 \%$ & 0.00 & 0.00 \\
\hline 4.00 & 0.01 & 2.00 & 0.15 & 0.15 & 0.15 & 0.00 & 0.00 & $100 \%$ & 1.01 & 1.63 \\
\hline 4.00 & 0.01 & 3.00 & 0.44 & 0.44 & 0.44 & 0.01 & 0.00 & $100 \%$ & 1.44 & 2.48 \\
\hline 4.00 & 0.01 & 4.00 & 0.95 & 0.94 & 0.88 & 0.06 & 0.01 & $99 \%$ & 2.02 & 2.71 \\
\hline 4.00 & 0.01 & 5.00 & 1.29 & 1.25 & 1.15 & 0.11 & 0.04 & $97 \%$ & 2.23 & 3.02 \\
\hline 4.00 & 0.01 & 6.00 & 1.79 & 1.63 & 1.43 & 0.19 & 0.16 & $91 \%$ & 2.41 & 3.38 \\
\hline 4.00 & 0.03 & 0.00 & 0.00 & 0.00 & 0.00 & 0.00 & 0.00 & $100 \%$ & 0.00 & 0.00 \\
\hline 4.00 & 0.03 & 2.00 & 0.26 & 0.26 & 0.26 & 0.00 & 0.00 & $100 \%$ & 1.04 & 2.81 \\
\hline 4.00 & 0.03 & 3.00 & 0.77 & 0.76 & 0.75 & 0.01 & 0.00 & $100 \%$ & 1.44 & 4.29 \\
\hline 4.00 & 0.03 & 4.00 & 1.65 & 1.60 & 1.54 & 0.06 & 0.05 & $97 \%$ & 2.03 & 4.69 \\
\hline 4.00 & 0.03 & 5.00 & 2.29 & 2.09 & 1.97 & 0.11 & 0.21 & $91 \%$ & 2.17 & 5.24 \\
\hline 4.00 & 0.03 & 6.00 & 3.04 & 2.54 & 2.39 & 0.16 & 0.49 & $84 \%$ & 2.22 & 6.72 \\
\hline 4.00 & 0.05 & 0.00 & 0.00 & 0.00 & 0.00 & 0.00 & 0.00 & $100 \%$ & 0.00 & 0.00 \\
\hline 4.00 & 0.05 & 2.00 & 0.34 & 0.34 & 0.34 & 0.00 & 0.00 & $100 \%$ & 1.04 & 3.62 \\
\hline 4.00 & 0.05 & 3.00 & 1.00 & 0.99 & 0.98 & 0.01 & 0.01 & $99 \%$ & 1.43 & 5.54 \\
\hline 4.00 & 0.05 & 4.00 & 2.14 & 2.03 & 1.97 & 0.06 & 0.11 & $95 \%$ & 2.02 & 6.05 \\
\hline 4.00 & 0.05 & 5.00 & 2.94 & 2.42 & 2.31 & 0.11 & 0.52 & $82 \%$ & 2.22 & 6.94 \\
\hline 4.00 & 0.05 & 6.00 & 3.93 & 2.87 & 2.75 & 0.12 & 1.06 & $73 \%$ & 2.61 & 6.52 \\
\hline 4.00 & 0.07 & 0.00 & 0.00 & 0.00 & 0.00 & 0.00 & 0.00 & $100 \%$ & 0.00 & 0.00 \\
\hline 4.00 & 0.07 & 2.00 & 0.40 & 0.40 & 0.40 & 0.00 & 0.00 & $100 \%$ & 1.04 & 4.29 \\
\hline 4.00 & 0.07 & 3.00 & 1.18 & 1.14 & 1.13 & 0.01 & 0.04 & $96 \%$ & 1.43 & 6.56 \\
\hline
\end{tabular}




\begin{tabular}{|c|c|c|c|c|c|c|c|c|c|c|}
\hline $\begin{array}{l}\text { shoulder } \\
\text { width [ft] }\end{array}$ & $\begin{array}{l}\text { longitudinal } \\
\text { slope [ft/ft] }\end{array}$ & $\begin{array}{l}\text { spread } \\
\text { [ft] }\end{array}$ & $\begin{array}{c}\text { flow rate } \\
\text { [cfs] }\end{array}$ & $\begin{array}{l}\text { total } \\
\text { flow } \\
\text { [cfs] }\end{array}$ & $\begin{array}{l}\text { front } \\
\text { flow } \\
\text { [cfs] }\end{array}$ & $\begin{array}{l}\text { side } \\
\text { flow } \\
\text { [cfs] }\end{array}$ & $\begin{array}{l}\text { bypass } \\
\text { flow [cfs] }\end{array}$ & $\begin{array}{c}\text { efficiency } \\
{[\%]}\end{array}$ & $\begin{array}{c}\text { max } \\
\text { depth } \\
\text { [in] }\end{array}$ & $\begin{array}{c}\text { mean } \\
\text { velocity } \\
{[\mathrm{ft} / \mathrm{s}]}\end{array}$ \\
\hline 4.00 & 0.07 & 4.00 & 2.53 & 2.23 & 2.16 & 0.07 & 0.30 & $88 \%$ & 2.03 & 7.16 \\
\hline 4.00 & 0.07 & 5.00 & 3.48 & 2.78 & 2.71 & 0.07 & 0.70 & $80 \%$ & 2.26 & 7.83 \\
\hline 4.00 & 0.07 & 6.00 & 4.63 & 3.28 & 3.19 & 0.10 & 1.35 & $71 \%$ & 2.60 & 7.71 \\
\hline 4.75 & 0.003 & 0.00 & 0.00 & 0.00 & 0.00 & 0.00 & 0.00 & $100 \%$ & 0.00 & 0.00 \\
\hline 4.75 & 0.003 & 2.00 & 0.08 & 0.08 & 0.08 & 0.00 & 0.00 & $100 \%$ & 1.01 & 0.94 \\
\hline 4.75 & 0.003 & 3.00 & 0.24 & 0.24 & 0.24 & 0.00 & 0.00 & $100 \%$ & 1.45 & 1.36 \\
\hline 4.75 & 0.003 & 4.00 & 0.52 & 0.52 & 0.48 & 0.04 & 0.00 & $100 \%$ & 2.03 & 1.48 \\
\hline 4.75 & 0.003 & 4.75 & 0.82 & 0.82 & 0.71 & 0.11 & 0.00 & $100 \%$ & 2.40 & 2.05 \\
\hline 4.75 & 0.003 & 6.75 & 1.41 & 1.31 & 1.05 & 0.25 & 0.10 & $93 \%$ & 2.93 & 1.86 \\
\hline 4.75 & 0.01 & 0.00 & 0.00 & 0.00 & 0.00 & 0.00 & 0.00 & $100 \%$ & 0.00 & 0.00 \\
\hline 4.75 & 0.01 & 2.00 & 0.15 & 0.15 & 0.15 & 0.00 & 0.00 & $100 \%$ & 1.01 & 1.63 \\
\hline 4.75 & 0.01 & 3.00 & 0.44 & 0.44 & 0.44 & 0.01 & 0.00 & $100 \%$ & 1.44 & 2.48 \\
\hline 4.75 & 0.01 & 4.00 & 0.95 & 0.94 & 0.88 & 0.06 & 0.01 & $99 \%$ & 2.02 & 2.71 \\
\hline 4.75 & 0.01 & 4.75 & 1.50 & 1.43 & 1.30 & 0.13 & 0.07 & $95 \%$ & 2.24 & 3.51 \\
\hline 4.75 & 0.01 & 6.75 & 2.53 & 2.12 & 1.85 & 0.27 & 0.41 & $84 \%$ & 2.93 & 3.34 \\
\hline 4.75 & 0.03 & 0.00 & 0.00 & 0.00 & 0.00 & 0.00 & 0.00 & $100 \%$ & 0.00 & 0.00 \\
\hline 4.75 & 0.03 & 2.00 & 0.26 & 0.26 & 0.26 & 0.00 & 0.00 & $100 \%$ & 1.04 & 2.81 \\
\hline 4.75 & 0.03 & 3.00 & 0.77 & 0.76 & 0.75 & 0.01 & 0.00 & $100 \%$ & 1.44 & 4.29 \\
\hline 4.75 & 0.03 & 4.00 & 1.65 & 1.60 & 1.54 & 0.06 & 0.05 & $97 \%$ & 2.03 & 4.69 \\
\hline 4.75 & 0.03 & 4.75 & 2.61 & 2.37 & 2.24 & 0.13 & 0.25 & $91 \%$ & 2.41 & 6.48 \\
\hline 4.75 & 0.03 & 6.75 & 4.39 & 3.32 & 3.09 & 0.23 & 1.07 & $76 \%$ & 2.83 & 7.06 \\
\hline 4.75 & 0.05 & 0.00 & 0.00 & 0.00 & 0.00 & 0.00 & 0.00 & $100 \%$ & 0.00 & 0.00 \\
\hline 4.75 & 0.05 & 2.00 & 0.34 & 0.34 & 0.34 & 0.00 & 0.00 & $100 \%$ & 1.04 & 3.62 \\
\hline 4.75 & 0.05 & 3.00 & 1.00 & 0.99 & 0.98 & 0.01 & 0.01 & $99 \%$ & 1.43 & 5.54 \\
\hline 4.75 & 0.05 & 4.00 & 2.14 & 2.03 & 1.97 & 0.06 & 0.11 & $95 \%$ & 2.02 & 6.05 \\
\hline 4.75 & 0.05 & 4.75 & 3.39 & 2.72 & 2.63 & 0.10 & 0.67 & $80 \%$ & 2.37 & 6.76 \\
\hline 4.75 & 0.05 & 6.75 & 5.66 & 3.93 & 3.70 & 0.22 & 1.73 & $69 \%$ & 2.83 & 9.11 \\
\hline
\end{tabular}

Hydraulic Study of the South Carolina DOT Catch Basin Type 25 


\begin{tabular}{|c|c|c|c|c|c|c|c|c|c|c|}
\hline $\begin{array}{l}\text { shoulder } \\
\text { width [ft] }\end{array}$ & $\begin{array}{l}\text { longitudinal } \\
\text { slope [ft/ft] }\end{array}$ & $\begin{array}{l}\text { spread } \\
\text { [ft] }\end{array}$ & $\begin{array}{c}\text { flow rate } \\
\text { [cfs] }\end{array}$ & $\begin{array}{l}\text { total } \\
\text { flow } \\
\text { [cfs] }\end{array}$ & $\begin{array}{l}\text { front } \\
\text { flow } \\
\text { [cfs] }\end{array}$ & $\begin{array}{l}\text { side } \\
\text { flow } \\
\text { [cfs] }\end{array}$ & $\begin{array}{l}\text { bypass } \\
\text { flow [cfs] }\end{array}$ & $\begin{array}{c}\text { efficiency } \\
{[\%]}\end{array}$ & $\begin{array}{c}\text { max } \\
\text { depth } \\
\text { [in] }\end{array}$ & $\begin{array}{c}\text { mean } \\
\text { velocity } \\
{[\mathrm{ft} / \mathrm{s}]}\end{array}$ \\
\hline 4.75 & 0.07 & 0.00 & 0.00 & 0.00 & 0.00 & 0.00 & 0.00 & $100 \%$ & 0.00 & 0.00 \\
\hline 4.75 & 0.07 & 2.00 & 0.40 & 0.40 & 0.39 & 0.00 & 0.00 & $100 \%$ & 1.04 & 4.29 \\
\hline 4.75 & 0.07 & 3.00 & 1.18 & 1.14 & 1.13 & 0.01 & 0.04 & $96 \%$ & 1.43 & 6.56 \\
\hline 4.75 & 0.07 & 4.00 & 2.53 & 2.23 & 2.16 & 0.07 & 0.30 & $88 \%$ & 2.03 & 7.16 \\
\hline 4.75 & 0.07 & 4.75 & 4.01 & 2.93 & 2.84 & 0.09 & 1.09 & $73 \%$ & 2.37 & 8.00 \\
\hline 4.75 & 0.07 & 6.75 & 6.70 & 4.08 & 3.92 & 0.16 & 2.62 & $61 \%$ & 2.83 & 10.78 \\
\hline 7.50 & 0.003 & 0.00 & 0.00 & 0.00 & 0.00 & 0.00 & 0.00 & $100 \%$ & 0.00 & 0.00 \\
\hline 7.50 & 0.003 & 2.00 & 0.08 & 0.08 & 0.08 & 0.00 & 0.00 & $99 \%$ & 1.01 & 0.94 \\
\hline 7.50 & 0.003 & 3.00 & 0.24 & 0.24 & 0.24 & 0.00 & 0.00 & $100 \%$ & 1.45 & 1.36 \\
\hline 7.50 & 0.003 & 4.00 & 0.52 & 0.52 & 0.48 & 0.04 & 0.00 & $100 \%$ & 2.03 & 1.48 \\
\hline 7.50 & 0.003 & 6.00 & 1.51 & 1.43 & 1.16 & 0.27 & 0.09 & $94 \%$ & 3.00 & 1.96 \\
\hline 7.50 & 0.003 & 7.50 & 2.79 & 2.27 & 1.79 & 0.47 & 0.52 & $81 \%$ & 3.54 & 2.56 \\
\hline 7.50 & 0.01 & 0.00 & 0.00 & 0.00 & 0.00 & 0.00 & 0.00 & $100 \%$ & 0.00 & 0.00 \\
\hline 7.50 & 0.01 & 2.00 & 0.15 & 0.15 & 0.15 & 0.00 & 0.00 & $100 \%$ & 1.01 & 1.63 \\
\hline 7.50 & 0.01 & 3.00 & 0.44 & 0.44 & 0.44 & 0.01 & 0.00 & $100 \%$ & 1.44 & 2.48 \\
\hline 7.50 & 0.01 & 4.00 & 0.95 & 0.94 & 0.88 & 0.06 & 0.01 & $99 \%$ & 2.02 & 2.71 \\
\hline 7.50 & 0.01 & 6.00 & 2.81 & 2.34 & 2.06 & 0.28 & 0.47 & $83 \%$ & 3.00 & 3.58 \\
\hline 7.50 & 0.01 & 7.50 & 5.11 & 3.58 & 3.06 & 0.51 & 1.53 & $70 \%$ & 3.54 & 4.68 \\
\hline 7.50 & 0.03 & 0.00 & 0.00 & 0.00 & 0.00 & 0.00 & 0.00 & $100 \%$ & 0.00 & 0.00 \\
\hline 7.50 & 0.03 & 2.00 & 0.26 & 0.26 & 0.26 & 0.00 & 0.00 & $100 \%$ & 1.04 & 2.81 \\
\hline 7.50 & 0.03 & 3.00 & 0.77 & 0.76 & 0.75 & 0.01 & 0.00 & $100 \%$ & 1.44 & 4.29 \\
\hline 7.50 & 0.03 & 4.00 & 1.65 & 1.60 & 1.54 & 0.06 & 0.05 & $97 \%$ & 2.03 & 4.69 \\
\hline 7.50 & 0.03 & 6.00 & 4.88 & 3.81 & 3.57 & 0.24 & 1.07 & $78 \%$ & 3.00 & 6.20 \\
\hline 7.50 & 0.03 & 7.50 & 8.85 & 5.28 & 4.81 & 0.47 & 3.56 & $60 \%$ & 3.54 & 8.10 \\
\hline 7.50 & 0.05 & 0.00 & 0.00 & 0.00 & 0.00 & 0.00 & 0.00 & $100 \%$ & 0.00 & 0.00 \\
\hline 7.50 & 0.05 & 2.00 & 0.34 & 0.34 & 0.34 & 0.00 & 0.00 & $100 \%$ & 1.04 & 3.62 \\
\hline 7.50 & 0.05 & 3.00 & 1.00 & 0.99 & 0.98 & 0.01 & 0.01 & $99 \%$ & 1.43 & 5.54 \\
\hline
\end{tabular}

Hydraulic Study of the South Carolina DOT Catch Basin Type 25

Page | 41 


\begin{tabular}{|c|c|c|c|c|c|c|c|c|c|c|}
\hline $\begin{array}{l}\text { shoulder } \\
\text { width [ft] }\end{array}$ & $\begin{array}{l}\text { longitudinal } \\
\text { slope [ft/ft] }\end{array}$ & $\begin{array}{l}\text { spread } \\
\text { [ft] }\end{array}$ & $\begin{array}{c}\text { flow rate } \\
\text { [cfs] }\end{array}$ & $\begin{array}{l}\text { total } \\
\text { flow } \\
\text { [cfs] }\end{array}$ & $\begin{array}{l}\text { front } \\
\text { flow } \\
\text { [cfs] }\end{array}$ & $\begin{array}{l}\text { side } \\
\text { flow } \\
\text { [cfs] }\end{array}$ & $\begin{array}{l}\text { bypass } \\
\text { flow [cfs] }\end{array}$ & $\begin{array}{c}\text { efficiency } \\
{[\%]}\end{array}$ & $\begin{array}{c}\text { max } \\
\text { depth } \\
\text { [in] }\end{array}$ & $\begin{array}{c}\text { mean } \\
\text { velocity } \\
{[\mathrm{ft} / \mathrm{s}]}\end{array}$ \\
\hline 7.50 & 0.05 & 4.00 & 2.14 & 2.03 & 1.97 & 0.06 & 0.11 & $95 \%$ & 2.02 & 6.05 \\
\hline 7.50 & 0.05 & 6.00 & 6.30 & 4.11 & 3.86 & 0.26 & 2.19 & $65 \%$ & 3.00 & 8.00 \\
\hline 7.50 & 0.05 & 7.50 & 11.42 & 5.20 & 4.75 & 0.45 & 6.22 & $46 \%$ & 3.69 & 9.17 \\
\hline 7.50 & 0.07 & 0.00 & 0.00 & 0.00 & 0.00 & 0.00 & 0.00 & $100 \%$ & 0.00 & 0.00 \\
\hline 7.50 & 0.07 & 2.00 & 0.40 & 0.40 & 0.40 & 0.00 & 0.00 & $100 \%$ & 1.04 & 4.29 \\
\hline 7.50 & 0.07 & 3.00 & 1.18 & 1.14 & 1.13 & 0.01 & 0.04 & $96 \%$ & 1.43 & 6.56 \\
\hline 7.50 & 0.07 & 4.00 & 2.53 & 2.23 & 2.16 & 0.07 & 0.30 & $88 \%$ & 2.03 & 7.16 \\
\hline 7.50 & 0.07 & 6.00 & 7.46 & 4.18 & 3.89 & 0.29 & 3.28 & $56 \%$ & 3.00 & 12.38 \\
\hline 7.50 & 0.07 & 7.50 & 13.52 & 5.23 & 4.77 & 0.47 & 8.28 & $39 \%$ & 3.54 & 12.38 \\
\hline 10.00 & 0.003 & 0.00 & 0.00 & 0.00 & 0.00 & 0.00 & 0.00 & $100 \%$ & 0.00 & 0.00 \\
\hline 10.00 & 0.003 & 2.00 & 0.08 & 0.08 & 0.08 & 0.00 & 0.00 & $99 \%$ & 1.01 & 0.94 \\
\hline 10.00 & 0.003 & 4.00 & 0.52 & 0.52 & 0.48 & 0.04 & 0.00 & $100 \%$ & 2.03 & 1.48 \\
\hline 10.00 & 0.003 & 6.00 & 1.51 & 1.43 & 1.16 & 0.27 & 0.09 & $94 \%$ & 3.00 & 1.96 \\
\hline 10.00 & 0.003 & 8.00 & 3.32 & 2.51 & 1.96 & 0.54 & 0.81 & $76 \%$ & 3.78 & 2.60 \\
\hline 10.00 & 0.003 & 10.00 & 6.02 & 3.84 & 2.93 & 0.92 & 2.18 & $64 \%$ & 4.78 & 3.02 \\
\hline 10.00 & 0.01 & 0.00 & 0.00 & 0.00 & 0.00 & 0.00 & 0.00 & $100 \%$ & 0.00 & 0.00 \\
\hline 10.00 & 0.01 & 2.00 & 0.15 & 0.15 & 0.15 & 0.00 & 0.00 & $100 \%$ & 1.01 & 1.63 \\
\hline 10.00 & 0.01 & 4.00 & 0.52 & 0.52 & 0.48 & 0.04 & 0.00 & $100 \%$ & 2.02 & 2.71 \\
\hline 10.00 & 0.01 & 6.00 & 2.81 & 2.34 & 2.06 & 0.28 & 0.47 & $83 \%$ & 3.00 & 3.58 \\
\hline 10.00 & 0.01 & 8.00 & 6.07 & 3.98 & 3.41 & 0.57 & 2.08 & $66 \%$ & 3.76 & 4.75 \\
\hline 10.00 & 0.01 & 10.00 & 11.00 & 5.97 & 5.08 & 0.89 & 5.03 & $54 \%$ & 4.77 & 5.52 \\
\hline 10.00 & 0.02 & 8.00 & 8.58 & 5.48 & 4.94 & 0.54 & 3.10 & $64 \%$ & 3.75 & 6.72 \\
\hline 10.00 & 0.02 & 10.00 & 15.56 & 7.33 & 6.37 & 0.97 & 8.23 & $47 \%$ & 4.76 & 7.80 \\
\hline 10.00 & 0.03 & 0.00 & 0.00 & 0.00 & 0.00 & 0.00 & 0.00 & $100 \%$ & 0.00 & 0.00 \\
\hline 10.00 & 0.03 & 2.00 & 0.26 & 0.26 & 0.26 & 0.00 & 0.00 & $100 \%$ & 1.04 & 2.81 \\
\hline 10.00 & 0.03 & 4.00 & 1.65 & 1.60 & 1.54 & 0.06 & 0.05 & $97 \%$ & 2.03 & 4.69 \\
\hline 10.00 & 0.03 & 6.00 & 4.88 & 3.81 & 3.57 & 0.24 & 1.07 & $78 \%$ & 3.00 & 6.20 \\
\hline
\end{tabular}

Hydraulic Study of the South Carolina DOT Catch Basin Type 25 


\begin{tabular}{|r|c|c|c|c|c|c|c|c|c|c|}
\hline $\begin{array}{c}\text { shoulder } \\
\text { width [ft] }\end{array}$ & $\begin{array}{c}\text { Iongitudinal } \\
\text { slope [ft/ft] }\end{array}$ & $\begin{array}{c}\text { spread } \\
\text { [ft] }\end{array}$ & $\begin{array}{c}\text { flow rate } \\
\text { [cfs] }\end{array}$ & $\begin{array}{c}\text { total } \\
\text { flow } \\
\text { [cfs] }\end{array}$ & $\begin{array}{c}\text { front } \\
\text { flow } \\
\text { [cfs] }\end{array}$ & $\begin{array}{c}\text { side } \\
\text { flow } \\
\text { [cfs] }\end{array}$ & $\begin{array}{c}\text { bypass } \\
\text { flow [cfs] }\end{array}$ & $\begin{array}{c}\text { efficiency } \\
\text { [\%] }\end{array}$ & $\begin{array}{c}\text { max } \\
\text { depth } \\
\text { [in] }\end{array}$ & $\begin{array}{c}\text { mean } \\
\text { velocity } \\
\text { [ft/s] }\end{array}$ \\
\hline 10.00 & 0.03 & 8.00 & 10.51 & 5.87 & 5.29 & 0.57 & 4.64 & $56 \%$ & 3.76 & 8.22 \\
\hline 10.00 & 0.03 & 10.00 & 19.09 & 7.62 & 6.72 & 0.90 & 11.47 & $40 \%$ & 4.77 & 9.56 \\
\hline 10.00 & 0.04 & 8.00 & 12.14 & 5.69 & 5.15 & 0.55 & 6.44 & $47 \%$ & 3.75 & 9.50 \\
\hline 10.00 & 0.04 & 10.00 & 22.01 & 7.23 & 6.40 & 0.84 & 14.78 & $33 \%$ & 4.74 & 11.03 \\
\hline
\end{tabular}




\section{Appendix B}

A design aid is provided in the form of a Microsoft Excel file, containing the necessary information, collected from the CFD simulations, as well as formulas, required to calculate the spacing between catch basins.

\section{The CB25DesignAid.xlsx file consists of four worksheets:}

1. The 'Directions' tab contains these instructions.

2. The 'RainfallIntensity' tab contains data on rainfall intensity (in/hr) for a 10-year event with a duration of 5 minutes at the center point location for each county. The data was taken from rainfall intensity values found on the NOAA website (https://hdsc.nws.noaa.gov).

3. The ' $\mathrm{CB}$ ' tab contains data obtained from the catch basin hydraulic efficiency study: shoulder width (ft), longitudinal slope (ft/ft), spread (ft), flow rate (cfs), total flow through the grate (cfs), front flow (cfs), side flow (cfs), bypass flow (cfs), efficiency (\%), max depth (in), mean velocity (ft/hr), allowable spread (ft).

4. The sheets at tabs numbered ' 1 ', ' 2 ', ' 3 ', etc. contain formulas that are used to perform calculations to determine drainage spacing. The green shaded cells are for entry of data by the user as detailed below. Data and information will appear in other cells as data needed to complete calculations for those cells is entered in the green shaded cells.

\section{Instructions on how to use the spreadsheets with calculations:}

1. Fill in the general information about the project in the header.

a. The following parameters are constant: the road cross-slope, equal to $2 \%$, and shoulder cross-slope, equal to $4 \%$. It was assumed that the inlet spacing calculations are conducted for a 10-year rain event and that the design spread is equal to the shoulder width for shoulder widths 6 feet or greater, or the minimum design value of 6 feet for narrower shoulders. The values for these items cannot be changed.

b. Select the county from a dropdown list of counties in the cell K8.

c. Fill in with information about the project as appropriate: 'Road', 'Roadside', 'Storm sewer system', 'Receiving Stream/Outfall', as well as 'Sheet No', 'Project ID', 'Project', 'Engineer', and 'Date'.

d. Enter the 'Drainage start station' in the green cell next to the heading. The value should be the location of the station in feet that is the starting point for the next section of inlets. This value will be used to calculate the first spacing between inlets in Row 12. If row 12 is not visible, scroll up until it is.

2. For each row beginning with row 12, enter information in the green cells to determine the design position for the next inlet until the design is compete for all inlets as follows:

a. Enter the catch basin number as an integer in the $\mathrm{CB}$ column $\mathrm{A}$.

b. Enter an estimate of the next inlet location in feet in the Station column B. When information in the remaining columns is complete, a value for the station giving the design spread is calculated and displayed in column $Z$. The station value can be iteratively refined based on this, and the result data in other columns, until desired design conditions are met.

c. Enter the runoff coefficient $\mathrm{Cw}$ in the Runoff coeff. column $\mathrm{F}$. 
d. Enter the roadway width in feet in the Roadway width column L.

e. Select the shoulder width in feet from the drop down menu in the Shoulder width column M.

f. Enter the roadway longitudinal slope in (feet of drop)/(feet of run) in the Longitudinal slope column $\mathrm{N}$.

g. Check the estimate of station location calculated to give the design spread in column Z. Refine the station value in column B until there are no warnings in column X, or values in other columns are satisfactory.

\section{Notes:}

1. The county name needs to be selected from the dropdown menu in the header so that column $\mathrm{H}$ is populated with the rainfall intensity for a 10 year event for the selected county. If some other rainfall intensity is required for specific designs, it may be entered manually in the rainfall intensity column, column $\mathrm{H}$, overriding the county value obtained from the header.

2. The spacing between inlets, $L$ (column $\mathrm{C}$ will be calculated as a difference between locations. Note: the spacing in row 12 will be calculated as a difference between the CB no.1 location and 'Drainage start station' location entered in the header.

3. The drainage area width $W$ (ft), (column $\mathrm{D}$ ) will be calculated by default as the shoulder width (column $\mathrm{M}$ ) plus roadway width (column $\mathrm{L}$ ). If the drainage area width is more than this value, it may be entered in column $\mathrm{D}$ overriding the calculated value.

4. The drainage area, $A$ (acre), (column E) will be calculated as $A=L W / 43560$.

5. The time of concentration, $t_{c}$ ( $\mathrm{min}$ ), will be calculated from HEC22 formula in column $\mathrm{G}$ as $t_{c}=\frac{L}{60 V}$, where $V$ is the gutter velocity $(\mathrm{ft} / \mathrm{sec})$. The minimum value is 5 minutes.

6. The flow rate, $Q$ (cfs), will be calculated in column I as follows: $Q=C_{w} I A$.

7. In column $\mathrm{J}$, the bypass flow from the previous inlet will be added.

8. Total flow rate is calculated as a sum of the flow rate and the previous bypass flow in column K.

9. Columns from $\mathrm{O}$ to $\mathrm{W}$ will be filled in with values calculated by linear interpolation of data from spreadsheet at tab $\mathrm{CB}$, using the total flow rate.

\section{Color coding in the spreadsheets:}

- Green cells - to be filled in by the user

\section{Warnings are issued (column ' $X$ ') in the following cases:}

- The efficiency of the grate in the selected flow conditions is less than desirable $(<90 \%)$ or the bypass flow is greater than $0.5 \mathrm{cfs}$. Reduce the station location until the efficiency or the bypass flow is acceptable.

- The selected longitudinal slope is out of range (SL $<=7 \%$ for shoulder width up to $7.5 \mathrm{ft}$, and $\mathrm{SL}<=3 \%$ for shoulder width $10 \mathrm{ft}$ ). If the longitudinal slope of the road is greater than the worksheet maximum, set the longitudinal slope to the maximum, $7 \%$ or $3 \%$, and reduce the station location to obtain a larger efficiency in the sheet calculations because the actual efficiency will be less due to the out of range slope.

- If the selected values are such that they give a flow rate (spread) outside of the tested range, Excel will issue a warning \#REF! in columns G, and from $\mathrm{O}$ to $\mathrm{X}$. Most likely the 
spacing is too large and entering a sufficiently reduced station location will solve this problem.

\section{Adding more numbered sheets with a create copy operation:}

- If needed, the spreadsheet with calculations can be copied multiple times to perform separate inlet spacing analysis for each run of highway drains. Please note that the sheets in the numbered tabs contain numerous hidden formulas and consequently creating a copy of a numbered tab sheet may take as long as 2 minutes or more depending on the computer used. The copy operation is not hung up. Please be patient. 
Table 9-1: Drainage design spreadsheet

\section{SCDOT Type 25 Inlet Spacing}

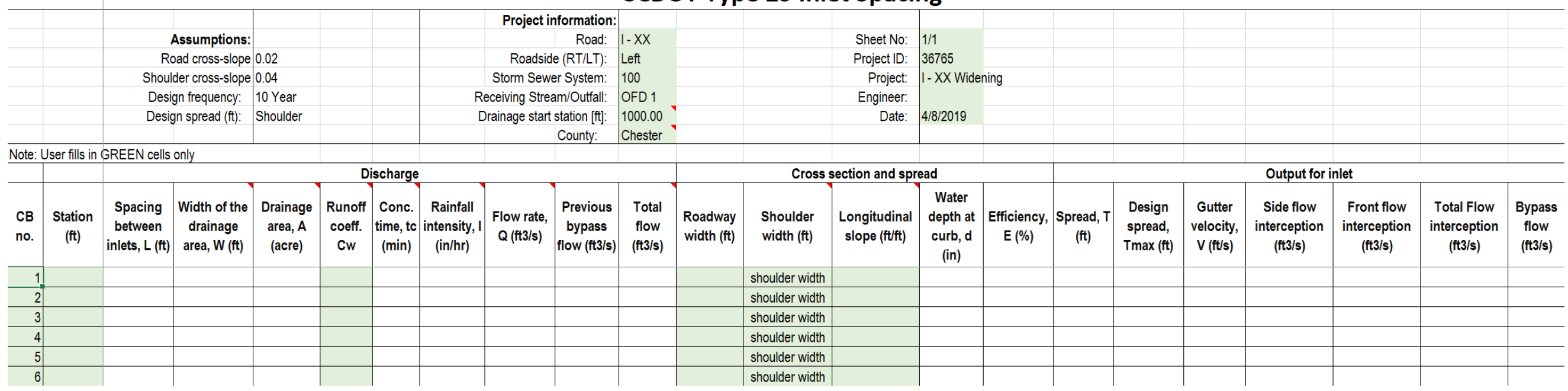




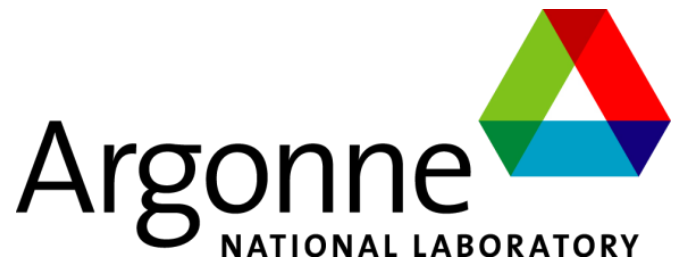

Nuclear Science and Engineering Division

Argonne National Laboratory

9700 South Cass Avenue

Argonne, IL 60439-4815

www.anl.gov

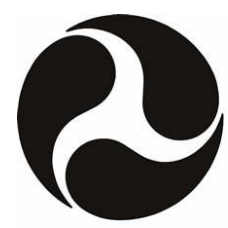

U.S. Department of Transportation

Federal Highway Administration 